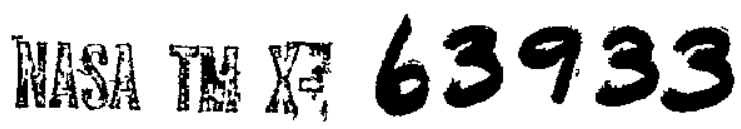

\section{ELECTRON AND. ION TEMPERATURES IN THE IONOSPHERE}

\author{
A. P. WILLMORE
}

APRIL 1970

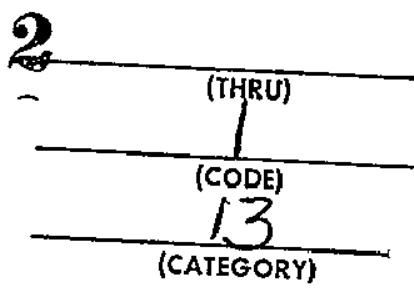




\title{
ELECTRON AND ION TEMPERATURES IN THE IONOSPHERE*
}

\author{
A. P. Willmore ${ }^{\dagger}$ \\ Physical Research Laboratory, Ahmedabad, India \\ and \\ Laboratory for Planetary Atmospheres, Goddard Space Flight Center \\ Greenbelt, Maryland
}

April 1970

*This review is based on material published up to January, 1970.

t On Ieave of absence from Mullard Space Science Laboratory, University College, London.

GODDARD SPACE FLIGHT CENTER

Greenbelt, Maryland 


\title{
ELECTRON AND ION TEMPERATURES IN THE IONOSPHERE*
}

\author{
A. P. Willmore ${ }^{\dagger}$ \\ Physical Research Laboratory, Ahmedabad, India \\ and \\ Laboratory for Planetary Atmospheres, Goddard Space Flight Center \\ Greenbeit, Maryland
}

\begin{abstract}
Many measurements of ionospheric temperature have been made during the last decade and have shown a considerable departure from thermal equilibrium there. Theoretical work has led to a general understanding of the processes which determine the energy balance of the charged particles, and most features of the experimental results are well understood in the F-region. The position in the E-region where different methods of measurement, known to agree well at greater heights, appear to disagree is less clear, whilst in the D-region no direct observations of charged particle temperature exist. The theoretical expectation here is that, on account of the rapid exchange of energy amongst the particles by collisional processes, temperature equality will prevail.
\end{abstract}

\footnotetext{
*This review is based on material published up to January, 1970.

† On leave of absence from Mullard Space Science Laboratory, University College, London.
} 
ELECTRON AND ION TEMPERATURES IN THE IONOSPHERE

\section{INTRODUCTION}

The first direct attempt at measurement of electron temperature in the ionosphere was made in 1947 by Reifman and Dow (1949). Subsequently, a large number of results has become available from rocket, satellite and ground-based observations, and it is found that generally the charged particle temperatures exceed, often by a considerable factor, that of the neutral particles. There are three main reasons why these results are of interest. The charged particle temperatures are important parameters for the distribution of ionisation in the topside ionosphere, where diffusive equilibrium prevails, and influence the rate of recombination at lower altitudes. The redistribution of ionisation following temperature changes may contribute in an apparently anomalous way to the diurnal changes at the layer peak, and changes in recombination rate during ionospheric storms may also be important. The major source of energy which maintains the temperature difference with the neutral gas, with which the charged particles are in thermal contact as a result of collisions, is solar EUV radiation, but the possibility exists of revealing the existence of other sources at night, at high latitudes or during ionospheric storms. Finally, the close relationship between the magnetosphere and ionosphere has to a considerable degree been recognised as a result of the study of charged particle temperatures and the diurnal interchange of energy between these regions.

After the pioneering but unsuccessful attempt of Reifman and Dow to apply in the ionosphere the laboratory technique of the Langmuir probe, development continued in several laboratories resulting in successful results being obtained 
in increasing quantity, both from rockets and from satellites, from 1959 onwards. Durng the same perıod the increasing availability of electron number density protiles for the topside ionosphere, obtained from topside sounding or by other techmques, lead to many analyses of these profiles using the diffusive equilibritm theory and the deduction of plasma temperature from them. Soon after, the suggestion originally made by W. E. Gordon in 1958 that electron temperature might be measured by observing the Thomson scatter of a radio wave from the ionosphere lead to a rapid development of the incoherent scatter technique and the establishment at several locations in Europe and America of observing stations.

This rapid development of experimental methods and the early discovery that at altitudes near $250 \mathrm{~km}$ at least the electron temperature appeared to be substantially above the neutral gas temperature stimulated an interest in the collisional processes which determine the charged particle temperatures. The original basıs of the theory was laid by Hanson and Johnson in 1961 who showed that solar radiation, in ionising the neutral gas, deposited a fraction of its energy in the lonospheric electrons thus raising their temperature significantly. This theory underwent substantial development in the hands of several other authors and it is now clear that it accounts for the major features of the quiet F-region during the day and, surprisingly, is even able to account for a departure from thermal equilibrium which is observed to occur at night when solar radiation is absent. Interest now centres largely around the complicated changes which occur in ionospheric storms, and effects which may be observed over the auroral zone. 
In the $\mathrm{D}$ and $\mathrm{E}-\mathrm{regions}$ the situation is unclear. Several direct comparisons of temperatures measured by different methods have been made, in particular between Langmuir probes and incoherent scatter, with excellent results above $130 \mathrm{~km}$. Below this altitude, no such comparison has been made and here rather a strange inconsistency between the results obtained by the two methods is found. It is thus not clear whether a departure from thermal equilibrium occurs in the E-region; if so, it cannot be sustained by the same collision processes as in the F-region as sufficient energy is not available. On the other hand, it is by no means impossible that solar radiation is the original energy source. At present no direct observations are available in the D-region.

In this paper the principal observing techniques will first be briefly reviewed. Then the theory of solar heating of the ionosphere will be described and' compared with observations of the quiet ionosphere in the F-region. Then the situation in the E-region will be described. Next observations of temperature variability over the solar cycle and during ionospheric storms will be discussed, followed by an açcount of processes of special importance at high latitudes.

\section{TEMPERATURE MEASUREMENTS BY LANGMUIR PROBES}

Electrostatic probes were first used in measurements of the potential distribution in gas discharges by J. J. Thomson, their theory of operation later receiving extensive development through the work of I. Langmuir and his collaborators [ Langmuir (1923) (a), (b), (c), Langmuir and Mott-Smith (1924), Mott-Smith and Langmuir (1926)] . This led to extensive application of probes in the study of gas discharges, and, together with some later developments, paved the way for the application in the ionosphere where conditions are actually 
more favourable for the utilisation of the method than in a gas discharge and where the most elegant applications of it have occurred. Although we shall be concerned with modes of operation of the electrostatic probe which Langmuir had not envisaged, it nonetheless seems appropriate to recognise his leading contributions to the theory by the use of the general term, Langmuir probe.

The Langmuir probe is then an electrode of arbitrary geometry immersed in a charged particle plasma, whose current-voltage characteristic is determined. From it, under suitable conditions, the number densities of the ions and electrons and their energy distribution functions may be obtained. The current to the probe will in general arise from the collection of positive ions, negative ions and electrons from the plasma. Negative ions, however, are present in significant concentrations only in the D-region where collisions near the probe due to the relatively high gas densities render the theory as discussed here inapplicable, so that the presence of negative ions will be ignored. Very few efforts have been made to produce a probe theory applicable in the D-region [Hoult (1965), Hoult and Ta-Jin Kuo (1966), Sonin (1967)]; the results suggest that information on the energy distribution function or temperature cannot be obtained when collisions are important. Besides the collection of charged particles from the plasma, contributions to the probe current may also arise from the emission of electrons from the probe surface due principally to irradiation by sunlight and from the collection of secondary or photo-electrons from the spacecraft surface.

The magnitude of each of these components of the current depends on the potential $V_{p}$ of the probe relative to that of the undisturbed ambient plasma. The basic problem of probe theory is to relate the observed current-voltage characteristic to the energy distribution function of the particles. The properties 
of the regime in which the probe accelerates a given particle type are fundamentally different from that where the particles are retarded, especially as far as the effect of the details of the electric field distribution about the probe are concerned. It is found that relations of more general validity exist for the retarding regime. In the accelerating regime, the results may be affected by the formation of a sheath about the probe. Immediately adjacent to the probe, the plasma will be deficient in particles for which $\mathrm{V}_{\mathrm{p}}$ is repulsive, leading to a region of net space charge density. This will also be a region of large electric field, so that in the presence of a plasma, the electric field strength is stronger close to the probe surface and weaker at large distances, than if the plasma is absent. The region of strong field is called the sheath; its effect is to screen the . plasma from the applied potential on the probe. The sheath thickness depends on $V_{p}$ but is usually $(5-20) \lambda_{D}$, where $\lambda_{D}=\left(\mathrm{kT}_{e} / 4 \pi \mathrm{n}_{\mathrm{e}} \mathrm{e}^{2}\right)^{\frac{1}{2}}$ is the Debye length in the ambient plasma. Obviously, the retarding and accelerating regimes occur simultaneously for the two types of plasma particle, and some experimental method of distinguishing their contributions as well as those of secondary or photoelectrons must be found.

In practice the electron current is usually very much larger than the other contributions except high in the magnetosphere so that a fairly simple correction is sufficient. This can be made by determining the probe current at a large negative potential where the electron current is effectively absent and using this value as the current zero. A more accurate determination, essential in the case of the ions, can be made by using a screened probe [Boyd (1968), Bordeau and Donley (1964)] in which grids are used to separate the different contributions to the 
current. This system requires careful design however because the effect of the fringe fields near the grid wires can be much larger than might have been anticipated.

In practice the Langmuir probe charactèristic can be calculated only in idealised cases and there is in consequence a lárge number of potential sources of error. Intercomparison of probe measurements and of probe and incoherent scatter results, described in Section 6, suggests that these are mostly understood. In this section, we first derive the probe characteristic for certain cases and then discuss briefly the sources of error.

\section{(a) The Retarding Régime}

Consider for definiteness the electron current to a probe of arbitrary geometry immersed in a plasma. We shall suppose the electrons to have a Maxwellian velocity distribution in a coordinate system fixed with respect to the probe. It will be shown in Section 7 that in the ionosphere the electron velocity distribution is quite closely Maxwellian referred to a coordinate system which is co-rotating with respect to the Earth. The mean thermal velocity of the electrons exceeds by an order of magnitude even satellite velocities and Ragab (1968) has shown that the effect of spacecraft movement on the electron probe characteristic is not large. In the retarding regime, the electron density near the probe surface will be given by Boltzman's relation

$$
n_{p}=n_{o} \exp \left(-e V_{p} / k T_{e}\right)
$$

where $n_{p}$ and $n_{0}$ are the electron densities near the probe surface and in the ambient plasma, respectively, and 
$T_{e}$ is the electron temperature,

e is the electronic charge and

$\mathrm{k}$ is Boltzman's constant.

This, of course, is an equilibrium relationship which will be applicable accurately only if the probe surface is perfectly reflecting. However, it will be a good approximation provided the probe surface current density $j_{p}$ is sufficiently small compared with the random current $j_{0}$ in the plasma,

$$
\begin{aligned}
& j_{p}<j_{0} \\
& j_{p}=\frac{1}{4} \text { en } \bar{c}_{e} \\
& j_{0}=\frac{1}{4} \text { en }_{\mathrm{o}} \bar{c}_{e}
\end{aligned}
$$

where $\bar{c}_{\mathrm{e}}$ is the mean thermal velocity of the electrons. In fact, even with this restriction, there are important limitations on the applicability of Eq. (1) which are fưrther discussed in Section $3(b)$ and (c). From (1) and (2) we then obtain Langmuir's expression for the electron retardation characteristic

$$
j_{p}=j_{0} \exp \left(-\mathrm{eV}_{\mathrm{p}} / \mathrm{kT}_{\mathrm{e}}\right)
$$

which may be used to derive both $n_{0}$ and $T_{e}$ from a measured characteristic.

For the ions, too, the assumption of a Maxwellian velocity distribution in co-rotating coordinates may be justified [though see Section 7 (a)], but in the reference frame of the measurements the probe velocity must now be taken into account as it is always comparable with the mean thermal speed of the ions and may exceed it by nearly an order of magnitude. In this case, we may use a 
generalisation of the above approach due to Druyvesteyn (1930). If the velocity distribution function of the particles is isotropic, the ordinate of the energy distribution function being given by $f(V)$, then the equivalent of Eq. (3) is

$$
\frac{\partial^{2} \mathrm{~J}_{\mathrm{p}}}{\partial^{2} \mathrm{~V}_{\mathrm{p}}^{2}}=\frac{\mathrm{e}}{2}\left(\frac{\mathrm{e}}{2 \mathrm{~m}}\right)^{\frac{1}{2}} \mathrm{~V}_{\mathrm{p}}^{-\frac{\mathrm{t}}{2}} \mathrm{f}\left(\mathrm{V}_{\mathrm{p}}\right)
$$

which reduces to (3) in the case of a Maxwellian distribution. In our case, where the velocity distribution is anisotropic it is easy to show that this relation still holds for a spherical probe.

Thus, from the probe characteristic in the retarding régime it is possible to find the energy distribution function (and hence, the number density) of the electrons or the ions. The results are quite independent either of the probe geometry or the precise distribution of the electric field about the probe and so of sheath formation, provided that the particle velocities are isotropic. Otherwise they are valid only for a spherical probe but are still unaffected by sheath formation if the electric field distribution remains spherically symmetric. This condition cannot be precisely satisfied for an anisotropic velocity distribution but appears to obtain with sufficient accuracy in practice.

(b) The Attracting Régime

When the probe potential is such that the particles are attracted to it, determination of the probe current requires that the particle trajectories themselves be determined. This requires a detailed knowledge of the electric field distribution and hence of the sheath formation. No simple solution of the general problem is now passible. It will be instructive to consider the case of a spherical or cylindrical probe of radius $a$. If the Debye length $\lambda_{D}>>a$, the effect of space 
charge can be ignored and the probe current ${ }_{p_{p}}$ is then found to be [Mott-Smith and Langmuir (1926)]

$$
I_{p}=I_{0}\left(1+\frac{V_{p}}{V_{0}}\right)^{a}
$$

where $1_{0}$ is the probe current when $v_{p}=0$

and $\alpha=\frac{1}{2}$ for a cylinder and 1 for a sphere

$\overline{\mathrm{V}}$ depends on the particle energy, being $\mathrm{k} T$ for a Maxwellian distribution and $\mathrm{V}_{\mathrm{o}}$ for a homogeneous stream of energy $V_{0}$. Under these circumstances the probe current is orbital motion limited.

If on the other hand $\lambda_{D}<<a$, the probe is surrounded by a thin sheath. The current density crossing the sheath edge will be $\mathrm{J}_{0}$ while because of the strong radial electric field in the sheath the particles entering the sheath will have a high probability of being swept to the probe. Hence, for all probe potentials

$$
i_{p}=i_{0}
$$

and the probe current is sheath limited.

For intermediate values of $\lambda_{D}$, which is the practical case, the problem arises of what relation should be used in place of (5) or (6). This question was discussed by Mott-Smith and Langmuir (1926) and by Allen, Boyd and Reynolds (1957). In fact (5) is derived from rather general considerations of conservation of angular momentum of the particle, and it is not immediately obvious why it is inapplicable for short $\lambda_{\mathbf{D}}$. It is shown that there is a critical trajectory which is such that all trajectories inside it correspond to particles which are collected, whilst all trajectories outside it are those of particles which miss the probe. 
Eq. (5) is then found to be valid if at the point of closest approach the critical trajectory grazes the probe surface, and ceases to be valid when the sheath field is so strong that the trajectory crosses the probe surface with a radial velocity component. This occurs when the distribution is such that the potential $\mathrm{v}_{\vec{r}}$ at radius $r$ satisfies the inequality

$$
\frac{V_{r}}{V_{p}}<<\frac{a^{2}}{r^{2}}
$$

Since in the absence of space charge the potential falls off less rapidly than (7), it follows that (5) is precisely applicable until some minimum value of $\lambda_{D}$ is reached which, unfortunately, has not been calculated though measured characteristics suggest that (5) is in fact applicable in the ionosphere for small values of probe radius.

Thus we see that in principle the same information, i.e. the number density and mean energy of the particles, may be available from the accelerating as from the retarding characteristic, but that the form of the characteristic now depends both on the geometry of the probe and on $\lambda_{D}$. Evidently such factors as the need for some means of supporting the probe will now result in the occurrence of exrors which would be absent in the retarding regime. The advantages of the latter have caused it to be generally used.

\section{(c) Determination of Ion Temperature}

The method of determining $T_{e}$ will be evident from (a) above, but that used for $T_{1}$ requires some discussion. By means of Eq. (4), the ton energy distribution function can be obtained [Bowen et al (1964(a)), Boyd and Raitt (1964)] Physically it is evident that the mean energy of each ion species of mass $M_{+}$is 
approxamately $E_{o}=\frac{1}{2} M_{+} v_{s}^{2}$ where $v_{s}$ is the spacecraft velocity, the energy spectrum thus containing peaks corresponding to each of the ion species present. Then each peak will be broadened by the ion thermal motions. Medicus (1962) has shown that the energy distribution function for a single species is

$$
\begin{gathered}
f(E)=\sqrt{\frac{k T_{1}}{\pi E_{o}}} \exp \left(\frac{-E-E_{o}}{k T_{1}}\right) \sinh \left[\frac{2\left(E E_{o}\right)^{\frac{1}{2}}}{k T_{1}}\right] \\
\sim \frac{1}{2} \sqrt{\frac{k T_{1}}{\pi E_{o}}} \exp \left(\frac{-\left(E-E_{o}\right)^{2}}{4 E_{o} k T_{1}}\right)
\end{gathered}
$$

when $E_{0}>k T_{1}, T_{1}$ being the ion temperature.

(9) shows that for the heavier ion species such as $\mathrm{O}^{+}$, the peak shape is nearly Gaussian with a width from which the temperature $T_{1}$ can be determined (Figures 3 and 4). The mass separation of the major ions in the $\mathrm{F}$-region $\left(\mathrm{H}^{+}, \mathrm{He}^{+}\right.$ and $\mathrm{O}^{+}$) is so large and the number densities of other constituents so small that the temperature determination is simple in practice.

It is not essential to use a spherical geometry if the form of the distribution function is assumed so that only the parameters $n_{0}$ and $T_{1}$ are to be determined from it. The current voltage characteristic for a plane probe facing in the direction of motion of the spacecraft has been calculated from the one-dimensional equivalent of (8) by Whipple (1959),

$$
\mathrm{J}_{\mathrm{p}}=\frac{e \mathrm{n}_{\mathrm{o}} \mathrm{v}_{\mathrm{s}}}{2}\left[1+\operatorname{erf}(\mathrm{x})+\sqrt{\frac{\mathrm{kT} \mathrm{T}_{1}}{\pi \mathrm{E}_{\mathrm{o}}}} \mathrm{e}^{-\mathrm{x}^{2}}\right]
$$


where

$$
x=\left(\sqrt{\frac{E_{o}}{k T_{1}}}-\sqrt{\frac{e V_{p}}{k T_{1}}}\right)
$$

A curve fitting technique is then used to determine the concentrations of the major ion species and the temperatures from a measured characteristic. The procedure, which is much more difficult than for the spherical probe, has been described by Moss and Hyman (1968) and by Patterson (1969).

\section{(d) Examples of the Method}

Many different probe geometries have been used by different workers (see Boyd (1968) for a description). Here we shall briefly describe two examples of such experiments which are of particular interest on account of the use we shall make of data which has been obtained by them and because they have been intercompared and also compared with incoherent scatter results.

The first is the cylindrical probe used by Spencer, Brace and their collaborators, which has been described for the Explorer XXXI satellite by Findlay and Brace (1969). The probe is a $0.057 \mathrm{~cm}$. diameter wire $46 \mathrm{~cm}$. long, with a guard cylinder over the wire at the support end to reduce the effect of irregularities in the electric field near the support. Such irregularities should not affect the evaluation of $\mathrm{T}_{\mathrm{e}}$ but may shorten the exponential region of the characteristic and lead to errors in the density. A sweep potential from $-3 \mathrm{~V}$ to $+10.5 \mathrm{~V}$ was applied to the probe with a repetition rate of 0.5 cycles/sec. The probe current was measured by two linear amplifiers each with two switched ranges of sensitivity, the outputs being telemetered. A generally similar arrangement has been used in rocket experiments except that the high telemetry sampling rate enables 
a higher sweep rate to be used [Spencer, Brace, Carignan, Taeusch and Neumann $(1965)]$. Figure $1(\mathrm{c})$ shows the accelerating portion of the probe characteristic which is only roughly of the form given by (5) with $a=\frac{1}{2}$. Since the current rises more rapidly than would be expected the difference from the expected form cannot be the result of sheath formation. It probably is due to the electric fields near the end of the probe remote from the guard electrode. Figure 1(b) shows the electron retardation characteristic, from which the method of determining the vehicle potential and also the probe current at space potential can be seen.

The use of probes based on Druyvesteyn's relation (4) has been described by Bowen et al [1964(a), 1964(b)] and by Wrenn (1969). Small amplitude sine waves of two different frequencies in the audio range are applied to the probe, and the intermodulation component, which is proportional to $\partial^{2} \mathrm{j}_{\mathrm{p}} / \partial \mathrm{V}_{\mathrm{p}}^{2}$, is selected by a tuned amplifier. By applying a sweep voltage as well, the quantity $V^{-\frac{1}{2}} f(V)$ is traced out, from which if desired $f(V)$ can be obtained. Figure 2 shows a spherical ion probe. The central ion collector is $9 \mathrm{~cm}$. in diameter. It is surrounded by an electroformed grid $10 \mathrm{~cm}$. in diameter with holes $0.7 \mathrm{~cm}$. diameter, the grid material being $65 \mu$ thick. The grid transparency is $35 \%$. The probe is mounted on a short boom to avoid the major effects of the spacecraft wake [ see Section $3(d)]$. Figure 3 shows the probe characteristic for an ion mixture and Figure 4 shows a comparison between the observed and best-fitting characteristics.

\section{SOURCES OF ERROR IN PROBE MEASUREMENTS}

Probe measurements are potentially subject to errors from a number of sources. It will be shown in Section 6 that reliable results can be obtained 
provided they are carefully taken into account. Here each of them will be . briefly discussed.

(a) Photo-emission

If any part of the probe system is at a negative or small positive potential with respect to the surrounding region, photo-electrons may be liberated by sunlight. Because of the large amount of the UV energy which is concentrated in the Lyman- $\alpha$ line at $1216 \AA$, which has sufficient quantum energy to release electrons from all the materials likely to be used, the photo-current is not greatly dependent on the work function of the material chosen. $5 \times 10^{-9} \mathrm{amp} / \mathrm{cm}^{-2}$ is a typicai value for tungsten, gold or rhodium. This is about equal to the positive ion component of the probe current for densities. in the range $(0.3-3) \times 10^{5} \mathrm{~cm}^{-3}$ so its effect must be eliminated in some way. Ov̀er the electron retardation characteristic the photo-current is constant so that it may be determined at a suitably large negative probe potential and simply subtracted at other negative potentials. Alternatively a suppressor grid can be used in front of the collector. Since the energies of the emitted photo-electrons do not exceed a few eV, a negative bias of this amount relative to the collector will suppress photo-emission from the collector although that from the grid still remains. When the probe is operated in the ac or Druyvesteyn mode, the effects of photo-emission are automatically suppressed over the electron retardation characteristic. The simplest solution of all, in some circumstances, is to ensure that the probe remains in the shadow of the spacecraft.

\section{(b) Geomagnetic Field}

In the theory briefly developed in Section 2 , the effects of the geomagnetic field were neglected, which is entirely justified for the positive ions on account 
of their large gyro-radius in comparison with the probe dimensions usually employed. For the electrons, where these quantities are of the same order, more careful consideration is needed. The presence of a magnetic field does not affect the electron energies, but by reducing $1_{0}$. makes the condition (2) more stringent. It would therefore be expected that at sufficiently negative potentials, $T_{e}$ could still be measured by the use of (3), but that $j_{\circ}$ and hence $n_{0}$ could not be accurately measured as $\mathrm{V}_{\mathrm{p}} \rightarrow 0$.

The application in the ionosphere of earlier theoretical work has been discussed by Dote et al (1965). They show that the retarding potential method for $\mathrm{T}_{\mathrm{e}}$ remains valid at sufficiently great probe potentials, i.e. when

$$
V_{p}>A B^{2} d^{2}
$$

where $B$ is the geomagnetic field intensity in oersted, $d$ is the sheath thickness in $\mathrm{cm}$. and the constant $\mathrm{A}$ is $8.8 \times 10^{-2}$ volts (oersted $\left.\mathrm{cm}.\right)^{-2}$ for a plane probe and $2.2 \times 10^{-2}$ volts (oersted $\left.\mathrm{cm}.\right)^{-2}$ for a cylindrical probe. Since in the ionosphere B does not exceed 0.6 oersted and $d$ is usually less than $2 \mathrm{~cm}$, we find even for a plane probe that (10) requires $V_{p}>0.126$ volts which is not in practice a very stringent condition except at low values of $T_{e}$ such as may occur in the $\mathrm{D}$ and $\mathrm{E}-\mathrm{regions}$.

The requirement that the effect of the magnetic field be small at $v_{p}=0$ can be met only if the probe radius a is sufficiently small, in the case of a spherical probe less than $0.5 \mathrm{~cm}$. in diameter. Smith (1969) has detected a magnetic field effect on a nose-tip probe maintained at an accelerating potential, the probe being approximately a cone with a base diameter of $2.5 \mathrm{~cm}$. and an included angle of $11^{\circ}$. 
Raitt (1969) on the other hand mounted two plane probes $2 \mathrm{~cm}$. diameter with a guard ring of outer diameter $4 \mathrm{~cm}$. on ESRO IA. This spacecraft was stabilised with respect to the geomagnetic field and the probes were mounted so that the field was parallel to the surface of one and perpendicular to that of the other. The electron densities determined by the two probes agreed to within $10 \%$ except when one of the probes was in its own wake. These results are qualitatively at least in agreement with the conclusions of Dote et al.

It appears that the geomagnetic field is unlikely to cause error in the measurement of $\mathrm{T}_{e}$ in view of the practice of using an extended portion of the exponential characteristic in estimating its slope but for probes larger than $1 \mathrm{~cm}$. in dimensions, errors in the determination of $\mathrm{n}_{0}$ will occur.

\section{(c) Collisions}

The discussion of Section 2 will be invalidated if the charged particles being collected collide either with neutral or other charged particles near the probe. It is probable that the accelerating characteristic will be most affected. It is possible that a similar argument to that advanced in the case of the geomagnetic field can be used here also, and that at sufficiently negative potentials the measwrement of $T_{e}$ is unaffected. The region of applicability of the Langmuir treatment in the ionosphere has never been precisely determined but it is usually assumed to apply when the mean free path exceeds either the sheath thickness or the effective probe dimensions, allowing for the effect of the electric field in the accelerating regime. This is at altitudes of $85-90 \mathrm{~km}$ for the dimensions usually employed. This assumption is of some importance in view of an apparent discrepancy between incoherent scatter and probe measurements of $\mathrm{T}_{\mathrm{e}}$ below 
$130 \mathrm{~km}$. which might be the result of unexpected collisional effects on the probe, though this does not seem very likely.

Hoult (1965), Hoult and Ta-Jin Kuo (1966) and Sonin (1967) have treated the case of the probe where many collisions occur; it appears in this case that the charged particle number densities can still be obtained but information on the energy distribution is lost.

(d) The Spacecraft Wake

The formation of the wake has been the subject of many theoretical studies [for an account see Henderson and Samir (1967)] . Of these one which gives a simple physical picture and results which are in excellent agreement with observations is that due to Gurevich (1962). The relatively large energies of the ions in the spacecraft reference frame and the limitation of the spacecraft electric field to a fairly thin sheath together ensure that the ion trajectories are little affected by the spacecraft unless they are intercepted at its surface. The spacecraft potential is usually attracting for the ions, and'its velocity is comparable with or greater than the mean ion thermal speed even for rockets so that ions in the path of the spacecraft are simply swept up on the front surface, leaving behind a void. Since few ions have sufficient speed to overtake the spacecraft a conical surface is formed as the ions behınd the spacecraft move in towards the axis with the mean thermal velocity. Thus the wake consists predominantly of an approximately conical rarefaction whose length is about $a_{s} v_{s} / \bar{C}_{1}$ where $a_{s}$ is the spacecraft radius (assumed spherical). Since $\lambda_{\mathfrak{D}}<<a_{\mathfrak{s}}$, the electron density must now adjust itself to the ion density, except for a small excess required to - charge the wake negative and so produce a density reduction in accordance 
with (1). The wake thus acquires a negative potential of $5-10 \mathrm{kT}_{e} / \mathrm{e}$. The electron density in the wake, for a satellite at altitudes where the ions are predominantly $\mathrm{O}^{+}$may fall to $1 \%$ of the ambient value, the ion densities being even less. In front of the spacecraft, which reflects the bulk of the electrons, a smaller negative potential, less than $\mathrm{k}_{\mathrm{e}} / \mathrm{e}$, will develop. This, acting on the ions, will slightly raise the density above the ambient value. Evidently, the spacecraft significantly modifies the density distribution in its vicinity. Changes in $T_{e}$, however, in the absence of significant collisions, are very much less likely to occur. Even the effects of the density changes may largely be avoided by suitably positioning probes on a spacecraft which is stabilised relative to the velocity vector, or by the use of booms whose length is $1-2$ spacecraft diameters.

The Ariel I wake has been extensively investigated [Samir and Willmore (1965), Henderson and Samir (1967)] and shown to conform to this picture. Figure 5 shows the electron density depletion observed.

\section{(e) Spacecraft Potential}

The probe has so far been treated as an isolated electrode, but the potential distribution about it is actually influenced by the charge distribution on the spacecraft. Moreover, the spacecraft is used as the reference potential for the probe sweep circuits and the probe and spacecraft act as a double probe which as a whole can collect no net current from the ionosphere because its capacitance is small [Boyd (1968)] .

The first of these effects will be greatest when the probe is mounted in the surface of the spacecraft. This case has been treated in detail by Whipple and Parker (1969) assuming that $\lambda_{D}$ is very large so that space charge effects are 
negligible. This is the worst case since the effect of space charge is to screen the probe from the influence of the spacecraft through the formation of a sheath. They show that, where the probe and spacecraft potentials have the same sign but the magnitude of the probe potential is smaller, or where the potentials are opposite in sign, a saddle point in potential develops in front of the probe. This is because the influence of the probe potential dominates near the probe, but that of the spacecraft at large distances. Thus for particles for which the spacecraft potential is repulsive - the electrons in the usual case - a potential barrier develops around the probe and the probe current density will not reach the value given by Eq. (3) if the total current drawn would exceed that across the barrier. In an extreme case the knee in the probe curve occurs at satellite potential instead of at space potential. This can be considered as the result of reducing $\mathrm{J}_{\text {。 }}$ In (2) and Langmuir recognised the possibility of such an effect in noting that a probe placed in a re-entrant cavity might not be able to draw the full current. The probe characteristic for large potentials of the same sign as that on the spacecraft is unaffected, so that in the usual case the electron retardation characteristic at large negative potentials is not affected, and measurements of $T_{e}$ can still be made.

Results in agreement with these conclusions have been obtained by Wrenn (1969) on Explorer XXXI. The electron density measured by a plane probe mounted in the spacecraft skin is found to be much lower under some circumstances than the ion density or the density obtained by the comparison topside sounder in Alonetto II. The difference is found (Figure 6) to decrease as $\lambda_{D}$ decreases and the screening effect of the spacecraft sheath is felt. On the other hand $\mathrm{T}_{\mathrm{e}}$ measured by this probe is in agreement with that derived from other 
probes on Explorer XXXI [see Section 6(a)]. The diameter of the guard ring of this probe was $4 \mathrm{~cm}$. Another plane probe $8.5 \mathrm{~cm}$. in diameter mounted on this satellite [Donley (1969)] did not show this effect.

The potential adopted by the spacecraft is"also of interest because this is in practice the reference for the probe sweep circuit. If for the moment it is supposed that the probe is at floating potential, i.e. the potential at which the-net current is zero, then the spacecraft must also be at floating potential, since the capacitance is too small for a current to flow for any significant time [Boyd (1968)]. The electron current far exceeds that due to photo-emission or positive ions except at great heights so that the spacecraft must acquire a negative charge to reeach floating potential, usually of about $(5-10) \mathrm{k} \mathrm{T}_{\mathrm{e}} / \mathrm{e}$. Photo-emission will tend to reduce or even to reverse this potential. Samir and Willmore (1966) have shown that the potential of Ariel I fits well this description. Whipple (1965) showed that certain spacecraft have taken up much larger potentials, invariably negative relative to the ionosphere. This was due to the presence of portions of the solar cell array and its wiring which were at large positive potentials relative to the spacecraft, which, tending to draw a large electron current, drove the whole system negative. It was noted in Section 2(d) that space or spacecraft potential can be determined from the probe curve. Laṛge negative values are only objectionable if the effect described by Donley and Parker occurs. The principal experimental problem, however, is that if the spacecraft attitude changes, as when for example it is rotating, then the different components of the current may vary causing instability in spacecraft potential and distortion of the probe curve. This effect is most severe at low sweep rates and for ion probes which have an extended retarding characteristic. A.C. probes are almost immune 
since only potential variations during the period of the lowest frequency used are important.

Next consider what happens as the probe potential itself varies as a result of the applied ramp voltage. The spacecraft potential must also change so this must either be made sufficiently small or be accurately predictable if the change. in probe potential relative to the plasma is to be known. No particular difficulty will be encountered with an ion probe as the current collected is always likely to be small, but the first condition can only be satisfied with an electron probe if its area is made $1000-2000$ times less than the superficial area of the spacecraft. If small parts of the spacecraft are at such positive potentials that they may approach space potential, their area should be subtracted from the permissible probe area calculated in this way. The alternative, rarely adopted, is to use a double probe in which the geometry and surface treatment of the spacecraft are such that it, too, can be treated as a probe. This imposes rather severe constraints and the double probe system must usually be a separate ejected package [Spencer et al (1962)] .

(f) Variations in Work Function

Also effectively in serres with the probe sweep generator is any contact potential difference between the probe and the spacecraft, so that the stability of the work functions of each of these is of as much importance as that of spacecraft potential. According to Wilson and Garside (1968), variatıons in work function over the surface of a probe may vary from a few $\mathrm{mV}$ where considerable precautions are taken to as much as $200 \mathrm{mV}$ if the surface is handled. It is easy to show that when the probe is so negative that the entire surface is on the 
exponential portion of the characteristic, measurements of $\bar{T}_{e}$ will be unaffected. The main effect is to increase the rounding of the characteristic near space potential and to introduce possible errors in the determination of $n_{0}$. A potentially more serious problem [Sayers (1969)] are slow variations in probe work function during the sweep since these distort the probe characteristic. A.C. probes, due to the short effective measuring time, have an inherent advantage here also.

\section{(g) Aerodynamic Effects}

It is usually assumed that aerodynamic effects will become impórtant only in the D-region where the mean free path becomes smaller than typical rocket dimensions and a shock wave and its associated heating effects will develop. Smith et al (1968), however, noted a tendency for higher electron temperatures to be measured on the ascent than on the descent of the rocket trajectory even in the E-region. He used a nose-tip probe and presumäbly larger effects would be expected than with the other geometries usually employed. In other measurements such a systematic assymetry does not seem evident.

\section{(h) Rocket Outgassing}

If gas is emitted either from the interior of the spacecraft or from a spent . or liquid fuel motor in the vicinity of the probe, the probe current may be reduced because of collisions between the charged and neutral particles and also because of the local depletion of ionisation as the neutral gas cloud expands. These effects can be controlled either by careful sealing or venting of the payload space and if necessary by ejecting the spent motor case. Since the evolution of gas will be greater on the ascent of a rocket trajectory the resulting errors will be greatest then. Comparison of ascent and descent results suggests that the effects on $T_{e}$ are not usually large. 


\section{MEASUREMENTS OF IONOSPHERIC PROPERTIES}

\section{BY INCOHERENT SCATTER}

It was first suggested by Gordon in 1958 that a sensitive radar with a large aperture aerial might be used to study the ionosphere by irradiating it with a radio wave and observing as a function of height the intensity of the scattered wave resulting from Thomson scattering by the free electrons. Próvided that the electrons are randomly distributed in space, the scattering cross-section per unit volume and solid angle is

$$
\sigma=\mathrm{n}_{\mathrm{o}} \sigma_{\mathrm{c}}
$$

where $\sigma_{c}$ is the classical value for the electron cross section

$$
\sigma_{c}=\left(\frac{\mathrm{e}^{2}}{\mathrm{mc}^{2}}\right)^{2}
$$

Moreover, on account of the thermal motions of the electrons Gordon believed that the scattered line would be Doppler broadened and that from its spectral distribution the electron temperature could be found. The first successful observations were made at $41 \mathrm{MHz}$ by Bowles (1958) who found that the spectral width of the scattered line was approximately two orders less than this prediction. This had the important practical consequence that a substantially less sensitive system could be used to make successful measurements. As to the explanation of the narrow scattered line, Bowles suggested correctly that since the wavelength employed was considerably larger than $\lambda_{\mathfrak{p}}$, fluctuations in the electron gas could not be considered without taking into account the effect of the ions. He proposed that the effect of the Coulomb forces was to give the electron 
density fluctuations (which are certainly predominantly responsible for the production of the scattered wave) the velocity spectrum of the ions, so that the spectral width was actually a function of $T_{1}$.

The problem of calculating the precise spectral distribution was tackled rather differently by Dougherty and Farley (1960), Fejer (1960), Salpeter [1960(a), 1960(b)] and Hagfors (1961) for the iso-thermal case, i.e. where $T_{e}=$ $\mathrm{T}_{1}$, identical results being obtained. In each case, the spatial distribution of the electrons is considered random, so that the scattered power is proportional to the number density of electrons and the Lorentz method in which an electron is considered to oscillate sinusoidally in the electric field of the radio wave is used. This leads to the following expression for the scattering cross-section per unit volume of a small volume element $\mathrm{V}$

$$
\sigma=\sigma_{\mathrm{c}} \mathrm{v}<|\mathrm{n}(\mathrm{K})|^{2}>
$$

where $K$ is the difference of the incident and scatter ed wave vectors $(K=4 \pi / \lambda$ for backscattering), and $n(K)$ is the spatial Fourier component of the electron density functions. $<>$ represents as usual the expectation value in the sense of statistical mechanics. Physically this relation implies that the scattering results from refractrve index variations of scale $\lambda / 2$.

Where the methods differ is in the calculation of $\left\langle\left.\operatorname{n}(\mathrm{K})\right|^{2}\right\rangle$. Hagfors uses Boltzman's distribution function exp $\left(-\frac{W}{K T}\right)$ for a state of the plasma of energy W. The plasma energy is the sum of that arising from the kinetic energy of the particles, and the electromagnetic energy. The latter term is attributed to electrostatic energy only, arising from the Coulomb interactions of the 
particles, which can be expressed in the terms of the ion and electron density fluctuations giving

$$
\left\langle\left.\underset{h}{n}(K)\right|^{2}\right\rangle=\frac{n_{0}}{V} \frac{1+2 X_{p}^{2}}{1+4 X_{p}^{2}}
$$

where

$$
X_{p}=\frac{1}{\sqrt{2}}\left(\frac{1}{k \lambda_{D}}\right)
$$

Thus, as $\mathrm{K} \rightarrow \mathrm{O}\left(\lambda>\lambda_{\mathrm{D}}\right.$, the case usually encountered $) \sigma \rightarrow \mathrm{n}_{\mathrm{o}} \sigma_{\mathrm{c}} / 2$. The scattering cross-section is one-half the value for Thomson scattering, the reduction resulting from the effect of the ions in inhibiting fluctuations in $\mathrm{n}_{\mathrm{e}}$. However, as $\mathrm{K} \rightarrow \infty$, the scale of the fluctuations becomes small and the coupling effect of the Coulomb fields negligible, so $\sigma \rightarrow \mathrm{n}_{\mathrm{o}} \sigma_{\mathrm{c}}$ as in (11).

In order to obtain the spectrum of the scattered wave, the Fourier transform of the density fluctuations both in space and time, $n(K, \omega)$ must be obtained. The component of frequency $\omega$ will lead to a Doppler shift of $\omega$ in the scattered wave. If the ion-electron mean free path were short compared with $\lambda$, fluctuations in density of wave vector $K$ would be sinusordal corresponding to an acoustic wave at a single frequency $\omega=\mathrm{C}_{\mathrm{ac}} \cdot \mathrm{K}$ where $\mathrm{C}_{\mathrm{ac}}$ is the acoustic velocity. When the mean free path is long (as in our case) such waves are heavily damped. Then, if the ions were absent, these sinusoidal fluctuations would be replaced by random fluctuations resulting from the thermal motions of the electrons and it is clear that the apparent velocity of regions of high or low density will be related to the mean thermal speed of the electrons. Similarly, the spectrum of the ion 
density fluctuations of wave vector $\mathrm{K}$ will be governed by the mean ion thermal speed. When Coulomb forces are considered the fluctuations in electron number density when $\mathrm{K} \lambda_{\mathrm{D}}$ is small are constrained to be nearly equal to those of the ions and take on correspondingly a frequency spectrum related to the ion thermal speed $\bar{c}_{1}$.

One aspect of this process is well revealed by the approach taken by Dougherty and his collaborators. They note that the density fluctuations (on the square of which the plasma energy depends in part) can be treated as a generalised coordinate of the plasma. Then, if a plasma admittance is defuned in terms of the response of this co-ordinate to a sinusoidal driving force at the frequency $\omega$, the density fluctuations can be obtained from the real part of this admittance using the "generalised Nyquist theorem". If the admittance is not purely imaginary, then dissipation of the wave in the plasma must occur (corresponding of course to the generation of the scattered wave) and the question of the mechanism of this energy dissipation then arises. In the absence of the wave, the electron density fluctuations in space will be random. When the radio wave is present, a degree of order is impressed on the electron gas which will now tend to fluctuate in density with wavelength $\lambda / 2$. Gonsider two regions of high density which are at some instant $\lambda / 2$ apart. Because of the thermal motions these will tend to move relative to each other but the influence of the wave is to maintain the separation at $\lambda / 2$. To do this, the electron velocities must be changed, i.e. work must be done on the plasma. This process is Landau damping and we see that the interaction of the waves is with the electrons whose kinetic velocity equals the "phase velocity" $\omega / \mathrm{k}$ of the fluctuations. 
Figure 7 shows a normalised spectrum of the scattered line calculated by Hagfors (1961) for an atomic oxygen plasma. The variable

$$
\mathrm{x}=\left(\frac{\mathrm{m}}{2 \mathrm{kT}}\right)^{\frac{1}{2}} \frac{\omega}{\mathrm{K}}
$$

is the ratio of the phase velocity to the most probable electron velocity. $x_{p}$ is the value of $X$ when $\omega=\omega_{p}$, the plasma frequency. For $X_{p}<1$, the scattered line is a single peak of width $\mathrm{X} \sim 1$ as expected from Thomson scattering. When $X_{p}>>1$, the principal peak is reduced in width by a factor $(M / m)^{\frac{1}{2}}(M$ the ion mass, $m$ the electron mass) which is 172 in this case. Some effect of the electron motions can still be seen when $X_{p}$ is not too large, in the form of a weak extension of the spectrum to $X=1.0$. Note that, since the presence of the ions has narrowed the line considerably whilst reducing the total scattering only by a factor of two, the amplitude is much enhanced. A striking feature also to be explained is the occurrence of a narrow scattered line, the "plasma" line, at $x=x_{p}$.

Whilst acoustic waves are strongly damped in a plasma of low collision frequency, one collective motion still exhibited by the electrons is longitudinal plasma waves. In the absence of a magnetic field the dispersion relation for these waves is

$$
\omega=\omega_{\mathrm{p}}\left[1+3\left(4 \pi \lambda_{\mathrm{D}} / \lambda\right)^{2}\right]^{\frac{1}{2}}
$$

showing that for waves of wave vector $K$

$$
\left.\begin{array}{rl}
\omega & =\omega_{\mathrm{p}}\left(1+3 \mathrm{~K}^{2} \lambda_{\mathrm{D}}^{2}\right)^{\frac{1}{2}} \\
& \sim \omega_{\mathrm{p}}
\end{array}\right\}
$$


The sinusoidal density fluctuations in these waves leads to a narrow line nearly at the plasma frequency. For a plasma in thermal equilibrium the power scattered in the plasma line is, relative to that in the main peak, $\mathrm{K}^{2} \lambda_{\mathrm{D}}^{2}$ which is much less than 1 [Perkins, Salpeter and Yngvessen (1965)]. However, the waves are as we have seen excited by electrons whose kinetic velocity is close to the phase velocity. For typical ionospheric values of $\omega_{p}$ and at wave frequencies of $400 \mathrm{MHz}$, electrons of about $10 \mathrm{eV}$ are required. Thus, the amplitude of the plasma line depends on the high energy tail of the electron energy distribution. We shall see in Section 7 that this is strongly enhanced in the daytime by a photoelectron flux resulting from photo-ionisation by sunlight. This enhancement is of the order of a factor of 50 and has been observed at Arecibo. The velocity distribution of the photo-electrons is strongly anisotropic as they are constrained to spiral up or down the geomagnetic field lines, so that the intensities of the two plasma lines on either side of the incident wave frequency are not necessarily equal, but enable the flux of photo-electrons towards and away from the transmitter to be determined. By observing the amplitude of the plasma line at various heights above $300 \mathrm{~km}$. where the photo-electrons are free from collisions, the variation of $\omega_{\mathrm{p}}$ enables the photo-electron spectrum to be explored from $6-20 \mathrm{eV}$ [ Yngvessen and Perkins (1968)].

The above treatment has been extended to the case where $T_{e}$ and $T_{1}$ are unequal, as is generally true in the ionosphere, by Fejer (1961) and Farley (1966). Results calculated by Loewenthal from Fejer's theory are shown in Figure 8. The spectrum now depends in detailed shape on $T_{e} / T_{1}$, though the width is still controlled by ${ }^{\prime} T_{1}$. 
The influence of the geomagnetic field has been discussed by Farley et al (1961), Fejer (1966), Hagfors (1961). It is found to be surprisingly small until the propagation is very nearly (i.e. within about $5^{\circ}$ ) perpendicular to the field . line. In the case of quasi-longitudinal propagation, by far the commonest case, the relations already given in the absence of $B$ can be accurately used. When the propagation is transverse however lines develop in the spectrum as shown in Figure 9 at multiples of the ion gyro-frequency. It was at first hoped that these would enable incoherent scatter to be used as a "magnetic mass spectrometer" , but the stringent observational criteria have prevented this hope from being realised. Physically, this is because the random motions of the ions along the field line (which are not inhibited by the field) smooth out the effects of their rotation about the field except at very large angles, where the Doppler. shift due to the movement along the field line becomes very small or zero. Hence therrather narrow peaks due to the rotation about the field become smoothed out in the quasilongitudinal case.

For the special conditions of thermal equilibrium (i.e. where $T_{e}=T_{1}$ ) the fact that the Boltzman distribution is still applicable in a magnetic field (since the charged particle energies are not changed) enables the argument which led to (14) still to be used. Thus, although the spectral distribution is modified by the magnetic field, the total scattering cross-section is unchanged. This is not true when $T_{e} \neq T_{1}$ [Barron and Petriceks (1967)].

At altitudes near and below $120 \mathrm{~km}$. the effects of collisions with the neutral particles must be considered [Dougherty and Farley (1963), Farley (1966), Seasholtz and Tanenbaum (1969)]. Again if $T_{e}=T_{1}$, the scattered power is 
unaffected because the Boltzman distribution may be used, but otherwise the scattered power, and in any case the spectrum, are changed.*

The theory thus far described predicts that the scattered line will be symmetrical about the incident wave frequency. If the ionosphere as a whole is moving relative to the transmitter along the line of sight, this will introduce a displacement of the scattered line. In this way the wind velocity in the line of sight can be measured. Such movements have been observed by Vasseur and Waldteufel (1969) who attributed them to the neutral atmosphere motion resulting from internal gravity waves.

In addition to measurements of the scattered power and its spectral distribution, we can add that of the polarisation of the scattered wave, at least provided a rather low frequency $(50 \mathrm{MHz})$ is used. The wave is subject to the usual Faraday rotation characteristic of quasi-longitudinal propagation in a magnetoionic medium (Ratcliffe, 1956) and from the variation of rotation with height the electron density can be obtained. Many parameters $-T_{e}, T_{1}$, ionic composition [Moorcroft (1964)], magnetic field (which can often be neglected), electron density and collision frequency - influence the spectral shape and in the presence of experimental errors it is not possible to determine them all by curve fitting and to obtain a reasonable precision. Hence some simplifying assumption must usually be made, or one of these parameters must be independently determined. The scattered power is determined by $\mathrm{T}_{\mathrm{e}} / \mathrm{T}_{1}$, electron density and the magnetic field (whose effect, once again, can usually be neglected). Ass it is difficult to determine the absolute scattered power with satisfactory precision, the usual

\footnotetext{
*There is an interesting parallel between the results of this and the preceding paragraph and the corresponding conclusions in the case of the regarding régime of the Langmuir probe.
} 
practice is to determine the shape of the electron density profile from the relative variation of the scattered power and to normalise the profile at some point such as the F-region maximum by an independent observation of electron density. Altérnatively, the process may be inverted if the electron density profile is known either from plasma line or Faraday rotation measurements [Farley (1967)] or otherwise [Maynard and Ducharme (1965)] and $T_{e} / T_{1}$ determined. This determines one parameter which must otherwise be determined from the spectral distribution.

The observed spectrum of the scattered line is also influenced by instrumental effects, since usually the operation as a radar requires that a pulse be transmitted in order to determine the range of the scattering region. Then, the scattered spectrum is the convolution of the pulse spectrum with that due to the ionosphere; this spectrum will be modified then due to the finite bandwidth of the receiver. These effects may be computed and the modified spectrum compared with that observed [Evans and Loewenthal (1964)] but rather more elegant procedures which involve either the use of a CW bistatic radar as at St. Santin - Nançay [Carru et al (1967)] or a dounble pulse techniques in which the auto-correlation function of the received pulse is determined [Farley et al (1967)] enable them to be avoided. With a pulsed radar, the resulting spectrum is an average over a height interval, typically $75 \mathrm{~km}$., governed by the pulse Iength. With a CW system, the determining factor is the intersection of the two aerial radiation patterns and the height resolution may be as good as $5 \mathrm{~km}$.

Table I gives brief characteristics of some incoherent scatter stations. The reduction procedures differ somewhat at these stations, and so also do the number of parameters determined from the scattered spectrum. For our purpose 
Table I

Characteristics of Some Incoherent Scatter Observatories

\begin{tabular}{|c|c|c|c|c|}
\hline Station & Arecibo & Jicamarca & Millstone Hill & St. Santin \\
\hline Latitude & $18^{\circ} \mathrm{N}$ & $11.95^{\circ} \mathrm{S}$ & $42.6^{\circ} \mathrm{N}$ & $44.7^{\circ} \mathrm{N}$ \\
\hline Longitude & $67^{\circ} \mathrm{W}$ & $76.87^{\circ} \mathrm{W}$ & $71.5^{\circ} \mathrm{W}$ & $2.2^{\circ} \mathrm{E}$ \\
\hline Radar type & Pulse & Pulse & Pulse & $\mathrm{CW}$ \\
\hline Aerial type & Parabola & $\begin{array}{l}\text { Dipole } \\
\text { array }\end{array}$ & Parabola & \\
\hline $\begin{array}{l}\text { Aerial aperture, } \\
\mathrm{m}^{2}\end{array}$ & $7.1 \times 10^{4}$ & $8.4 \times 10^{4}$ & $1.9 \times 10^{3}$ & $2 \times 10^{3} *$ \\
\hline $\begin{array}{l}\text { Operating frequency } \\
\qquad \mathrm{MHz}\end{array}$ & 430 & 49.92 & 440 & \\
\hline $\begin{array}{l}\text { Peak Transmitter } \\
\text { Power MW }\end{array}$ & 2 & 5 & & $0.075^{\dagger}$ \\
\hline Pulse Length, $\mu \mathrm{S}$ & & 200,267 & 500,1000 & - \\
\hline
\end{tabular}

it is sufficient to note that $T_{e}$ and $T_{1}$ are determined separately at each, except that the assumption may be made in the E-region that $T_{e}=T_{1}$.

\section{INDIRECT DETERMINATIONS OF PLASMA TEMPERATURE}

Many attempts have been made to determine the plasma temperature by methods less direct than those described in the previous sections, e.g. from the 
altitude variation of ion composition. The method most extensively employed uses observations of the altitude profile of electron number density in the topside ionosphere. The scale height $\mathrm{H}$ defined by

$$
\partial\left(\ln n_{0}\right) / \partial Z=-1 / H
$$

is assumed to have the value appropriate to an isothermal ionosphere

$$
\mathrm{H}=2 \mathrm{k} \mathrm{T}_{\mathrm{p}} / \overline{\mathrm{M}}_{1} \mathrm{~g}
$$

where $\mathrm{k}$ is Boltzmann's constant, $\mathrm{g}$ the local value of the acceleration of gravity, $M_{x}$ the mean positive ion mass and $T_{p}=\left(T_{e}+T_{1}\right) / 2$ the plasma temperature. Either $\mathrm{H}$ is determined for an altitude at which it is believed that some constituent such as $\mathrm{O}^{*}$ is so predominant as to give $M_{1}$ as the mass of that constituent, or an attempt is made to determine an ion composition which will reproduce the observed number density profile.

The equilibrium of the ionisation in the topside $\mathrm{F}$-region has been discussed by Bauer (1969). The equation of continuity

$$
\partial n_{0} / \partial t=q-L+\nabla \cdot\left(n_{0} v\right)
$$

where $v$ is the transport velocity of the ionssation and $q$ and $L$ are respectively the volume production and loss rates of ionisation, shows that several scale heights above the F-region maximum where $\mathrm{q}$ and $\mathrm{L}$ have become small, and under steady state conditions where $\partial \mathrm{n}_{\mathrm{o}} / \partial \mathrm{t}$ approaches zero,

$$
\nabla \cdot\left(\mathrm{n}_{\mathrm{o}} \mathrm{v}\right)=0
$$

This has two solutions, $n_{\circ} r=$ constant and $r=0$, the electron density profiles for which will approach one another at increasing altitudes as the 
ambipolar diffusion coefficient increases. The solution $v=0$ leads to

$$
H=\frac{2 T_{p}-}{2 \partial T_{p} / \partial Z+M_{1} g / k}
$$

In the presence of the geomagnetic field this result will still be correct provided that it is applied to the electron number density variation with altitude measured along the field line since this is the direction in which the ionisation diffuses. The importance of this is greatest at low dip latitudes [Rishbeth et al (1966)]

The first point which arises is the applicability of (22) in view of the assumptions, particularly that $v=0$, which have been made in its derivation. For this simultaneous measurements of $n_{0}, T_{p}$ and ion composition are required. Brinton et al (1969) and Brace et al (1969) analysed profiles obtained in a rocket flight and found the scale height between 300 and $400 \mathrm{~km}$ to be only about half the value given by (22), increasing between 400 and $500 \mathrm{~km}$ to the expected value without any large corresponding change in $\mathrm{T}_{\mathrm{p}}$. The difference was attributed to ionisation movements, the combined results of an upward flux of $\mathrm{H}^{+}$and a neutral wind. Wrenn and Smith (1969) obtained scale height values from topside 'sounder electron density profiles from Alouette II and values of $M_{2}$ and $T_{p}$ from a.c. probes on Explorer XXXI for effectively identical locations and deduced the required values of $\partial T_{p} / \partial Z$ from (22). Values ranging from -1 to $+1.5 \mathrm{~K} / \mathrm{km}$ were obtained. Colin et al (1969), in a very similar analysis using different data from the same spacecraft, obtained similar results. Gradients of $0.2-1.0^{\circ} \mathrm{K} / \mathrm{km}$ are also obtained from incoherent scatter profiles of $T_{e}$ and $T_{1}$ at lower altitudes, and values of $0.6-1.2^{\circ} \mathrm{K} / \mathrm{km}$ may be deduced from satellite observations of $\mathrm{T}_{\mathrm{e}}$ at different altitudes [Prasad (1968), Moorcroft (1969), Willmore (1965), Mahajan 
and Brace (1969)], except that negative gradients have not been observed. Over a limited altitude range negative gradients in $T_{1}$ could result from composition changes [Banks (1966b)] resulting in negative gradients of $T_{p}$. It seems likely that the temperature gradients deduced from the diffusive equilibrium density distribution thus agree well with those measured directly, hence confirming the applicability of the scale height expression over a wide range of ionospheric conditions above $500 \mathrm{~km}$. at least to an accuracy of $\pm 10 \%$.

On the other hand, the application of this result to the deduction of $T_{p}$ is very difficult, since neither the temperature gradient nor the proportion of light ions is easily predicted. Matuura and Ondoh (1967) analysed Alouette II profiles and showed that, even if the atmosphere was assumed isothermal, it was impossible to determine whether or not a small proportion of $\mathrm{He}^{+}$was present, leading to uncertainty of about $20 \%$ in $\mathrm{T}_{\mathrm{p}}$ from this cause alone. Taieb (1969) combined Alouette electron density profiles with near-simultaneous values of $T_{p}$ obtained from incoherent scatter, and so was able to deduce values of the temperature gradient and the light ion proportion, but it seems unlikely that this would have been possible unless $T_{p}$ had been known. In all other attempts to deduce $T_{p}$, the temperature gradient and the effects of contamination by light ions were simply ignored. This, for results obtained near $500 \mathrm{~km}$, may lead to errors of between $-25 \%$ and $+100 \%$. Evidently these results are less reliable than those obtained by the other methods we have described, and we shall not therefore discuss them further. 


\section{COMPARISON OF TEMPERATURES OBTAINED BY, PROBES AND INCOHERENT SCATTER}

Measurements of temperature obtained by probes mounted on satellites and by incoherent scatter stations are somewhat complimentary, the satellites giving good geographical coverage and also results to higher altitudes, whilst the radars give good seasonal, diurnal and altitude coverage up to their maximum altitude of operation. It is therefore of importance to know how far both sets of observations are consistent and how well different variants of each basic method can be compared, though the latter comparison is possible only for the probes. The first attempt at such a comparison was made by Evans (1965c) using incoherent scatter results from Millstone Hill and probe results from Explorer XVII and Ariel I. Large day-by-day fluctuations in $\mathrm{T}_{\mathrm{e}}$ occur at any location, so that unless strictly simultaneous observations for a given location are used, a sufficiently large number of observations to give accurate mean values must be used. Moreover, the sets of observations used by Evans did not cover the same epoch. Evans did make one near-simultaneous set of observations with a rocket launch of the cylindrical probe, but rather large scatter in his results makes the comparison inconclusive. Subsequently several sets of observations have been obtained which enable a more satisfactory comparison to be made.

\section{(a) Intercomparison of Langmuir Probes}

In the ISIS series of satellites, Explorer XXXI was launched as a piggy-back to Alouette II. The Iatter carried a topside sounder and a cylindrical probe, whilst the former carried cylindrical and planar Langmuir probes operated in a dc mode, and a plane probe operated in an ac mode [Brace and Findlay (1969), Donleý (1969), 'Wrenn (1969)] together with a plane ion trap operated in a dc mode 
and a spherical ion probe operated in an ac mode [Donley (1969), Wrenn (1969)] . The cylindrical probes on the two spacecraft were similar and so afford an opportunity of assessing the possible influence of the spacecraft on the probe. The two spacecraft separated at $13 \mathrm{~km} /$ day, passing through the same region of space with a time delay which increased from zero at launch at a rate of $1.6 \mathrm{sec} /$ day. Brace and Findlay (1969) compared corresponding probe curves and concluded that they were generally in agxeement to better than $10 \%$, nor was there evidence for any systematic difference between the results for the two spacecraft, despite the presence on Alouette II of long aerials and the topside sounder transmitter.

The three Langmuir probes on Explorer XXXI were intercompared on five passes where $T_{e}$ ranged from $1500-4000^{\circ} \mathrm{K}$ [Donley et al (1969)]. The results were generally consistent to within $20 \%$. The ac mode Langmuir probe gave a result which on'an average was $12 \%$ less than the cylindrical probe, whilst the dc mode plane probe was $3 \%$ lower than the cylinder. It appears that there is no evidence for an effect of geometry on the result, but the ac technique gives a result 10-12\% lower than the de version. No intercomparison of the probe calibrations was carried out prior to launch, so any effects of calibration errors are allso reflected in these results. The rms deviations of the ratios of the temperatures obtained by the two pairs of probes were $13 \%$ and $9 \%$ so that considerable non-systematic differences also existed. Since the probe measurements were not strictly simultaneous, these could arise from temperature fluctuations along the satellite track, but examination of the results shows that the temperature ratios are usually more consistent within each pass than they are from pass to pass, which suggests that this is not the explanation. The discrepancies are greatest at the lowest altitudes. 
The ion temperatures cover a range of $1000-3000^{\circ} \mathrm{K}$. The results obtained on the five passes, on three of which $\mathrm{H}^{+}$was the dominant ion and on two $\mathrm{O}^{+}$, show marked discrepancies, the mean ratio of $T_{2}$ for the plane to the spherical probe being 1.454 with no clear dependence on ion species. The latter feature is surprising, since the most likely source of error seems to be stray electric fields in the sheath or near the grids used, which should affect $\mathrm{H}^{+}$far more than $\mathrm{O}^{+}$on account of the much lower mean energy. Knudsen (1966) concluded however that these errors would actually be negligible for a plane probe and it is not obvious that they should be greater for a spherical probe. The spherical probe is operated in an ac mode which we have seen also gives lower electron temperatures. Donley et al (1969) concluded that the plane probe $T_{2}$ values are in better general agreement with incoherent.scatter results which were however not taken simultaneously. Subsequently simultaneous results were obtained for the St. Santin and Malvern incoherent scatter stations which provide strong support for the spherical probe results. These will be described in the next section. The unexplained discrepancy between the two probes is clearly unsatisfactory and suggests that measurements of $T_{1}$ were not made by these methods with the same reliability as $T_{e}$.

A comparison of the values of $n_{e}$ with those obtained from the Alouette II topside sounder was also made. If the results from the spherical ion probe which was mounted on a boom are ignored, a small systematic discr.epancy remains, the probe values of $n_{e}$ being about $3 \%$ higher than those given by the topside sounder. Since the probe measurements are all made on the forward side of the satellite relative to the velocity vector, this may be the density enhancement there due to the ram effect. 
(b) Comparison of Probes with Incoherent Scatter

The first attempt to compare probe and incoherent scatter observations was that of Hanson et al (1969) using passes óf Explorer XXXII near the incoherent scatter radar at Jicamarca. A comparison of 5 passes distributed in local time showed the probe results for $T_{e}$ to be systematically higher, on an average by a factor of 1.7. On 1968 March 17, rockets carrying (inter alia) cylindrical probes were launched near the Arecibo station in Puerto Rico at local times of $03^{\mathrm{h}} 30^{\mathrm{m}}$ and $15^{\mathrm{h}} 30^{\mathrm{m}}$ [Brace, Carlson and Mahajan (1969)] . The day profiles of $\mathrm{T}_{\mathrm{e}}$ show agreement within $5 \%$, whilst at night the probe results were systematically $10-15 \%$ the higher, though the successive radar profiles show fluctuations of this order which may account for the difference. The altitùde range of comparison was $130-290 \mathrm{~km}$ in the day and $210-290 \mathrm{~km}$ at night.

- Booker and Smith (1969) have compared cylindrical probe results $\left(\mathrm{T}_{\mathrm{S}}\right)$ from Explorers XXXI and XXXII and Alouette II with incoherent scatter values $\left(T_{B}\right)$ of $\mathrm{T}_{\mathrm{e}}$ taken near-simultaneously at Jicamarca, Arecibo and Millstone Hill and have concluded that the relation between these is

$$
T_{B}=084 T_{S}-400
$$

This corresponds to a considerably larger disagreement between the two estimates of $T_{e}$ than in the case of the rocket flights just mentioned.

On 1968 April 23 a day pass of Explorer XXXI near St. Santin enabled a' comparison of the ac probe and incoherent scatter results to be obtained [Henderson et al (1969)]. Unfortunately the radar profiles could not be taken above $425 \mathrm{~km}$ whilst the satellite altitude was $575 \mathrm{~km}$ at closest approach. 
Figure 11 shows the results from which it is clear that the satellite observations represent reasonable extrapolations of the radar data with a gradient of $0.8^{\circ} \mathrm{K} / \mathrm{km}$ for $\mathrm{T}_{1}$ and $2.0^{\circ} \mathrm{K} / \mathrm{km}$ for $\mathrm{T}_{\mathrm{e}}$. A discrepancy exceeding $200^{\circ} \mathrm{K}$ or $10 \%$ for $\mathrm{T}_{\mathrm{e}}$ and $15 \%$ for $T_{1}$ would be unlikely. In particular, raising $T_{1}$ by a factor of 1.454 , as required by the ion trap [see Section $6(\mathrm{a})$ ] would bring $\mathrm{T}_{1}=\mathrm{T}_{\mathrm{e}}$ at $600 \mathrm{~km}$, which also seems unlikely.

Similar (but more extensive) comparisons between the Explorer XXXI ac probes and Malvern incoherent scatter values of $T_{e}$ and $T_{1}$ were made by Taylor and Wrenn (1970). They found the values of $\mathrm{T}_{e}$ over the range $1000-3000^{\circ} \mathrm{K}$ to be in excellent agreement. The values of $\mathrm{T}_{1}$ over the range $700-1500^{\circ} \mathrm{K}$ showed a large scatter but there was little evidence of systematic disagreement.

The difference between the ac and cylindrical probes on Explorer XXXI may either reflect the characteristics of the particular instruments on that spacecraft, or a more fundamental effect of the different techniques used. This point is of sufficient interest to suggest a more extensive comparison of the earlier satellite measurements of Ariel I and Explorer XVII with the radar data. No direct comparisons were of course made. The principal difficulty arises from the day-today variability of electron temperature. This will be minimized in observations made at moderate altitudes near the geomagnetic equator since here $\mathrm{T}_{\mathrm{e}}$ never rises far above $T_{n}$. Figure 11(a) shows that Jicamarca and Ariel $I$ values of agree well with determinations of $T_{n}$ from the drag on Explorer $I$, and fairly well with exosphere temperatures estimated from the Harris and Priester formula [Priester, Roemer and Volland (1967), Jacchia and Slowey (1966)] . The Explorer XVII $\mathrm{T}_{e}$ values, however, agree well only after adjustment by Eq. (23). These observations were made at a geomagnetic latitude of $10^{\circ} \mathrm{N}$, so that in the 
day temperatures up to $250^{\circ} \mathrm{K}$ above the equatorial values might be expected. The adjusted values are $100-150^{\circ} \mathrm{K}$ higher.

A similar comparison can be made for latitudes near $40^{\circ} \mathrm{N}$ geomagnetic [Figure 11(b)] . At night the Ariel I and adjusted Explorer XVII observations are in good agreement with Arecibo values. The pronounced seasonal variation which is a feature of the Millstone Hill temperatures [see Section 7(c)] makes comparison with that station more difficult, but the summer temperatures do not agree too badly. It seems possible that the Ariel I temperatures are about $100^{\circ} \mathrm{K}$ low. During the day, the variability of $\mathrm{T}_{e}$ - indicated by the range shown for the Arecibo values - makes the comparison no longer possible.

From these results it seems most probable that the Ariel I ac probe gave results close to the radar values and hence that the discrepancy between the two types of probes, reflects a genuine difference resulting from the different techniques employed.

We can conclude that the cylindrical and planar dc probes are in good agreement, that the de probes give higher values of $T_{e}$ than either the ac probes or the incoherent scatter, and that the last two techniques are in good agreement. The high values obtained by the dc probes are not associated with the geometry, the use of retardıng grids or the spacecraft, and presumably therefore arise as a result of measuring the dc current rather than the derivatives of the characteristic. The high consistency obtained between the cylindrical probes on different spacecraft shows that this is not connected with the current measuring system itself. The most likely explanation appears to be that advanced by Sayers (1969) that the effective contact potential of the probe surface varies slowly with the probe 
potential, the varuations being small in the rather short time period of the low frequency waves used in the ac technique $(2 \mathrm{mSec})$ but significant in the rather longer time (tens to hundreds of $\mathrm{mSec}$ ) required to sweep through the retarding characteristic. Further laboratory and ionospheric experiments would be needed to confirm this hypothesis.

In the E-region, below $130 \mathrm{~km}$, there is no such direct comparison data available. The situation there will be further discussed in Section 8 .

\section{TEMPERATURE OF THE MIDLATITUDE IONOSPHERE ABOVE $140 \mathrm{~km}$}

It will be convenient to consider aspects of the behaviour of the temperature distribution in the ionosphere under several different headings. Above $140 \mathrm{~km}$ the major and probably the only source of energy heating the ionosphere is solar radiation, except under conditions of exceptional disturbance or at high latitude. We can thus divide the ionosphere into regions above and below $140 \mathrm{~km}$. Under very disturbed conditions, such as in the vicinity of aurorae, this division ceases to have any significance and simular processes occur at all altitudes. Below $140 \mathrm{~km}$, cooling of the ionosphere by collisions becomes very efficient, and it is very difficult to account for the temperature enhancement often observed.

The first account of the processes determining the ion and electron temperatures in the regron with which we are now concerned was given by Hanson and Johnson (1961) and was soon extended by Hanson (1962). When a neutral particle is ionised by a solar EUV or X-ray photon, the photo-electron produced has as kinetic energy the excess of the quantum over the ionisation energy of the neutral. This energy, which is typically $10 \mathrm{eV}$, is then imparted by collisions to the neutral gas and to the ambient electrons, the latter predominating at high altitudes 
and when the photo-electron energy falls below $1.5 \mathrm{eV}$. Thus, out of the initial energy, at $300 \mathrm{~km}$, most of it is passed directly to the ambient electrons, the amount falling at lower altitudes to $1 \mathrm{eV}$ at $100 \mathrm{~km}$. This energy is rapidly randomised by electron-electron collisions, resulting in an enhancement of $\mathrm{T}_{\mathrm{e}}$ * above the gas temperature $\mathrm{T}_{\mathrm{g}}$. Because of this temperature difference, the electron gas now loses energy by collisions both to the positive ions and to the neutral gases. This results in an enhancement of $\mathrm{T}_{1}$, so that the positive Ions also lose energy to the neutral gas in ion neutral collisions, the ions taking up an intermeduate temperature between $\mathrm{T}_{\mathrm{e}}$ and $\mathrm{T}_{\mathrm{g}}$.

Thus all the photo-electron energy terminates in the neutral gas and is finally removed by downward conduction and by radiation. The conductivity of the atmosphere is high so that through most of the region $\mathrm{T}_{\mathrm{g}}$ varies little with altitude [Figure 12(a)] and its geographical variation is largely determined simply by the zenith distance of the sun [Figure 12(b)] leading to a small decrease in $\mathrm{T}_{\mathrm{g}}$ at high Iatitudes. These figures are taken from the review by Jacchia (1965) which discusses other influences on $\mathrm{T}_{\mathrm{g}}$.

Above about $300 \mathrm{~km}$, the range of the photo-electrons emitted in an upward direction becomes very long, so that an upward flux through the magnetosphere and into the conjugate ionosphere is produced. Some energy is deposited in the magnetosphere, raising the temperature there, whilst the rest contributes to heating the conjugate ionosphere. The magnetospheric heat is removed bythermal conduction to low altitudes where it is passed to the neutral gas by collisions so that a gradient of $T_{e}$ and $T_{x}$ along the field lines is established throughout the magnetosphere and upper ionosphere. 
Thìs basic picture has undergone a good deal of refinement and elaboration without modification in essentials. In subsequent sections a detailed account will be given and compared with observation. Before"doing so, however, it will be natural to ask whether,-under conditions which depart so markedly from thermal equilibrium, it is permissible to talk of kinetic temperature at all. The photoelectrons of course represent an enhanced high energy tail in the Maxwellian distribution which was shown by Hoegy et al (1965) to contain $10^{-3}-10^{-4}$ of all the electrons present. The effect of an electric field component perpendicular to the geomagnetic field was considered by Megill and Cahn (1964) who showed that for a field of $100 \mathrm{mV} / \mathrm{m}$, an extremely large value, a depletion of the tail occurs above $1.6 \mathrm{eV}$, the relative deficiency amounting to about $10^{-3}$ of all the particles. Dalgarno and Henry (1965) consider ed the possible effect of photodetachment from $\mathrm{O}_{2-}$ in the $\mathrm{D}$-region which has a similar effect to ionisation at greater heights in releasing energetic electrons, and found that the enhanced tail included about $10^{-3}$ of the electrons. Thus it appears likely that electron-electron collisions are effective at maintaining a Maxwellian distribution except above $1 \mathrm{eV}$ where deviations involving about $10^{-3}$ of the electrons are to be expected. Banks (1968) has considered the effects of collisions on the ions. For an $\mathrm{H}^{+}-\mathrm{O}^{+}$ mixture, in which $\mathrm{H}^{+}$is in the minority, he finds that a Maxwellian distribution will be maintained for $\mathrm{O}^{+}$, but significant distortion of the velocity distribution for $\mathrm{H}^{+}$will occur. Thus when light ions are minor constituents we may expect them to have non-Maxwellian distributions, although the major ions will still have a Maxwellian distribution. Except in this case therefore, no difficulty is likely to arise in the interpretation of experimental results, or in the idealisation. of the velocity distribution in theoretical computations by the use of a Maxwellian function. 
Hitherto, the linearity of the semi-log plots obtained with Langmuir probes has been considered strong evidence for the existence of a Maxwellian energy distribution for the electrons. On the other hand, the discrepancies between the dc probes and incoherent scatter could result from non-Maxwellian distributions at low energies, to which the semi-log plots are not very sensitive. This possibility should be borne in mind in the subsequent discussion.

\section{(a) Energy Balance During The Day}

All solar radiation at shorter wavelengths than the photo-ionisation thresholds of the atmospheric gases contributes to the energy input in the day. Of the excess quantum energy of the ionising photon which appears as kinetic energy of the photo-electron, a fraction only, called the heating efficiency $\epsilon$, is available to heat the electron gas. The remainder is lost in collisions with other particles, predominantly those of the neutral gas. The starting point in calculations of $\epsilon$ and the total heat input $Q$ (which below the photo-electron escape level is $\epsilon$ multiplied by the rate of ionisation) is a measurement of the absolute intensity of the solar spectrum [see, e.g. Hinteregger (1969)] . Together with a model atmosphere and Iaboratory or theoretical data on photo-ionisation cross-sections, this enables the rate of production of photo-electrons of various energies to be determined. Several collisional processes contribute to the degradation of this initial energy. At higher altitudes, where the neutral particle concentration is sufficiently low, Coulomb elastic collisions with the ambient electrons dominate, and nearly the entire photo-electron energy is available for heating. Here $\epsilon$ approaches the mean initial kinetic energy. Lower down scattering by the neutral gas first predominates. For photo-electron energies above $5 \mathrm{eV}$, the important 
collisional process is electronic excitation-of $0, \mathrm{O}_{2}$ or $\mathrm{N}_{2}$, but for energies between $1.5 \mathrm{eV}$ and $5 \mathrm{eV}$ this is replaced by vibrational excitation of $\mathrm{N}_{2}$. Only when vibrational excitation becomes ineffective at still lower energies is the energy loss to the electrons once again important, so that only the last $1.5 \mathrm{eV}$ of the photo-electron energy contributes to the heating and $\epsilon=1.5$ at these altitudes. $\epsilon$ and $Q$ have been calculated in this way by several workers [Hanson (1962), Dalgarno et al (1963), Dalgarno et al (1967), Dalgarno et al (1968b), Herman and Chandra (1969), Nagy et al (1969)], with typical results shown in Figure 12. In these calculations the escape of the photo-electrons is neglected so that it must be remembered that not all of the available energy is deposited where it is released above $300 \mathrm{~km}$, although $\epsilon$ correctly indicates the relative importance of the different scattering processes at these altitudes. Since both the production and loss rates of the photo-electrons are obtained, the number density drstribution may also be calculated [Dalgarno et al (1963), Hoegy et al (1965), Nisbet (1968)], (Figure 12). At lower altitudes the structure in the energy spectrum resulting from the transition from one collision process to another can be clearly seen; this disappears at greater heights where only collisions with the ambient electrons are important. At these altitudes the spectrum is rather flat, extending from about $1 \mathrm{eV}$ to $30 \mathrm{eV}$. The energy spectrum of the escaping photo-electron flux will be similar to this.

The values of $Q$ shown in Figure 12 neglect the effect of photo-electron excape. From an analysis of Ariel I data which showed high values of $\mathrm{T}_{\mathrm{e}}$ to be maintained to $1200 \mathrm{~km}$, Willmore (1964) noted the need for a source of energy at this height in excess of the direct solar input and suggested Coulomb collisions with the ambient electrons of the photo-electrons which were spiralling upwards 
from lower altitudes as Hanson proposed. Geisler and Bowhill (1965b) called this non-local heating and they, from a discussion of the escape process, showed (Figure 15) that it exceeded the local heating by an order of magnitude a few scale heights above the escape level, which is at approximately $300 \mathrm{~km}$. Physically it is evident that the escape flux will be a fraction of all the ionisations occurring above the escape level $\mathrm{z}_{\mathrm{e}}$, the fraction depending on the proportion of electrons emitted in an upward direction, and on the proportion of these which are scattered downwards. Geisler and Bowhill found for the escape flux $G$ the expression

$$
G=\frac{H Q\left(z_{e}\right)}{6}
$$

where $\mathrm{H}$ is the scale height of the ionisable constituent and $\mathrm{Q}\left(\mathrm{z}_{\mathrm{e}}\right)$ the ionisation rate at the escape level. A detailed discussion of the process is complicated. The angular distribution of the emitted photo-electrons must first be taken into account as well as the effects of the magnetic field along which they spiral [Mariani (1964)] . Scattering by both neutral particles and electrons will be important in defining the escape level [Geisler and Bowhill (1965b)] . A single collision will not always be sufficient to stop an electron moving upwards and multiple scattering must be taken into account [Geisler and Bowhill (1965b), Lejeune and Petit (1969)]. Nisbet (1968) has shown that in estimating the escape flux at various phases of the solar cycle, variations in the escape level due to changes in atmospheric temperature are important. He finds values for the particle and energy fluxes as shown in Table II.

These results can be compared with several measurements of the photoelectron flux. It was noted in Section 4 that the upward and downward fluxes 
Table II

\begin{tabular}{ccc}
\hline $\begin{array}{c}10.7 \mathrm{~cm} \text { Solar Flux } \\
\left(\times 10^{-22} \mathrm{~W} / \mathrm{cm}^{2} \mathrm{sec} \mathrm{Hz}\right)\end{array}$ & $\begin{array}{c}\text { Escaping } \\
\text { Photo-Electron Flux } \\
\left(\mathrm{el} / \mathrm{cm}^{2} \mathrm{sec}\right)\end{array}$ & $\begin{array}{c}\text { Escaping } \\
\text { Energy Flux } \\
\left(\mathrm{eV} / \mathrm{cm}^{2} \mathrm{sec}\right)\end{array}$ \\
\hline 75 & $5.24 \times 10^{8}$ & $5.43 \times 10^{9}$ \\
150 & $4.81 \times 10^{8}$ & $5.70 \times 10^{9}$ \\
225 & $7.28 \times 10^{8}$ & $9.81 \times 10^{9}$ \\
\hline
\end{tabular}

can be deduced from the intensity of the plasma line in incoherent scatter observations. Moreover, a portion of the electron energy spectrum can be scanned from the height variation of the line intensity since as the height and hence the plasma frequency vary, so does the electron velocity required to excite the plasma waves. Observations of this kind made at Arecibo by Yngvesson and Perkins (1968) showed the spectrum to fall smoothly from 6 to $20 \mathrm{eV}$. In the day, upward and downward fluxes were about equal, showing that at this latitude most photo-electrons survived the passage through the magnetosphere. In the period 1966 Dec-1967 Mar. soon after the solar minimum, the particle flux was in the range $(3-10) \times 10^{8} \mathrm{el} / \mathrm{cm}^{2} \mathrm{sec}$ and the energy flux $(3-13) \times 10^{9} \mathrm{eV} / \mathrm{cm}^{2} \mathrm{sec}$. Measurements made in 1965 Dec.-1966 June by Narasinga Rao and Donley (1969) and by Maier (1969) using retarding potential analysers on Explorer XXXI show the spectrum to have a broad peak from 3-13 eV, the maximum particle fluxes being $2.5 \times 10^{8} \mathrm{el} / \mathrm{cm}^{2} \mathrm{sec}$. All these measurements are in good general agreement with the figures in Table II and with the calculations of Nagy et al (1969) but are substantially greater than those calculated earlier by Geisler and Bowhill. 
Once the photo-electron flux and spectrum are known the energy gained by the ambient electrons is readily calculated from the expression given by Butler and Buckingham (1962) for the energy loss by Coulomb collisions by electrons of energy $\mathrm{E}$, which reduces when $\mathrm{E}>3 \mathrm{eV}$ [Dalgarno et al (1963)] to

$$
\frac{\mathrm{dE}}{\mathrm{dx}}=-195 \times 10^{-12} \mathrm{n}_{\mathrm{e}} / \mathrm{E} \mathrm{eV} / \mathrm{cm}^{2}
$$

A number of collisional processes contribute to the cooling of the electron gas by the neutral atmosphere, including elastic collisions, rotational and vibrational excitation of $\mathrm{O}_{2}$ and $\mathrm{N}_{2}$ and excitation of $\mathrm{O}\left({ }^{3} \mathrm{P}\right.$ ) to the ${ }^{1} \mathrm{D}$ level [Dalgarno et al (1967b)] . However, Dalgarno and Degges (1968) showed that transitions by electron impact amongst the three fine structure levels of 0

$$
e+0\left({ }^{3} P^{2}\right) \rightarrow e+0\left({ }^{3} P_{\mathrm{J}^{3}}\right)
$$

where it was assumed that collisions with the neutral gas were sufficiently rapid to maintain the distribution amongst these levels close to that corresponding to the gas temperature $T_{g}$, would represent the dominant loss process to the neutral atmosphere. The relative rates of these processes are shown in Figure 16*.

Above $300 \mathrm{~km}$, the falling density of 0 makes this process less effective than the direct energy transfer to the positive ions in elastic collisions. This leads to a loss rate

$$
L_{1 e}=\frac{810^{-6}}{M_{1} T_{e}^{3 / 2}} n_{e_{1}} n_{1}\left(T_{e}-T_{1}\right) e V / c c s e c
$$

\footnotetext{
*In the discussions of this problem published prior to that of Dalgamo and Degges, and in some which appeared subsequently, the neglect of fine structure cooling leads to a sertous underestimate of the electron cooling rate.
} 
[Banks (1966c)], where $T_{1}$ and $n_{2}$ are the temperature, and number density of ions of mass $M_{x}$ (in $\left.a m u\right)$. Because of the more efficient energy transfer to light ions the thermal coupling of the ion and electron gases increases with altitude.

The processes by which the energy thus gained by the ions from the electrons is communicated to the neutrals have been extensively discussed by Banks (1966c). The energy transfer rate is

$$
L_{1 g}=A n_{1} n_{g}\left(T_{1}-T_{g}\right)
$$

where $\mathrm{n}_{\mathrm{g}}$ is the number density of a neutral constituent. For ions which are not moving in their parent gas (e.g., $\mathrm{He}^{+}$in O) the energy loss is largely due to elastic collisions and may be calculated from the polarisability of the gas. The values of $A_{p}$ given in Table III have been obtained in this way. The errors resulting from the use of the polarisation interaction in the case of $\mathrm{H}^{+}$in He at temperatures higher than $300^{\circ} \mathrm{K}$ have been considered by Dalgarno and Dickinson (1968) who whow that the error does not exceed $20 \%$. For ions which are moving in their parent gas (e.g., $\mathrm{O}^{+}$in $\mathrm{O}$ ) an important additional contribution to the energy loss arises from charge exchange which has a large cross-section at low energies in this case. It is also an effective cooling process as the initial velocities of ion and neutral particle are intercharged in the collision. The effect is important when $\left(\mathrm{T}_{1}+\mathrm{T}_{\mathrm{g}}\right)$ exceeds $500-1000^{\circ} \mathrm{K}$, i.e. generally in the atmosphere. The appropriate loss coefficient $A_{c e}$ is given also in Table III.

The steady state value of the ion temperature will now be established between $T_{e}$ and $T_{g}$ at such a value that the difference between the energies gained and lost by collisions with the electrons and the neutrals is just balanced by the 
Energy Transfer Coefficients (eV/cc sec) For Ion-Neutral Collisions According To Banks (1966c)

\begin{tabular}{lccc}
\hline Particles & $\mathrm{A}_{\mathrm{p}} \times 10^{14}$ & Particles & $\dot{\mathrm{A}}_{\mathrm{c} e}\left(\mathrm{~T}_{2}+\mathrm{T}_{\mathrm{g}}\right)^{-1 / 2} \times 10^{15}$ \\
\hline $\mathrm{O}^{+}-\mathrm{N}_{2}$ & 6.6 & $\mathrm{H}^{+}-\mathrm{H}$ & 14.0 \\
$\mathrm{O}^{+}-\mathrm{O}_{2}$ & 5.8 & $\mathrm{O}^{+}-\mathrm{O}$ & 2.1 \\
$\mathrm{O}^{+}-\mathrm{He}$ & 2.8 & $\mathrm{~N}^{+}-\mathrm{N}$ & 2.1 \\
$\mathrm{O}^{+}-\mathrm{H}$ & 3.3 & $\mathrm{He}^{+}-\mathrm{He}$ & 1.4 \\
$\mathrm{H}^{+}-\mathrm{O}$ & 3.5 & $\mathrm{O}_{2}^{+}-\mathrm{O}_{2}$ & 2.7 \\
$\mathrm{H}^{+}-\mathrm{N}_{2}$ & 3.1 & $\mathrm{~N}_{2}^{+}-\mathrm{N}_{2}$ & \\
$\mathrm{H}^{+}-\mathrm{He}$ & 5.5 & & \\
$\mathrm{He}^{+}-\mathrm{O}$ & 5.8 & & \\
$\mathrm{He}^{+}-\mathrm{H}$ & 10.0 & 5.3 & \\
$\mathrm{He}^{+}-\mathrm{N}$ & & & \\
\hline
\end{tabular}

net transport due to thermal conduction. If for the moment the latter contribution is ignored, this requires that $\mathrm{L}_{1 \mathrm{e}}=\mathrm{L}_{1 \mathrm{~g}}$. At low altitudes where $\mathrm{n}_{\mathrm{g}}$ is large, $\mathrm{T}_{1} \sim \mathrm{T}_{\mathrm{g}}$; at greater altitudes (in practice at $600-800 \mathrm{~km}$ ) $\mathrm{T}_{1} \sim \mathrm{T}_{\mathrm{e}^{\cdot}}$ Because of the dependence of $\mathrm{L}_{1 \mathrm{e}}$ on $\mathrm{M}_{1}^{-1}$, and because of the different constants which enter into $\mathrm{L}_{\mathrm{ig}}$, the different ion species present will tend to take up different temperatures [Banks (1967), Dalgarno and Walker (1967)]. The energy, transfer rates between different ion species are about an order greater than those to the neutrals, so the variation in $T_{1}$ is substantially less than $T_{e}-T_{1}$. Moreover, the collision rate between ions of the same species is larger yet except for the minor constituents so that as we have already noted a Maxwellian velocity 
distribution is maintained except for minor species. Banks finds that $\mathrm{T}\left(\mathrm{H}^{+}\right)-$ $\mathrm{T}\left(\mathrm{O}^{+}\right)$may reach $170^{\circ} \mathrm{K}$ at $310 \mathrm{~km}$ (or a rather larger value when the distortion of the velocity distribution of $\mathrm{H}^{+}$is considered) whilst the difference for $\mathrm{He}^{+}$is only one-quarter as large.

When $T_{1} \sim T_{e}$ at considerable altitudes the effective energy loss rate for the electron gas becomes $\mathrm{L}_{1 \mathrm{~g}}$, which falls in proportion to $\mathrm{n}_{\mathrm{e}} \mathrm{n}_{\mathrm{g}}$, whilst from (25) the energy input due to the photo-electrons is proportional to $\mathrm{n}_{e}$. Thus at some altitude due to the fall in $n_{g}$, we might expect very large values of $T_{e}$. In fact the temperature rise in the topside ionosphere is limited by the fairly high conductivity $\mathrm{K}$ of the electron gas along the magnetic field lines [Hanson (1963), Willmore (1964), Geisler and Bowhill (1965b)]. Spitzer (1956) gives

$$
\begin{aligned}
\mathrm{K} & =20(2 / \pi)^{3 / 2}\left(\mathrm{kT}_{\mathrm{e}}\right)^{5 / 2} \mathrm{k} / \mathrm{m}^{1 / 2} \mathrm{e}^{4} \ln \Lambda \\
& =7.7 \times 10^{5} \mathrm{~T}_{\mathrm{e}}^{5 / 2} \mathrm{eV} / \mathrm{cm} \text { sec deg } \mathrm{K}
\end{aligned}
$$

where $\Lambda$ is a cut-off parameter for the Coulomb interaction, taken to be 15 in the ionosphere (may be 13-19). Above $500 \mathrm{~km}$ a temperature gradient of about $1-2^{\circ} \mathrm{K} / \mathrm{km}$ is established which is sufficient for all the energy deposited to be conducted down to altitudes where it can be passed to the neutral gas by collisions. Whereas in the lower ionosphere the temperature is governed by the balance between local heating and collisional cooling, in the upper ionosphere it is determined by non-local heating and thermal conduction.

This situation was first discussed by Geisler and Bowhill (1965b) and subsequently by Nisbet (1968). It is found that some effect of thermal conduction is 
observed even near and below the F-region peak in smoothing out local irregularities of temperature which might occur. Geisler and Bowhill also suggested that it may cause $T_{e}$ to fall below $T_{g}$ in the E-region, but Banks (1966a) pointed out that there the high gas density limits the electronic thermal conductivity to a lower value than Spitzer's expression gives and that allowing for this eliminates the negative values of $\mathrm{T}_{\mathrm{e}}-\mathrm{T}_{\mathrm{g}}$. Above $500 \mathrm{~km}$ the temperature rises steadily to a value which, in the equatorial plane, is calculated to be $3000-5000^{\circ} \mathrm{K}$. Temperatures of this order have been observed by Serbu and Maier (1966) at altitudes of several thousand $\mathrm{km}$.

Banks (1967b) has studied the effect of thermal conduction amongst the ions. Below 500-600 km, there is little effect, $T_{2}$ being slightly enhanced by heat conducted down from above. At greater heights $T_{1}$ remains significantly lower than $\mathrm{T}_{\mathrm{e}}$. In one example where $\mathrm{T}_{\mathrm{e}}=2600^{\circ} \mathrm{K}, \mathrm{T}_{\mathrm{g}}=1000^{\circ} \mathrm{K}, \mathrm{T}_{\mathrm{i}}$ is $2500^{\circ} \mathrm{K}$ without and $2250^{\circ} \mathrm{K}$ with thermal conduction.

(b) Behaviour of Ionospheric Temperature by Day

Taking all of the factors described in the lasst section into account, it becomes possible to calculate model profiles of $T_{e}$ and $T_{2}$ which can be compared with observation. Dalgarno et al (1968) made calculations of this sort for comparison with incoherent scatter results for Millstone Hill for 1963 July (Figure 17). The agreement is generally good except that the heat input must be reduced by about $60 \%$ at $200 \mathrm{~km}$ where the calculated temperatures are too high. "Nagy et al (1969) also made calculations for Millstone Hill and obtain temperatures which were rather too low near $200 \mathrm{~km}$ suggesting that the discrepancy may be quite sensitive to the details of the calculation such as the assumed solar spectrum and 
photo-ionisation cross-sections. Herman and Chandra (1969) made a similar computation for Arecibo, but obtained $\mathrm{T}_{\mathrm{e}}$ values which were slightly too low above $170 \mathrm{~km}$. Lejeune and Petit (1969) calculated Q values for St. Santin profiles of $T_{e}$ and $T_{1}$ from $120-500 \mathrm{~km}$, and found the observed values to be less than the calculated, which they attributed to the effect of non-local heating which they believed to be important down to $200 \mathrm{~km}$. Despite these relatively small discrepancies, there is little doubt that the solar radiation provides the majority of the energy input to the day ionosphere.

Another respect in which the calculations of Dalgarno et aI (1968) failed to match the observations was that the computed temperatures show a smaller height gradient in the topside ionosphere than is observed. In these calculations, non-local heating and thermal conduction was neglected. In the calculations of Nagy et al, not only were these effects included, but so also was the energy balance of the magnetosphere. This allows both the energy conducted downwards from the magnetosphere and the photo-electrons from the conjugate hemisphere to be allowed for. When these contributions are included, a gradient in $\Upsilon_{e}$ of $2^{\circ} \mathrm{K} / \mathrm{km}$ throughout the topside ionosphere is obtained. The downward flux of photo-electron energy from the conjugate ionosphere is found to be $2.8 \times 10^{9}$ $\mathrm{eV} / \mathrm{cm}^{2} \mathrm{sec}$, whilst the heat conducted downwards from the magnetosphere (which by $14^{\mathrm{h}} \mathrm{LST}$, the time for which the calculation is made, is assumed to have reached a steady state with all the heat deposited being conducted downwards) is found to be $8 \times 10^{9} \mathrm{eV} / \mathrm{cm}^{2} \mathrm{sec}$. Thus for this rather high magnetic latitude the greater part of the escaping photo-electron energy is deposited in the magnetosphere. The proportion will be smaller at lower latitudes because of the smaller electron content of the geomagnetic field tubes. 
The importance of thermal conduction and non-local heating are very clearly demonstrated by comparing the Millstone Hill profiles in Figure 18 with those for Jicamarca. Since the dip latitude at Jicamarca is only $1^{\circ}$, the magnetic field lines are nearly horizontal and these effects are suppressed there. $T_{e}$ then rises to a maximum near $230 \mathrm{~km}$, falling back to $\mathrm{T}_{\mathrm{g}}$ at greater heights precisely as predicted originally by Hanson, in a theory which neglected these effects.

Geisler and Bowhill (1965a) showed by scaling various parameters in the calculation of $\mathrm{T}_{\mathrm{e}}$ that at high values of the collisional cooling rate in the 200$300 \mathrm{~km}$ range, the monotonically increasing temperatures shown in Figure 18(a) might be replaced by a variation similar to those of Figure $18(\mathrm{~b})$ even at middle latitudes. Such a behaviour could indeed be seen in the profiles, obtained on some early rocket flights [Spencer et al (1962)]. Results both from Arecibo [Mahajan (1967a)] and St. Santin [Carru et al (1967b)] show that on days when $n_{e}$ at the $F$ peak exceeds $(5-6) \times 10^{5} \mathrm{cc}^{-1}$ a minimum in $T_{e}$ develops near 250-300 $\mathrm{km}$ as a result of the increased collisional cooling. On days when $n_{e}$ is lower a monotonic increase in $\mathrm{T}_{\mathrm{e}}$ is observed.

The general features of the diurnal variation of temperature are shown in Figure 19. Throughout the day the variation is slight, with a fall during the night hours towards $\mathrm{T}_{\mathrm{g}}$. A striking feature, shown by all reported observations in the topside ionosphere [Bordeau et al (1964), Evans (1965a), Brace et al (1965), Sagalyn et al (1965), Willmore (1965), Carlson (1966), Farley et al (1967), Brace et al (1967)], at least during some epochs, is that the temperature maximum does not occur near or after noon, but at around $09^{\mathrm{h}}$ local time. The magnitude of this early morning overshoot varies from $100-2000^{\circ} \mathrm{K}$. The effect is greatest 
between 300 and $500 \mathrm{~km}$ altitude and also near the magnetic equator where the overshoot is between 700 and $2000^{\circ} \mathrm{K}$, falling at magnètic latitudes of $30^{\circ}-50^{\circ}$ to $200-600^{\circ} \mathrm{K}$. At high latitudes the effect may be confined to the summer months [Evans (1965a)]. This-dawn maximum appears to be the result of a more rapid build up of neutral gas density (and so of heat input) than of ionisation (or collisional cooling) during the early morning, so that the cooling rate lags relative to the heating rate. The inhibition of upward diffusion of ionisation near the magnetic equator would then account for the enhanced effect seen there. That such an effect should 'occur was first predicted by Dalgarno and McElroy (1965); da Rosa (1966) solved the timemdependent heat balance equations for the dawn period and obtained results very similar to those which are observed.

The principal geographical feature of the day electron temperature is an increase from equator to latitude $50^{\circ}$ of about $600^{\circ} \mathrm{K}$, after which the temperature slightly decreases (Figure 20) [Bowen et al (1964c), Brace et al (1967)]. The distribution shows marked geomagnetic control, being symmetrical about the magnetic not the geographic equator. Dalgarno suggested that this did not indicate an additional high latitude heat source but arose only from the decrease in $\mathrm{n}_{\mathrm{e}}$ and so of the collisional cooling rate. To this effect, at high altitudes, must be added that of the suppression of non-local heating near the magnetic equator. From an analysis of Ariel I data, Willmore (1964) showed this explanation to be correct. Superimposed on the latitude effect are smaller scale variations of $\pm 200^{\circ} \mathrm{K}$ [Willmorè (1965)]. Since these are invariably negatıvely correlated with $\mathrm{n}_{\mathrm{e}}$ variations that also occur they appear to arise merely from local anomalies in $n_{e}$ which produce variations in the collisional cooling rate. Thus all the geographical features in the $\mathrm{T}_{\mathbf{e}}$ distribution can be explained by variations in electron number density. 
The behaviour of $T_{1}$ is also shown in Figure 18. It will be seen that $T_{1}$ rises from $T_{g}$ to $T_{e}$ as described in the previous section. In particular, values of $T_{i}$ greater than $\mathrm{T}_{\mathrm{e}}$ have not been observed, thus confirmung the absence in general of a strong direct heat source for the ions. In the transition region from $\mathrm{H}^{+}$to $\mathrm{O}^{+}$ the enhanced collisional cooling may produce negative temperature gradients [Banks (1967b)] which may posszbly have been observed [Wrenn and Smith (1969), Colin et al (1969)] .

(c) Behaviour of Ionospheric Temperature By Night

On the basis of the account presented in Section $6(\mathrm{a}), \mathrm{T}_{\mathrm{e}}$ would be expected after sunset to fall rapidly to $\mathrm{T}_{\mathrm{g}}$. Whilst this is observed to happen at altitudes near $200 \mathrm{~km}$, it is clear from Figure 20 that it does not do so at greater heights, but falls slowly to a minimum at $02-03^{\mathrm{h}}$. There is a good deal of evidence that $\mathrm{T}_{\mathrm{e}}>\mathrm{T}_{\mathrm{g}}$ at many places through the night. It is found (Figure 18) [Bowen et al $(1964 \mathrm{c})$, Brace et al (1967)] that there is still a latitude increase at night although the temperature minimum over the equator is much broader than it is by day, the rise occurring at a geomagnetic latitude of about $30^{\circ}$. Considerable altitude gradients are observed from 400-800 km, especially in the winter when values of $0.9^{\circ} \mathrm{K} / \mathrm{km}$ or more are recorded, indicating a significant downward heat transport [Prasad (1968), Mahajan and Brace (1969)] . Finally there are substantial seasonal and storm-time variations of $\mathrm{T}_{\mathrm{e}}$ [Evans (1965b), (1965a), (1967b)], which do not result from variations in $\mathrm{T}_{\mathrm{g}}$ alone. Thus, $\mathrm{T}_{\mathrm{e}}>\mathrm{T}_{\mathrm{g}}$ at least for some latitudes, altitudes and seasons and we are forced to admit the existence of a night time source of energy. Geisler and Bowhill suggested that this might be the energy which had been stored in the magnetosphere during the day when it is raised to a high temperature. Nagy et al (1968) using Geisler and 
Bowhill's estimates of magnetospheric temperature solved the time-dependent heat balance equation and showed that heat fluxes exceeding $10^{8} \mathrm{eV} / \mathrm{cm}^{2} \mathrm{sec}$ could be maintained for several hours after sunset. Nisbet (1968) predicted rather higher temperatures in the magnetosphere in agreement with observations [Serbu and Maier (1966), Norman (1969)] so that Nagy's values may be an under-estimate. Moorcroft (1969) determined the night time temperature gradients over Arecibo and deduced downward heat fluxes 85 min after sunset of $4.3 \times 10^{8} \mathrm{eV} / \mathrm{cm}^{2} \mathrm{sec}$, declining 5 hours after sunset to $3.4 \times 10^{7} \mathrm{eV} / \mathrm{cm}^{2}$ sec. It thus appears that magnetospheric heat storage is adequate at least to explain the night enhancement of $\mathrm{T}_{\mathrm{e}}$, the latitude effect arising from the greater storage on longer field lines. Mahajan and Brace (1969) deduced the temperature gradients at night from nearsimultaneous passes of Explorer XXII at $1000 \mathrm{~km}$ with Alouette II at $2500 \mathrm{~km}$. The temperature gradients at $1000 \mathrm{~km}$ were deduced to be $0.6^{\circ} \mathrm{K} / \mathrm{km}$ and $1.2^{\circ} \mathrm{K} / \mathrm{km}$ for the $30^{\circ}$ and $50^{\circ}$ field lines, values which were considered to be consistent with magnetospheric heat storage. In addition if the conjugate ionosphere is illuminated, photo-electrons generated there may contribute to heating in the nighttime, an effect which will be further discussed below.

It has also been suggested [Willmore (1964), Spencer et al (1965), Brace et al (1965)] that precipitated or partly trapped electrons with kinetic energies of the order of $100-2000 \mathrm{eV}$ might be responsible for the maintenance of nighttime temperatures. Whilst magnetospheric heat storage is certainly the predominant process, the possibility still remains that soft electron heating may produce additional heating at some times or places. Thus, Knudsen (1968) observed various regions of intense electron precipitation, the strongest being one near the S. Atlantic magnetic anomaly where the particle flux exceeded $10^{11} / \mathrm{cm}^{2}$ sec 
and the energy flux $1 \mathrm{erg} / \mathrm{cm}^{2}$ sec. In this case it was concluded that the soft electrons were secondaries resulting from interaction of the radiation belt particles with the atmosphere. Other high flux regions coincided with areas where enhanced electron temperatures were observed in Ariel I. Probably these fluxes were unusually large since they much exceed those reported by Maier (1969).

Dalgarno (1964) remarked that the excitation of the $\mathrm{N}_{2}^{+}$bands in the night airglow places an upper limit on the precipitated electron flux of $10^{-2} \mathrm{ergs} / \mathrm{cm}^{2} \mathrm{sec}$. Nathan and Seaton (1966) showed that at $400 \mathrm{~km}$ a trapped flux 100 times as great can exist, so that the heating may be due to an electron flux of $1 \mathrm{erg} / \mathrm{cm}^{2} \mathrm{sec}$ without undue airglow intensity. These may have a heating effect comparable with or greater than that of conduction from the magnetosphere and so would produce a significant effect on the night ionosphere.

After the minimum in the early morning hours, the electron temperature starts to rise again somewhat before ground sunrise. During the summer months this rise occurs at sunrise at $100 \mathrm{~km}$ but in the winter an initial increase may be observed several hours earlier, followed by an increase in the heating rate at local dawn [Carison (1966), Carru et al (1967b), Evans (1967b)]. The effect has been observed even at altitudes of $2500 \mathrm{~km}$ [Shepherd and Wrenn (1969)]. The time of the initial rise in $T_{e}$ correlates well with the time of ionospheric sunrise at the magnetically conjugate point which is of course in the summer hemisphere where sunrise is earlier. The effect is therefore ascribed to the production of photo-electrons in the summer hemisphere which, travelling through the magnetosphere, produce heating in the winter hemisphere. This process was first suggested by Cole (1965) in connection with the predawn enhancement of the 
$\lambda 6300$ airglow. In their observations of photo-electrons from the plasma line at Arecibo referred to previously, Yngvesson and Perkins (1968) indeed found downward fluxes of photo-electrons during this period. The pre-dawn heating rate will be a measure of the photo-electron flux; it ranges from $4-6^{\circ} \mathrm{K} / \mathrm{min}$ at Arecibo and St. Santin down to $1^{\circ} \mathrm{K} / \mathrm{min}$ at Millstone Hill. The latter station is at a high magnetic latitude $(\mathrm{L}=3.2$ ) suggesting that a large proportion of the photoelectrons is absorbed in the long magnetospheric path for this station. This is in agreement with the calculations of Nagy et al (1969) for this location which showed $74 \%$ of the photo-electron energy to be absorbed in the magnetosphere.

The coupling of the two hemispheres which results from the existence of the photo-electrons has a significant influence on the seasonal variation of the night temperatures which may become large at high latitudes [see Figure 11(b)]. The winter temperatures at Millstone Hill exceed the summer values by about $800^{\circ} \mathrm{K}$. Evans (1967b) has pointed out that the conjugate location to Millstone Hill is at $72^{\circ} \mathrm{S}, 81^{\circ} \mathrm{W}$ where the atmosphere remains sunlit throughout the day for several weeks during the northern hemisphere winter. This will result in high night-time temperatures in the magnetosphere and in sustained photo-electron heating which are presumably responsible for the high winter temperatures at Millstone Hill. Prasad (1968) has noted a similar seasonal variation in the night temperature gradient above $400 \mathrm{~km}$ at Arecibo. The temperature gradient is a maximum in winter, presumably because due to the late sunset in the summer hemisphere the magnetosphere has less time to cool. To this effect must be added the greater photo-electron heating in the winter hemisphere.

It may be noted that these two effects, the maintenance of high electron temperatures at night and the predawn increase of $T_{e}$, depend on a fortuitous 
circumstance, since the first requires that the photo-electrons deposit a significant fraction of their energy in the magnetosphere whilst the second requires that the fraction should not be too large so that considerable energy still impinges on the conjugate hemisphere. It is very remarkable that magnetospheric densities should just be such as to satisfy these opposing conditions over a wide range of latitudes and other conditions.

\section{IONOSPHERIC TEMPERATURES BELOW $140 \mathrm{~km}$}

It will immediately be apparent from Figures $13(\mathrm{~b})$ and 16 that below $140 \mathrm{~km}$, $Q$ is falling whilst the loss rate is increasing so that $T_{e}$ will be expected to approach $\mathrm{T}_{\mathrm{g}}$. We have also noted that the reduction of electronic thermal conduction by the neutral gas prevents the ingress of heat from above. Before discussing the observations, which unfortunately do not lead to an unambiguous picture, we will discuss some possible alternative mechanisms for maintaining enhanced elèctron temperatures.

Walker (1968) has suggested that in the E-region the electrons will be in thermal equilibrium with the vibrational levels of $N_{2}$. The vibrational temperature of $\mathrm{N}_{2}$ may be enhanced through collisional deactivation of $\mathrm{O}\left({ }^{1} \mathrm{D}\right)$ by $\mathrm{N}_{2}$. A Iarge amount of solar energy is absorbed in the E-region in the dissociation of $\mathrm{O}_{2}$ through the Schumann-Runge bands and the production of $\mathrm{O}\left({ }^{1} \mathrm{D}\right)$. Thus the total energy gained by $\mathrm{N}_{2}$ is considerable but the fraction of it which goes to vibrational excitation is not known, Walker estimates that $1 / 3-1 / 7$ of the total would suffice to maintain $\left(\mathrm{T}_{e}-\dot{\mathrm{T}}_{\mathrm{g}}\right)$ at several hundred ${ }^{\circ} \mathrm{K}$, though as fine structure cooling was neglected, this is an underestimate. Measurements of $\mathrm{N}_{2}$ vibrational temperature can be made in aurorae when it is not invariably enhanced above $T_{g}$, 
so an additıonal quenching mechanism would be required on some occasions. $\mathrm{T}_{\mathrm{e}}$ is not invariably enhanced in the ionosphere, so a variable quenching mechanism would be required here also. On the other hand Dalgarno et al (1968) suggest that other collisional processes will always maintain the population of the vibrational Ievels at that corresponding to the gas temperature, so preventing. such an enhancement of $\mathrm{T}_{\mathrm{e}}$.

Dalgarno and Henry (1965) showed that in the D-region, $T_{e}$ would similarly be determined by the rotational temperature of $\mathrm{N}_{2}$ which is presumably equal to $\mathrm{T}_{\mathrm{g}}$. Photodetachment from $\mathrm{O}_{2}^{-}$which produces electrons with a kinetic energy of $2.9 \mathrm{eV}$, a process originally proposed by Sears (1963), is not effective in raising $\mathrm{T}_{\mathrm{e}}$. Moreover, complex ions based on $\mathrm{NO}_{3}^{-}$and not $\mathrm{O}_{2}^{-}$are the dominant negative ions of the $\mathrm{D}$ region.

The effect of electric fields in the E-region has been discussed by Rees and Walker (1968). Their results will be discussed in more detail in a later section, but we may note here that electric fields of the order associated with the Sq current systems in the ionosphere, i.e. about $1 \mathrm{mV} / \mathrm{m}$, will not produce a significant effect except in the vicinity of the equatorial electrojet [Satya Prakash et al (1968)]. At middle and high latitudes the principal effect of the electric field (assumed to be perpendicular to the magnetic field) is to raise the ion temperature. Near the equator the effect is strongly enhanced by the production of a vertical polarisation field whose principal effect is to heat the electrons. For an applied field of $1 \mathrm{mV} / \mathrm{m}$ and an electrojet current density of $5 \mathrm{amp} / \mathrm{km}^{2}$, the energy input is sufficient to raise $\mathrm{T}_{\mathrm{e}}$ by $2-300^{\circ} \mathrm{K}$. Walker (1966) has also discussed the D-region heating by electric fields of about $2.5 \mathrm{mV} / \mathrm{m}$ arising from neutral winds and concludes that the temperature rise here also will be insignificant. 
The effects of wind motrons in the E region has been studied by Gleeson and Axford (1967) who find that a windshear pattern which produces a strong $E_{s}$ layer with a peak density of 8.5 times the ambient value would lead to a depression of about $70^{\circ} \mathrm{K}$ in $\mathrm{T}_{e}$ at the centre of the layer, a slight enhancement occurring above and below. Hooke (1969b) points out that the wind shears are themselves the result of atmospheric wave phenomena which will be accompanied by variations in $\mathrm{T}_{\mathrm{g}}$ estimated to be $\pm 50^{\circ} \mathrm{K}$. When this is taken.into account, it is found that $T_{e}$ in the $E_{s}$ layer may either be enhanced by $60^{\circ} \mathrm{K}$ or depressed by as much as $60^{\circ} \mathrm{K}$ relative to its value in the undisturbed ionosphere above and below the layer.

In general, then, there is no clear indication on theoretical grounds of any mechanism which will maintain $\mathrm{D}$ and $\mathrm{E}$ region electron temperatures significantly (i.e. $400^{\circ} \mathrm{K}$ ) above the gas temperature, although temperature variations of a detectable magnitude may occur in the vicinity of the equatorial electrojet, $\mathrm{E}_{\mathrm{s}}$ Iayers or (as will be seen in Section $10 \mathrm{~b}$ ) in aurorae.

No direct measurements of $T_{e}$ have been made much below $100 \mathrm{~km}$ where the occurrence of collisions vitiates the usual theory of the probe. Between 100 and $140 \mathrm{~km}$, the experimental evidence is, at least to some degree, conflicting. Figure 21 shows temperatures obtained during the day from three incoherent scatter stations [Carru et al (1967a), Evans (1967a), Ward and Perkzns (1968)] . A complex altitude and diurnal varıation is observed and attributed to the variations of $\mathrm{T}_{\mathrm{g}}$ associated with internal gravity waves. For St. Santin the range at each altitude during daylight hours is indicated by a vertical line which thus indicates real variations as well as random errors which are smaller. It will be seen that $T_{e}$ obtained in this way and $T_{g}$ are in good general agreement up to 
$130 \mathrm{~km}$. It is possible that $T_{e}$ is systematically higher than $T_{g}$ but if this is so, the difference does not exceed $50-100^{\circ} \mathrm{K}$.

Many rocket measurements of $\mathrm{T}_{\mathrm{e}}$ in the $\mathrm{E}$ region by Langmuir probes have been reported. Generally speaking, in the region from 100 to $140 \mathrm{~km}$, values between $500^{\circ} \mathrm{K}$ and $1000^{\circ} \mathrm{K}$ are obtained. There is often a pronounced scatter of the measurements. Smith et al (1968) have summarised the results of 29 rocket flights at $145 \mathrm{~km}$. They conclude that $\mathrm{T}_{\mathrm{e}}$ shows a general trend towards $\mathrm{T}_{\mathrm{g}}$ at the minimum of the solar cycle and that it shows considerable variability at any site with a time scale greater than several hours, but less than several days. There is thus a clear conflict with the incoherent scatter results in contrast to the situation at greater altitudes. The cylindrical probe comparison at Arecibo [Brace et al (1969)] is the only one where results at these altitudes were obtained, the comparison having been made down to $130 \mathrm{~km}$ without any indication of a discrepancy. Both methods are subject to the effect of collisions in the neutral gas at low altitudes. This necessitates a correction to the results of incoherent scatter below $120 \mathrm{~km}$, and it is possible that this is not made with sufficient accuracy. In the case of the Langmuir probes, no theory which would allow a correction to be made is available and in fact the altitude at which a significant error may occur in $\mathrm{T}_{\mathrm{e}}$ cannot be identified with certainty. However, collisions become important for incoherent scatter when the electronic mean free path is comparable with the radio wavelength, and for the probe when it is comparable with the probe dimensions which are usually much smaller. Thus collisions should not usually be important for the probe until $100 \mathrm{~km}$ or less is reached and some versions of the probe should be much less affected than others. Thus the cylindrical probe, on account of its small diameter, should function to much 
lower altitudes than the nose-tip probe. Yet in the observations discussed by Smith et al (1968) which were obtained by both these methods, no such difference is apparent. Another possible source of error may be neglect of the geomagnetic field if for some reason its effect were more pronounced in the E-region. Once again, because of the relative sizes, the nose-tip probe should be more affected than the cylindrical probe. If the difference between probe and incoherent scatter arises from a defect in one technique or the other of this kind, it should always be present. In Figure 21 are shown probe results for four rocket flights, two each by the cylindrical probe and the ac probe which were shown in Section $6(\mathrm{~b})$ to be in good agreement with incoherent scatter at greater heights. To take account of the possibility of an error due to aerodynamic heating as suggested by Smith [Section 3(g)], results from the downleg only of the trajectory have been used, although this is not obviously relevant for the probe systems employed here, and the ascent values were actually lower for two of the rocket flights. The ac probe results [Aubry et al (1966)] were obtained during the afternoon at Hammaguir at almost the same local time two days apart. The rocket installations were similar. On the first day, $\mathrm{T}_{\mathrm{e}}$ was found to be close to the CIRA 1965 values of $T_{g}$. They also agree well with the incoherent scatter values, tending to be on the low side of these. On the second flight two days later, $T_{e}$ values more than twice as great were obtained. Similar results were obtained from the second pair of flights [Brace et al (1969a)]. These were made from Fort Churchill. The first, during the day, showed temperatures systematically about $100^{\circ} \mathrm{K}$ above $\mathrm{T}_{\mathrm{g}}$, whilst the second which occurred during the subsequent night showed results nearly twice as great. The high temperatures on this occasion may easily be explained in terms of excitation processes in the auroral zone 
[ see Section $10(\mathrm{~b})$ ]; the day results show that they are certainly not the result of a systematic error in the cylindrical probe technique.

Since there are certainly some occasions when relatively low temperatures are observed by Langmuir probes, a defect in the theory of operation which would lead to a systematic error can be ruled out. Moreover, in the cases cited, there appears to be no reason to believe that the measurements leading to high $T_{e}$ values were less satisfactory in quality than the others. In rocket measurements of $T_{e}$ in general, enhanced values are more common than values close to $T_{g}$, though it is often noticeable that there is a Iarge scatter in $T_{e}$, with the lowest values close to $T_{g}$, rather than being symmetrically distributed about $T_{g}$ as might occur simply from random experimental errors. Since high values of $T_{e}$ are apparently not observed at all by incoherent scatter, the discrepancy between the two methods can hardly be an accidental effect of sampling alone. Thus it seems that the difference is real and yet does not arise simply from an inadequacy in the experimental technique in either case. A possible explanation is that $T_{e}$ enhancements which are localised occur, so that $T_{e}$ exhibits a very spikey variation. The high spatial resolution of the Langmuir probe would enable these to be partly or completely resolved. This would account for the large scatter often observed and for the fact that despite this scatter $T_{e}$ values lower than $T_{g}$ are not observed. The radar, however, has a relatively poor spatial resolution ranging from $3 \mathrm{~km}$ at St. Santin to $30 \mathrm{~km}$ at Millstone Hill and so may measure the mean value of these variations, which need be only moderately greater than $\mathrm{T}_{\mathbf{g}}$. Alternatively it may be that in the $\mathrm{E}$-region, despite theoretical predictions to the contrary, the electron energy distribution is non-Maxwellian. If temperature is an unsuitable parameter to describe the energy distribution, it would not be surprising if different techniques gave discordant estimates of it. 
If it is supposed that small scale enhancements of $T_{e}$ above $T_{g}$ occur (though it should be noted that high values of $\mathrm{T}_{\mathrm{e}}$ might, in principle at least, reflect similar small scale enhancements of $T_{g}$, presumably such strong turbulence does not exist in this region) then a source of energy to maintain the difference must be found. We have seen that enhanced values were observed at night at Fort Churchill. Moreover, Smith et al (1965, 1968) made observations in two eclipses (1963 July 20 and 1966 Nov. 12) and found no evidence for a fall during the eclipse. Thus it appears that a direct effect of solar radiation is not responsible unless a molecule with a long life time excited state is involved. Walker (1968) states that the excited vibrational states of $\mathrm{N}_{2}$ will persist throughout the night so that high temperatures might be maintained both at night and through an eclipse.

A much smaller number of measurements of $T_{1}$ has also been made between 100 and $140 \mathrm{~km}$ by both techniques with more consistent results. Knudsen and Sharp (1965) using an ion trap on a rocket fired near local noon, observed a wavelike variation of $\mathrm{T}_{1}$ between 100 and $160 \mathrm{~km}$, the amplitude of the variation being . $100^{\circ} \mathrm{K}$ and the wavelength $12 \mathrm{~km}$. The mean value of $\mathrm{T}_{1}$ was only $100^{\circ} \mathrm{K}$ above the expected $\mathrm{T}_{\mathrm{g}}$. They suggested that the variation of $\mathrm{T}_{1}$ reflected the variations of $\mathrm{T}_{\mathrm{g}}$ resulting from density variations in intense gravity waves, although waves such short wave-length would be strongly damped by thermal conduction, and the wave amplitudes also were an order of magnitude greater than Hines (1965) had estimated for such waves in the E-region. Using a similar method, Harris et al (1969) observed wavelike variations of $\mathrm{T}_{1}$ from a satellite near $200 \mathrm{~km}$ altitude. These were not invariably present and were generally observed at high latitudes. The wavelength was around $200 \mathrm{~km}$ and the wave amplitude $13 \%$ of the mean temperature. Once again the wavelengths are shorter than expected for gravity waves. 
Wand and Perkins (1968) using incoherent scatter at Arecibo observed the variation of $T_{x}$ (presumed equal to $T_{e}$ ) from 97-128 km. The results showed an oscillation of peak amplitude $50^{\circ} \mathrm{K}$ about the CIRA values of $\mathrm{T}_{\mathrm{g}}$. Hooke (1969a) suggested that these might be associated either with internal gravity waves or with tidal motions of the neutral atmosphere, and that only the latter was consistent with the temporal stability of the observed patterns.

Vasseur and Waldteufel (1969) observed both plasma drift motions and $T_{x}$ at St. Santin. They showed that these were consistent with the occurrence of internal gravity waves with a period of $2 \mathrm{~h}$. The peak amplitude of the variation of $\mathrm{T}_{1}$ was $50^{\circ} \mathrm{K}$. The vertical wavelength was found to be $520 \mathrm{~km}$. Correlated variations in $N_{e}$ at the F2 peak were observed, a fact which was utilised to study the horizontal variations using ionosonde data. Thus it was determined that the horizonta1 wavelength was $4000 \mathrm{~km}$ and that the waves propagated southward across Europe from the auroral zone where it was suggested that they were generated.

Thus there appears to be quite good evidence for the observation of temperature variations of $\pm 50^{\circ} \mathrm{K}$ or a little more, associated with atmospheric movements in internal gravity waves and possibly also of both shorter and longer scales than these waves. It also appears that the gravity wave pattern has a major influence on the apparent diurnal variation of temperature in the $\mathrm{E}$ region [Carru et a1 (1967a)] .

9. SOLAR CYCLE VARIATIONS IN F-REGION IONOSPHERIC TEMPERATURE

The calculations of Geisler and Bowhill (1965a) suggested that the solar cycle variations in $\mathrm{T}_{\mathrm{e}}$ would not be very large. From the results shown in Figure 11 
it is evident that, except under circumstances where $T_{e}$ is not too much greater than $T_{n}$ so that it shows a similar variation, the day-to-day variability from other causes such as ionospheric storms is such as to mask the solar cycle changes unless careful averaging of substantial numbers of observations is carried out. This will best be done with results from incoherent scatter stations when these have operated for a sufficient period.

Attempts have been made to correlate changes in $\mathrm{T}_{\mathrm{e}}$ with variations in solar EUV flux over shorter periods using the $10.7 \mathrm{~cm}$ radio emission as a monitor of the latter. Willmore (1965) found a variation of $(4.6 \pm 2.3)^{\circ} \mathrm{K} /$ flux unit* in the day at $500 \mathrm{~km}$. Here, the $10.7 \mathrm{~cm}$ flux on the day of the $T_{e}$ observation was used. Mahajan (1967b) correlated Arecibo values of $T_{e}$ for 1965-7 with $27^{\circ}$ day averages of $10.7 \mathrm{~cm}$ emission, obtaming a night-time change of $3.4^{\circ} \mathrm{K} / \mathrm{flux}$ unit and, at noon, below $400 \mathrm{~km}, 4.5^{\circ} \mathrm{K} / \mathrm{flux}$ unit. Since it is found for variations in exospheric temperature that the coefficient relating changes during one solar rotation $\left(1.9^{\circ} \mathrm{K} / \mathrm{flux}\right.$ unit) is less than that for long-term variations $\left(3.46^{\circ} \mathrm{K} / \mathrm{flux}\right.$ unt $)$, a difference which presumably reflects the real behaviour of the EUV and radio emissions, the two results are not really in as good agreement as at first appears. Nonetheless, the variations in $\mathrm{T}_{\mathrm{e}}$ appear to be similar to those in exo- spheric temperature.

\section{IONOSPHERIC TEMPERATURES UNDER DISTURBED CONDITIONS}

(a) Ionospheric Storms at Moderate and Low Latitudes

The behaviour of $T_{e}$ in several small ionospheric storms was studied using Ariel I observations by Willmore (1965), who found rather localised reductions

\footnotetext{
*The flux unt is $10^{-22} \mathrm{~W} / \mathrm{cm}^{2} \sec \mathrm{Hz}$.
} 
to occur at many places on the globe, the decreases amounting to $100^{\circ} \mathrm{K}$ or móre. The behaviour was much the same by day or night and the decreases.in $T_{e}$ were well correlated with increases in electron density. Only on one occasion, at 4 locations near to the $\mathrm{S}$. Atlantic magnetic anomaly was an increase in $\mathrm{T}_{\mathrm{e}} \cdot \mathrm{re}-$ corded. Knudsen (1968) made observations with a retarding potential analyser of $\mathrm{T}_{1}, \mathrm{n}_{\mathrm{e}}$ and $10 \mathrm{eV}$ electron flux. He found intense particle fluxes (exceeding $10^{11} \mathrm{el} / \mathrm{cm}^{2} \mathrm{sec}$ ) near the magnetic anomaly which he attributed to secondaries produced by particles of the radiation belt. Two of the high flux regions coincided with the region of enhancement observed in Ariel-I. Reddy et al (1967) obtained very similar results from Explorer XXII though the depressions in temperature which they observed were larger in magnitude, reaching $300^{\circ} \mathrm{K}$. It seems that this behaviour is typical of rather weak storms, and possibly of the initial phase of more intense storms [Bauer and Krishnamurthy (1968)] .

It was suggested by Willmore that the change in $T_{\mathrm{e}}$ resulted largely or completely from changes in the collisional cooling rate consequent on the enhancement of $n_{e}$. Thus, the principal change in the storm is that of $n_{e}, T_{e}$ changing thereafter in a manner dictated by the energy balance of the ionosphere. In particular, no additional energy source than that provided by solar radiation need be present. Reddy et al advanced an alternative explanation, that the photoelectron flux is reduced in regions of enhanced electron density because of increased scattering which raises the escape level. However, if $\mathrm{T}_{e}$ and $\mathrm{n}_{\mathrm{e}}$ both increase, as in the regions near the magnetic anomaly, it is at least possible that an additional source of energy must be postulated in these regions.

Evans (1965) made observations through two storms of moderate severity at Millstone Hill in 1963 September. $T_{1}$ was observed to be little affected except 
below $400 \mathrm{~km}$ where small increases of $100-200^{\circ} \mathrm{K}$ occurred. $T_{e}$ however was enhanced substantially, by $700-800^{\circ} \mathrm{K}$. At night this implied an increase in the energy input by a factor of three. At Millstone Hill, where most of the photoelectron energy is normally deposited in the magnetosphere, it is doubtful whether the magnetospheric heat output can be increased by so large a factor.

Henderson and Wrenn (1970) used Explorer XXXI observations to study several storms early in 1967 . They found that both enhancements and depressions of considerable magnitude, i.e. $500-1000^{\circ} \mathrm{K}$, could occur at all heights from $500-1600 \mathrm{~km}$ at least. In a given storm, different effects may be observed at different locations. Thus in the storm of 1967 June $6 \mathrm{~T}_{e}$ increased by $400^{\circ} \mathrm{K}$ over S. America together with a large increase of electron density. A few orbits later over Africa it was found that a similar increase of $T_{e}$ had occurred there but with only minor decrease in density. Such cases, where $T_{e}$ increases and $n_{e}$ either increased or only decreases slightly, are suggestive of an enhancement in the energy input and so of an additional energy source besides solar radiation. However, Henderson and Wrenn also observed very substantial changes in ion composition during storms, which will result in changes in the collisional cooling rate. Atmospheric temperature changes must also be allowed for. It follows that very careful calculations are needed before it is possible to decide what . changes have actually occurred in the energy input. No clear pattern in the temperature changes in 1onospheric storms emerges from the results available so far. Because these changes, which will result in redistribution of ionisation along the geomagnetic field lines and may also be accompanied by changes in the loss rate near the F2 peak, can considerably modify the morphology of the ionosphere, it is desirable to obtain a clear picture of them as a contribution to 
building a theory of the ionospheric storm. Moreover, if an additional source of ionospheric energy exists during the storm, it would be most important to identufy it. The question of the existence of such a source seems one of the most significant unanswered questions concerning ionospheric temperatures in the F-region.

(b) Ionospheric Temperatures in the Auroral Zone

In the neighbourhood of an aurora and in the auroral zone generally additional heating processes are likely to modify substantially the picture previously given, since large amounts of energy are certainly available in the production of aurorae and the associated high latitude current system and some part of this is likely to be dissipated as ionospheric heating. The energy loss mechanisms under these circumstances will not differ from those that have already been discussed so that it is only necessary to describe the heating processes.

The first of these to be proposed was Joule heating from electric fields produced in the magnetosphere [Cole (1962), Megill et al (1963), Walker (1966), Cummings and Dessler (1967), Rees and Walker (1968)] . Considerations of the magnetic field changes in storms show that the electromagnetic energy density available over the auroral zone is not far short of that due to solar EUV radiation in the sunlit hemisphere, so this is potentially a significant source. Components of the electric field E perpendicular to the magnetic field have been measured by barium cloud releases over Kiruna [Foppl et al (1968)], values in the range $2-20 \mathrm{mV} / \mathrm{m}$ being obtained. A rather larger value of $50 \mathrm{mV} / \mathrm{m}$ is required to account for the current flowing in the auroral electrojet [Bostrom (1964)]. At high latitudes where the dip angIe is large, the polarisation field 
which occurs in the equatorial electrojet is absent and the heating process is rather different from that which occurs near the magnetic equator. In perpendicular electric and magnetic fields, similar drift velocities are imparted to ions and electrons, so that unlike all the other mechanisms discussed the energy gain of the ions in this process is much larger than that of the electrons [Rees and Walker (1968)]. Also, the heating effect Is evidently greatest when the ion collision and gyrofrequencies are comparable, i.e. in the E-region. In consequence of these two facts, $T_{1}$ rises above $T_{e}$, this rise commencing in the E-region and being maintained into the $F$-region. $T_{e}$ is in fact largely enhanced not as a result of the direct heating by the electric field, but as a result of ionelectron collisions just as the ion temperature is enhanced in the normal Fregion. For electric fields up to $50 \mathrm{mV} / \mathrm{m}$; the effect on $\mathrm{T}_{e}$ is small, but $\mathrm{T}_{2}$ rises to $2000^{\circ} \mathrm{K}$ over the range $160-300 \mathrm{~km}$.

An obvious source of heating under auroral conditions is the precipitated electron flux responsible for the optical excitation. Cole (1967) showed that such a precipitated flux would generate a space charge resulting in the flow of field aligned currents, and that the accompanying Joule heating would exceed that of the primary electrons in some circumstances. Walker and Rees (1968a) and Stolarski (1968) pointed out that the incident beam of primary particles in the atmosphere is accompanied by a shower of low energy secondaries produced by ionisation of the neutral gas. Because of the increase of the Coulomb and other relevant cross-sections at low energies, the heating produced by the secondary electrons is very effective and in fact they and not the field-aligned currents represent the dominant energy source. They clearly play the same rôle as the photoelectrons in the heating by solar EUV photons, their initial energy being 
degraded by collision in a similar way. They have a heating efficiency ranging from a fraction of an $\mathrm{eV}$ at low altitudes to several $\mathrm{eV}$ at $400 \mathrm{~km}$. Rather than starting directly from an assumed flux and energy distribution of precipitated electrons, Walker and Rees considered five auroral arcs ranging in brightness from 7.2 to $34.7 \mathrm{kR}$, for each of which a luminosity profile of the $3914 \AA \mathrm{N}_{2}^{+}$band had been measured. Since the optical luminosity enables the excitation rate to be determined, and since the relation between the excitation and ionisation crosssections is known, the volume ionisation rate can be determined directly from the luminosity profile. This has only to be multiplied by the value of the heating efficiency for the appropriate altitude to obtain the heat input. Then $T_{e}$ and $T_{1}$ can be calculated in the usual way (Figure 22). Maximum temperatures of 2900$3500^{\circ} \mathrm{K}$ were found to occur at $300-400 \mathrm{~km}$. In these calculations, non-local heating was not considered, the temperature above $400 \mathrm{~km}$ being maintained largely by thermal conduction. The inclusion of non-local heating would presumably remove the temperature maximum in the F-region, resulting in the maintenance of high temperatures throughout the topside ionosphere. More seriously, cooling by excitation of the fine structure levels of atomic oxygen was also neglected, so that the temperature rise would be seriously overestimated at low altitudes, though the error in the maximum value might not be so great. An important feature of the process is that as the precipitated electron flux increases both the energy input and the collisional cooling rate, which depends on $\mathrm{n}_{\mathrm{e}}$ and hence the ionisation rate, increase; hence the temperatures are not very sensitive to the precipated flux and will be much the same in intense as in weak aurorae. 
Thus we see that the precipated electrons responsible for the production of aurorae will raise $T_{e}$ rather than $T_{1}$, producing an enhancement to $2900-3500^{\circ} \mathrm{K}$ at $300-400 \mathrm{~km}$. Higher values than this are unlikely to be produced simply by the particles even in very intense fluxes. If in addition an electric field $\mathrm{E}$ is present $T_{1}$ will be raised with relatively little effect on $T_{e}$. Since the energy input varies as $\mathrm{E}^{2}$, the enhancement will increase rapidly with $\mathrm{E}$, reaching values of $2000^{\circ} \mathrm{K}$ at a fairly large value of $50 \mathrm{mV} / \mathrm{m}$. The two effects are nearly independent, and measurements of $T_{e}$ and $T_{1}$ would enable them to be distinguished.

Some measurements are available which seem to confirm these predictions at least in part. Ulwick et al (1964) measured electron temperatures from a rocket through an auroral form over Fort Churchill, and found maximum values of $3500^{\circ} \mathrm{K}$. Baker et al (1966) made measurements in a discrete auroral form, finding temperatures of $3500^{\circ} \mathrm{K}$ in the aurora and lower values of $2000^{\circ} \mathrm{K}$ outside. In a diffuse aurora, $T_{e}$ was no higher than $1800^{\circ} \mathrm{K}$, the value rising with altitude up to the peak of the rocket trajectory at $193 \mathrm{~km}$. Raitt (1969) made observations with an ac probe on ESRO IA at an altitude of $800 \mathrm{~km}$ during the event of 1969 Feb. 25-26, which was of moderate intensity. He found $\mathrm{T}_{\mathrm{e}}$ enhancements over the night time auroral zone of only $500^{\circ} \mathrm{K}$.

One major disturbance has been unusually well observed, results having been reported from three satellites, Explorer XXII, Ariel III and Explorer XXXI [Findlay et al (1969), Loftus (1968) and Henderson and Wrenn (1969)]. This was a large storm on 1967 May 25-26 when aurorae were visually reported from many locations in the US near an invariant latitude of $50^{\circ}$. The most remarkable observations were those of Findlay et al, who found that $T_{e}$ was enhanced from a pre-storm value of $2200^{\circ} \mathrm{K}$ to $6500^{\circ} \mathrm{K}$ near invariant latitude $50^{\circ}$. In the night 
hours, where reports of the position of the aurora were available, it was concluded that the temperature enhancements were directly above the aurora. The electron number density was also enhanced by a factor of 2 . In the day, the enhancement of $T_{e}$ was less striking and $n_{e}$ was depressed. At invariant latitudes greater than $65^{\circ}$ the enhancement of $T_{e}$ was much smaller and $n_{e}$ was again depressed. Considerable fine structure in $T_{e}$ was observed. Henderson and Wrenn detected no storm effect at all over Alaska, in agreement with these results.

It is quite clear that the theoretical discussions described thus far would not account for the occurrence of temperatures as high as $6500^{\circ} \mathrm{K}$. Whilst it is not certain that the event observed by Findlay et al is of this type, the most relevant study seems to be that of the mechanism of the stable auroral red arc (SACARC) by Walker and Rees (1968). The principal feature of these arcs is the strong emission of the $6300 / 6364 \AA$ lines relative to other wavelengths thus requiring preferential exitation of the $O\left({ }^{1} D\right)$ level. It is suggested that a high electron temperature is responsible, excitation arising from electron impact in the high energy tail of the Maxwellian velocity distribution. This will give strong excitation of $O\left({ }^{1} D\right)$ on account of its relatively low excitation energy. Walker and Rees discussed the following heating mechanisms:

(a) an electric field E

(b) heat conducted from high temperature regions in the magnetosphere and (c) precipitated electrons.

They attempted to reproduce the characteristics of a particular red arc whose luminosity profile was recorded at Fritz peak, Colorado on 1961 June 22. It 
was found (Figure 23) that an electric field of $180 \mathrm{mV} / \mathrm{m}$ would be required, being raised to $12000^{\circ} \mathrm{K}$ at $200 \mathrm{~km}$, falling by $700 \mathrm{~km}$ to equal $\mathrm{T}_{e}$, which would reach $5000^{\circ} \mathrm{K}$ from 200 to $1000 \mathrm{~km}$. However, a very large amount of energy would be imparted to the neutral atmosphere which would be raised to $3400^{\circ} \mathrm{K}$ in the arc, a value which Walker and Rees considered improbable. Moreover, such large electric fields have not yet been observed. Heat conducted from the magnetosphere in a flux of $(4-10) \times 10^{10} \mathrm{eV} / \mathrm{cm}^{2} \mathrm{sec}$ or about an order of magnitude more than that due to the photoelectrons, would also suffice, raising $T_{e}$ at $1000 \mathrm{~km}$ to $6000^{\circ} \mathrm{K}$. The existence of magnetospheric energy source to maintain this supply of heat is of course hypothetical. If precipitated electrons are re- ' sponsible, they must be of such low energy that direct excitation of the line emission is small. Thus, electrons of about $15 \mathrm{eV}$ in energy in fluxes of more than $10^{9} / \mathrm{cm}^{2} \mathrm{sec}$ would be required. Walker and Rees note that the distinction between such low energy electrons and the heat conduction mechanism is not altogether clear. However, Maier (1969) has observed soft electron fluxes of the required magnitude over the auroral zone.

Thus, if it is accepted that the electric field hypothesis is untenable, either thermal conduction of magnetospheric energy or a precipitation of very soft electrons from the magnetosphere are at least capable of reproducing the very high temperatures observed by Findlay et al. Measurements of $T_{1}$ would show whether or not electric fields were important in this case.

Rees and Walker (1968) also noted that even in the absence of visible aurora the zenith intensity of the $5577 \AA$ airglow is usually enhanced relative to midlatitude values by a factor of 10 , and suggested the existence of a steady excitation source' at all times. This may tend to raise $T_{e}$ and $T_{1}$ and certaunly Brace 
et al (1969a) and Nagy and Walker (1967) observed rather high night temperatures over Ft. Churchill. Rees and Walker found that a rather weak flux of precipitated electrons might give $T_{e}-T_{g}$ rising from zero at $120 \mathrm{~km}$ to $600-800^{\circ} \mathrm{K}$ at $300 \mathrm{~km}$, whilst an electric field of $50 \mathrm{mV} / \mathrm{m}$ would give $T_{x}-T_{g}$ rising from $400^{\circ} \mathrm{K}$ at $120 \mathrm{~km}$ to $850^{\circ} \mathrm{K}$ at $300 \mathrm{~km}$, the two effects being nearly independent. $T_{e}$ enhancements of this magnitude are in good agreement with the rocket measurements, except that, as at lower latitudes, the latter usually show enhanced temperatures below $140 \mathrm{~km}$ which are apparently no easier to account for as the effect of precipitated electrons than as the effect of solar radiation.

\section{ACKNOWLEDGMENTS}

The greater part of this review was written whilst Visiting Professor at the Physical Research Laboratory, Ahmedabad, an opportunity for which I am much indebted to Professor Vikvain Sarabhai. It was completed during the term of a National Academy of Sciences Resident Research Associateship at Goddard Space Flight Center. It is a pleasure to express my thanks to colleagues at these establishments and the Mullard Space Science Laboratory for stimulating discussions and also for permission to use material in advance of publication. 


\section{BIBI,IOGRAPHY}

Langmuir, I., Science, 58, 290, 1923(a)

Langmuir, I., Gen. Elec. Rev., 26, 731, 1923(b)

Langmuir, I., J. Franklin Inst., 196, 751, 1923(c)

Langmuir, I., and Mott-Smith, H., Gen. Elec. Rev., 27, 449, 538, 616, 762, 810, 1924

Mott-Smith, H., and Langmuir, I., Phys. Rev., 28, 727, 1926

Druyvesteyn, M. J., Z. Phys., 67, 790, 1930

Reifman, A., and Dow, W. G., Phys. Rev., 76, 987, 1949

Ratcliffe, J. A., Magneto-ıonic Theory, 1956

Spitzer, L., Physics of Fully Ionized Gases, Interscience Publ., p. 86, 1956

Allen, J. E., Boyd, R. L. F., and Reynolds, P., Proc. Phys. Soc., B, 70, 297, 1957

Bowles, K. L., Phys. Rev. Lett., 1, 454, 1958

Whipple, E. C., Jr., Proc. I.R.E., 47, 2023, 1959

Bowles, K. L., J. Res, Nat. Bur. Std., 65 D, 1, 1961 
Dougherty, J. P., and Farley, D. T., Proc. Roy. Soc. $\underline{\text { A }} \underline{259}, 79,1960$

Fejer, J. A., Canad. J. Phys., $\underline{38}, 1114,1960$

Salpeter, E. E., JGR, $\underline{65}, 1851,1960$ (a)

Salpeter, E. E., Phys. Rev., 120, 1528, 1960(b)

Farley, D. T., Dougherty, J. P., and Barron, D. W., Proc. Roy. Soc. 트, 263, 238,1961

Fejer, J. A., Canad. J. Phys., 39, 716, 1961

Hagfors, T., JGR, $\underline{66}, 1699,1961$

Hanson, W. B., and Johnson, F. S., Mem. Roy. Soc. Liége, 4, 390, 1961

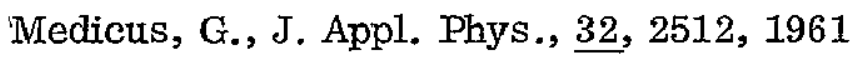

Butler, S. T., and Buckingham, M. J., Phys. Rev., 126, 1, 1962

Cole, K. D., Aust. J. Phys., 15, 223, 1962

Gurevich, A., PASS, 9, 321, 1962

Spencer, N. W., Brace, L. H., and Carignan, G. R., JGR, 67, 157, 1962

Dalgarno, A., McElroy, M. B., and Moffett, R. J., PASS, 11, 463, 1963 
Dougherty, J. P., and Farley, D. T., JGR, $\underline{68}, 5473,1963$

Hanson, W. B., Space Res. III, 282, 1962

Megill, L. R., Rees, M. H., and Droppleman, L. K., PASS, 11, 45, 1963

Sears, R. D., JGR, 68, 5135, 1963

Bordeau, R. E., and Donley, J. L., Proc. Roy. Soc. AA, 281, 487, 1964

Bostrom, R., JGR, $\underline{69}, 4983,1964$

Bowen, P. J., Boyd, R. L. F., Raitt, W. J., and Willmore, A. P., Proc. Roy. Soc. A, 281, 504, 1964(a)

Bowen, P. J., Boyd, R, L. F., Henderson, C. L., and Willmore, A. P., Proc, Roy. Soc. A, 281, 514, 1964(b)

Bowen, P. J., Boyd, R. L. F., Henderson, C. L., and Willmore, A. P., Proc. Roy. Soc. $\underline{A}, \underline{281}, 526,1964(\mathrm{c})$

Boyd, R. E. F., and Raitt, W. J., Space Res. IV, 207, 1964

Dalgarno, A., Ann. Geophys., 20, 65, 1964

Evans, J. V., JGR, 69, 1435, 1964

Evans, J. V., and Loewenthal, M., PASS, 12, 915, 1964 
Milriani, F., JGR, $\underline{69}, 556,1964$

Megill, L, R., and Cahn, J. H., JGR, 69, 5041, 1964

Moorcroft, D. R., JGR, $\underline{69}, 955,1964$

Ulwick, J. C., Pfister, W., Haycock, O. C., and Baker, K. D., Space Res. IV, 293, 1964

Willmore, A. P., Proc. Roy. Soc. A, 281, 140, 1964

Brace, L. H., Spencer, N. W., and Dalgarno, A., PASS, 13, 647, 1965

Cole, K. D., Ann. Geophys., 21, 156, 1965

Dalgarno, A., and Henry, R. J. W., Proc. Roy. Soc. A, 288, 521, 1965

Dalgarno, A., and McElroy, M. B., PASS, 13, 143, 1965

Dote,' T., Amemiya, H., and Ichimaya, T., JGR, 70, 2258, 1965

Evans, J. V., JGR, 70, 1175, 1965(a)

Evans, J. V., JGR, 70, 2726, 1965 (b)

Evans, J. V., JGR, 70, 4365, 1965(c)

Geisler, J. E., and Bowhil1, S. A., JATP, 27, 457, 1965(a) 
Geisler, J. E., and Bowhill, S. A., JATP, 27, 1119, 1965(b)

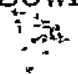

Hines, C. O., JGR, 70, 177, 1965

Hoegy, W. R., Fournier, J-P, and Fontheim, E. G., JGR, 70, 5464, 1965

Hoult; D. P., JGR, $\underline{70}, 3183,1965$

Jacchra, L. G., CIRA, 1965

Knudsen, W. C., and Sharp, G. W., JGR, 70, 143, 1965

Maynard, L. A., and Ducharme, E. D., Canad. J. Phys., $\underline{43}, 2088,1965$

Perkins, F. W., Salpeter, E. E., and Yngvesson, K. O., Phys. Rev. Lett., 14, 579,1965

Sagalyn, R. C., Smiddy, M., and Bhargava, Y. N., Space Res. V, 189, 1965

Samir, U., and Willmore, A. P., PASS, $\underline{13}$, 285, 1965

Smith, L. G., Accardo, C. A., Weeks, L. H., and McKinnon, P. J., JATP, 27, 803,1965

Spencer, N. W., Brace, L. H., Carignan, G. R., Taeusch, D. R., and Niemann, H., JGR, $\underline{70}, 2665,1965$

Willmore, A. P., Proc. Roy. Soc. A, 286, 537, 1965 
Whipple, E. C., Jr., Equilibrium Electric Potential of a Body in the Upper Atmosphere and in Interplanetary Space, Ph.D. Thesis, The George Washington University, 1965 (NASA Tech. Note X615-65-296, 1965)

Aubry, M., Blanc, M., Chauvel, R., Taieb, C., Bowen, P. J., Norman, K., Willmore, A. P., Sayers, J., and Wager, J. H., Radio Sci., 1, 170, 1966

Baker, K. D., Pfister, W., and Ulwick, J. C., Space Res. VII, 665, 1966

Banks, P. M., Earth and Plan. Sci. Lett., 1, 151, 1966(a)

Banks, P. M., Earth and Plan. Sci. Lett., 1, 270, 1966 (b)

Banks, P., PASS, 14, 1105, 1966(c)

Carlson, H. C, JGR, 71, 195, 1966

Carlson, H. C., and Gordon, W. E., JGR, 71, 5573, 1966

Farley, D. T., JGR, $\underline{71}$, 4091, 1966

Hoult, D. P., and Ta-Jin Kuo, JGR, 71, 3191, 1966

Jacchia, L., and Slowey, J., Space Res. VII, 1077, 1966

Knudsen, W. C., JGR, 포, 4669, 1966

Nathan, N. V. S. K., and Seaton, M. J., Nature, 209, 701, 1966 
da Rosa, A. V., JGR, $\underline{71}, 4107,1966$

Rishbeth, H., Van Zandt, T. E., and Norton, R. B., Ann. Geophys., 22, 538; 1966

Samir, U., and Willmore, A. P., PASS, 14, 1131, 1966

Serbu, G. P., and Maier, E. J. R., JGR, 포, 3755, 1966

Walker, J. C. G., PASS, 14, 987, 1966

Banks, P. M., PASS, 15, 77, 1967 (a)

Banks, P. M., JGR, $\underline{72}, 3365$, 1967(b)

Baron, M., and Petriceks, J., JGR, 72, 5325, 1967

Brace, L. H., Reddy, B. M., and Mayr, H. G., JGR, $\underline{72}, 265,1967$

Carru, H., Petit, M., Vasseur, G., and Waldteufel, P., Ann. Geophys. 23, 455, 1967 (a)

Carru, H., Petit, M., Waldteufel, P., JATP, 29, 351, 1967 (b)

Cole, K. D., PASS, 15, 873, 1967

Cummings, W. D., and Dessler, A. J., JGR, $\underline{72}, 257,1967$

Dalgarno, A., and Walker, J. C. G., PASS, 15, 200, 1967 
Dalgarno, A., McElroy, M. B., and Walker, J. C. G., PASS, 15, 331, 1967

Evans, J. V., JGR, 72, 3343, 1967 (a)

Evans, J. V., PASS, 15, 1387, 1967(b)

Farley, D. T., McClure, J. P., Sterling, D. L., and Green, J. L., JGR, 72, 5837, 1967

Gleason, L. J., and Axford, W. I., PASS, 15, 123, 1967

Henderson, C. L., and Samir, U., PASS, 15, 1499, 1967

Mahajan, K. K., JATP, 29, 1137, 1967(a)

Mahajan, K. K., JATP, $\underline{29}$, 1153, 1967(b)

Matuura, N., and Ondoh, T., Space Res. IX, 297, 1967

Nagy, A. F., and Walker, J. C. G., PASS, 15, 95, 1967

Priester, W., Roemer, M., and Volland, H., Sp. Sci. Rev., 6, 707, 1967

Reddy, B. M., Brace, L. H., and Findlay, J. A., JGR, 72, 2709, 1967

Sonin, A. A., JGR, $\underline{72,} 4547,196 \underline{7}$

Banks, P. M., PASS, $\underline{16}$, 759, 1968 
Bauer, S. J., and Krishnamurthy, B. V., PASS, 16, 653, 1968

Boyd, R. L. F., in Plasma Diagnostıcs, Ed. Lochte-Holtgreven, W., N. Holland Pub. Co., ch. $\underline{12}, 1968$

Dalgarno, A., and Degges, T. C., PASS, $\underline{16}$, 125, 1968

Dalgarno, A., and Dickinson, A. S., PASS, 16, 911, 1968

Dalgarno, A., McElroy, M. B., Rees, M. H., and Walker, J. C. G., PASS, 16, 1371,1968

Foppl, H., Haerendel, G., Haser, L., Lust, R., Melzner, F., Meyer, E., Neuss, H., Rabben, H. H., Reiger, E., Stockuer, J., Stoffregen, W.; JGR, 73, 21, 1968

Knudsen, W. C., JGR, 73, 841, 1968

Loftus, B. T., Ariel III Symposium, May 23, 1968, G.S.F.C. Conference Rep., p. 97

Moss, S. J., and Hyman, E., JGR, $\underline{73}, 4315,1968$

Nagy, A. F., Bauer, P., and Fontheim, E. G., JGR, $\underline{73}, 6259,1968$

Nisbet, J. S., JATP, 30, 1257, 1968

Prasad, S. S., JGR, $\underline{73}, 6795,1968$ 
Ragab, F., University of London Ph.D. Thesis, "Study of the Energy Distribution of Ionospheric Charged Particles by High Altitude Sounding Rockets", 1968

Rees, M. H., and Walker, J. C. G., Ann. Geophys., 24, 193, 1968

Satya Prakash, B. H. Subbaraya, and S. P. Gupta, JATP, $\underline{30}$, 1193, 1968

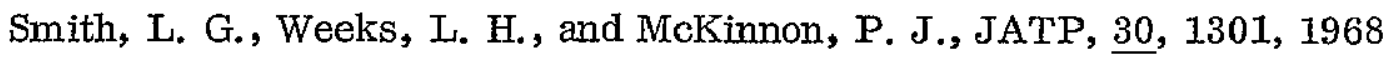

Stolarski, R. S., PASS, 16, 1265, 1968

Walker, J. C. G., PASS, $\underline{16}, 321,1968$

Walker, J. C. G., and Rees, M. H., PASS, 16, 459, 1968(a)

Walker, J. C. G., and Rees, M. H., PASS, 16, 915, 1968(b)

Wand, R. H., and Perkins, F. W., JGR, $\underline{73}, 6370,1968$

Wilson, J. W. G., and Garside, G., PASS, 16, 257, 1968

Yngvesson, K. O., and Perkins, F. W., JGR, $\underline{73}, 97,1968$

Bauer, S. J., Proc. IEEE, 57, 1114, 1969

Booker, H. G., and Smith, E. K., Sub Group Report to URSI, 1969

Brace, L. H., Carlson, H. C., and Mahajan, K. K., JGR, 74, 1883, 1969 
Brace, L. H., and Findlay, J. A., Proc. IEEE, 57, 1057, 1969

Brace, L. H., Mayr, H. G., Carıgnan, G. R., JGR, 프, 257, 1969

Brace, L. H.,.Mayr, H. G., and Findlay, J. A., JGR, $\underline{74}$, 2952, 1969

Brinton, H. C., Pharo, MI. W., III, Mayr, H. G., and Taylor, H. A., JGR, 74, 2941,1969

Colin, L., Dufour, D. W., and Willoughby, D. S., Proc. IEEE, $\underline{57}, 1154,1969$

Donley, J. L., Proc. IEEE, 57, 1061, 1969

Donley, J. L., Brace, L. H., Findlay, J. A., Hoffman, J. H., and Wrenn, G. L., Proc. IEEE, 57, 1078, 1969

Findlay, J. A., and Brace, L. H., Proc. IEEE, 57, 1054, 1969

Findlay, J. A., Dyson, P. L., Brace, L. H., Zmuda, A. J., and Radford, W. E., JGR, $\underline{74}, 3705,1969$

Hanson, W. B., Brace, L. H., Dyson, P. L., McClure, J. P., JGR, 74, 400, 1969

Harris, K. K., Sharp, G. W., and Knudsen, W, C., JGR, 74, 197, 1969

Henderson, C. L., Wrenn, G. L., and Waldteufel, P., private communication, 1969 
Herman, J. R., and Chandra, S., PASS, 17, 1247, 1969

Hinterregger, H. E., in Annals of the IQSY, M.I.T. Press, 1969 (in press)

Hooke, W. H., JGR, 74, 1870, 1969(a)

Hooke; W. H., PASS, 17, 737, 1969(b)

Lejeune, G., and Petit, M., PASS, 17, 1763, 1969

Mahajan, K. K., and Brace, L. H., JGR, 74, 5099, 1969

Maier, E. J. R., Proc. IEEE, 57, 1068, 1969

McClure, J. P., JGR, 74, 279, 1969

Moorcroft, D. R., JGR, 74, 315, 1969

Nagy, A. F., Fontheim, E. G., Stolarski, R. S., and Beutler, A. G., JGR, 74, 4667,1969

Narasinga Rao, B. C., and Donley, J. L., JGR, 74, 1715, 1969

Norman, K., private communication, 1969

Patterson, T. N. I., JGR, 74, 4799, 1969

Raitt, W. J., private communication, 1969 
Sayers, J., Report of URSI Sub-Group on Probes, 1969

Seasholtz, R. G., and Tanenbaum, B. S., JGR, 프, 2271, 1969

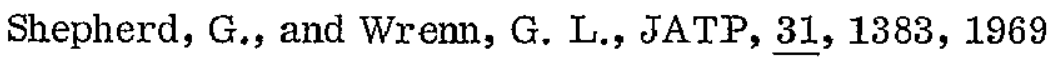

Smith, L. G., in Small Rocket Instrumentation Techniques, Ed. Maeda, K. I., p. 6, North-Holland Pub1. Co., 1969

Taieb, C., Proc. IEEE, 57, 1161, 1969

Vasseur, G., and Waldteufel, P., JATP, 31, 885, 1969

Whipple, E. C., and Parker, L. W., JGR, 74, 2962, 1969

Wrenn, G. L., Proc. IEEE, 57, 1072, 1969

Wrenn, G. L., and Smith, P. A., Proc. IEEE, 프, 1085, 1969

Henderson, C. L., and Wrenn, G. L., to be published in Space Res. X. (1970)

Taylor, G. N., and Wrenn, G. L., to be published in PASS 


\section{FIGURE CAPTIONS}

Figure 1(a). Cylindrical probe characteristic obtained from ISIS-1 at latitude $26^{\circ}$, longitude $72^{\circ}$, altitude $600 \mathrm{~km}$ at $21^{\mathrm{h}} 33^{\mathrm{m}}$ GMT on 1969 October 4.

Figure 1(b). Exponential portion of the characteristic after subtraction of the ion current, showing the determination of $T_{e}, 1_{e o}$ and space potential.

Figure 1(c). Actual and ideal characteristics in the accelerating regime, the ideal characteristic being calculated using $T_{e}$ and $1_{e}$ determined from (6). [In practice, current ranges of different sensitivity would be used for the temperature and density determinations, leading to a better resolution of each quantity.] (Courtesy of Mr. L. H. Brace.)

Figure 2. Explorer $X X X I$, showing the Langmuir probes. A spherical ion probe is mounted at the top on a short boom. On the left front face is the ac electron probe, on the right front face the screened plane probe; on the right side projects a cylindrical probe.'

Figure 3. First and second derivatives of a spherical ion probe characteristic for an ion mixture, obtained on Explorer XXXI. [From Wrenn (1969)]

Figure 4. Comparison of measured and theoretical second derivative characteristic for an $\mathrm{O}^{+}$plasma. The rms deviation of the measured points is $1.4 \%$ of the peak amplitude. [From Wrenn (1969)]

Figure 5. The wake of a satellite (Ariel I) observed close to the surface. The relative currents to identical probes mounted on the base of the spacecraft and on a boom in relatively undisturbed plasma are shown as a function of 
the attack angle, i.e. the angle between the spacecraft axis and the velocity vector. Because the probe is in the base, it is on the forward or ram side of the spacecraft when the angle of attack is $180^{\circ}$ and in the wake when this angle is $0^{\circ}$. The predominant ion was $\mathrm{O}^{+}$. [From Samir and Willmore (1965)]

Figure 6. Ratıo of electron densities measured with a probe in the surface of Explorer XXXI and those obtained by the topside sounder on Alouette II. The low densities measured at large Debye lengths are the result of the limitation of the probe current by a potential barrier caused by the proximity of the spacecraft. At about $\lambda_{\mathrm{D}}=0.8 \mathrm{~cm}$ the effect disappears when a sheath forms about the spacecraft. [Courtesy of Dr. G. W. Wrenn.]

Figure 7. Normalised incoherent scatter spectra calculated for an $\mathrm{O}^{+}$plasma $\left(\mathrm{K}=(\mathrm{N} / \mathrm{m})^{1 / 2}=172\right)$ for propagation parallel to the magnetic field or no magnetic field. For $X_{p}=0.1\left(k \lambda_{D}=0.1\right)$ the spectral distribution is little affected by the presence of the ions. For $x_{p}=3.0$, the plasma line can be . seen at $X=3$. [From Hagfors (1962)]

Figure 8. Computed incoherent scatter spectra for ratios of the parameter $T_{e} / T_{1}$ from 1.0 to 4.0 . A plasma frequency of $5 \mathrm{MHz}$ and' an ion temperature of $1500^{\circ} \mathrm{K}$ were assumed. The results apply for $\mathrm{O}^{+}$ions and were made for a radar carrier frequency of $440 \mathrm{MHz}$ and a pulse length of $1 \mathrm{msec}$. [ From Evans (1964)]

Figure 9. Computed incoherent scatter spectrum for propagation almost perpendicular to the magnetic field. The angles are (top) $87^{\circ}$ and (bottom) $88^{\circ}$; the dotted line shows the spectral distribution normal to the field. The 
calculations are for a radar frequency of $40 \mathrm{MHz}$ and typical ionospheric conditions. [ From Farley, Dougherty and Barron (1961)]

Figure 10. $\mathrm{T}_{\mathrm{e}}$ and $\mathrm{T}_{1}$ measured by the ac probes on Explorer XXXI compared with simultaneous and near-coincident observations by the St. Santin incoherent scatter station on 1968 April 23. [From Henderson, Wrenn and Waldteufel (1969)]

Figure 11. Exospheric and electron temperatures determined by satellites and by incoherent scatter. The results are all for an altitude of $400 \mathrm{~km}$ and are for latitudes near $0^{\circ}$ and $40^{\circ}$ geomagnetic. The bracketed Explorer XVII points show the results of adjustment according to Eq. (23). The large variation of the night temperatures at Millstone $H_{1} l 1$ is a seasonal effect." The vertical lines on the Arecibo observations indicate the range encountered and are not an exror indication. [Data for these figures was obtained from: Explorer I - Jacchia and Slowey (1966); Jicamarca - Farley, McClure, Sterling and Green (1967); Ariel I - Willmore (1965); Explorer XVII Brace, Spencer and Dalgarno (1965); Millstone Hill - Evans (1965a, 1967b); Arecibo - Mahajan (1967a), Prasad (1968).]

Figure 12. (a) Variation of gas temperature $T_{g}$ with altitude in the ionosphere.

(b) Variation of exosphere temperature with geographic position. [From Jacchia (1965)]

Figure 13. Variation of (a) the electron heating efficiency $\epsilon$ and (b) the heat input Q with altitude at noon. (Non-local heating is neglected.). [ From DaIgarno, McElroy, 'Rees and Walker (1968)] 
Figurè 14. Photoelectron energy distribution for various altztudes from 200$300 \mathrm{~km}$. [From Hoegy, Fourrier and Fontheim (1965)]

Figure 15. Variation with altitude of the heat input $Q$ showing both the local heating and also the additional non-local heating which results from including the contribution from photoelectrons originating below $300 \mathrm{~km}$. [From Geisler and Bowhill (1965)]

Figure 16. Calculated electron cooling rates by various collision processes for 1963 July at noon. The curves refer to excitation of (a) vibrational levels of $\mathrm{N}_{2}$, (b) rotational levels of $\mathrm{N}_{2}$, (c) fine-structure levels of $\mathrm{O}$, (d) metastable levels of $O$, and (e) elastic collisions with positive ions. The cooling due to elastic collisions with neutrals and from rotational excitation of $\mathrm{O}_{2}$ are negligible. [From Dalgarno, McEIroy, Rees and Walker (1968)]

Figure 17. Variation of electron temperature with altitude at Millstone Hill for 1963 July at various local times. The solid curves are calculated including fine-structure cooling by atomic oxygen whilst it is neglected in the dashdot curves. The dashed curves are values measured by Evans by incoherent scatter. [ From Dalgarno, MeElroy, Rees and Walker (1968)]

Figure 18. Altitude profiles of $T_{e}$ and $T_{1}$ taken (a) at Jicamarca and (b) at Millstone Hill. The effect on $T_{e}$ of the virtual suppression at Jicamarca of nonlocal heating is very striking. [From Farley, McClure, Sterling and Green - (1967) and Evans (1965)]

Figure 19. Diurnal variation of $\mathrm{T}_{e}$ at Arecibo in winter. Also shown are times of sunrise and sunset at Arecibo and at the magnetically conjugate location. 
Whilst at $225 \mathrm{~km} \mathrm{~T}_{\mathrm{e}}$ falls sharply at local sunset, and rises again at sunrise, at $400 \mathrm{~km}$ it declines steadily to a minimum in the early morning hours, starting to rise again at sunrise in the conjugate ionosphere. The early morning maximum-is most pronounced at $300 \mathrm{~km}$ on this occasion. [From Carlson (1966)]

Figure 20. Latitude variation of $\mathrm{T}_{e}$ as determined by probe measurements on Ariel I [ (a) and (b)] and Explorer XX [ (c) and (d)]. The Explorer XX results refer to an altitude of $1000 \mathrm{~km}$. [From Willmore (1965) and Brace, Reddy and Mayr (1967)]

Figure 21. Measurements of $\mathrm{T}_{\mathrm{e}}$ in the E-region by Langmuir probes and incoherent scatter compared with gas temperature from CIRA 1965 (solid lines). 6 and 7 refer to similar rocket flights, 6 near midnight and 7 near noon. 8 and 9 were also similar, the two flights occurring at approximately the same local time, two days apart.

Figure 22. Calculated temperature profiles for an auroral arc with $\lambda 3914 \AA$ brightness of $34.7 \mathrm{kR}$. [ $\mathrm{T}_{\mathrm{e}}^{\prime}$ is the result neglecting thermal conduction, from Walker and Rees (1968a)]

Figure 23. Calculated temperature profiles in a SACARC when the heating is supposed to result from (a) electric fields of various magnitudes normal to the magnetic field and (b) heat fluxes conducted from the magnetosphere. The temperature gradients are those at $1000 \mathrm{~km}$. [From Walker and Rees $(1968 \mathrm{~b})]$ 


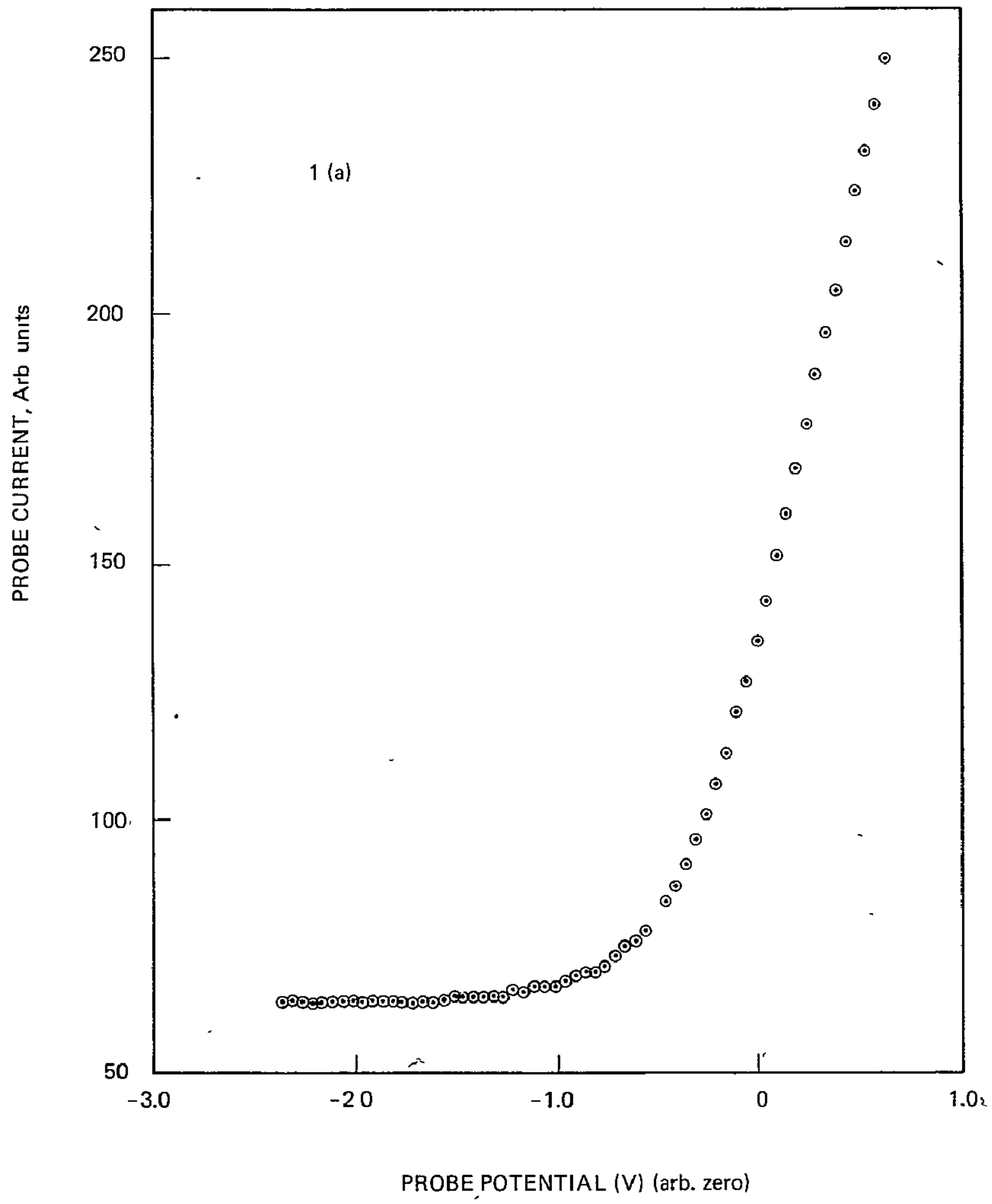

FIgure 7(a). Cylındrical probe characteristic obtained from ISIS-1 at latıtude $26^{\circ}$, longitude $72^{\circ}$, altitude $600 \mathrm{~km}$ at $21^{\mathrm{h}} 33^{\mathrm{m}} \mathrm{GMT}$ on 1969 October 4. (Courtesy of Mr. L. H. Brace) 


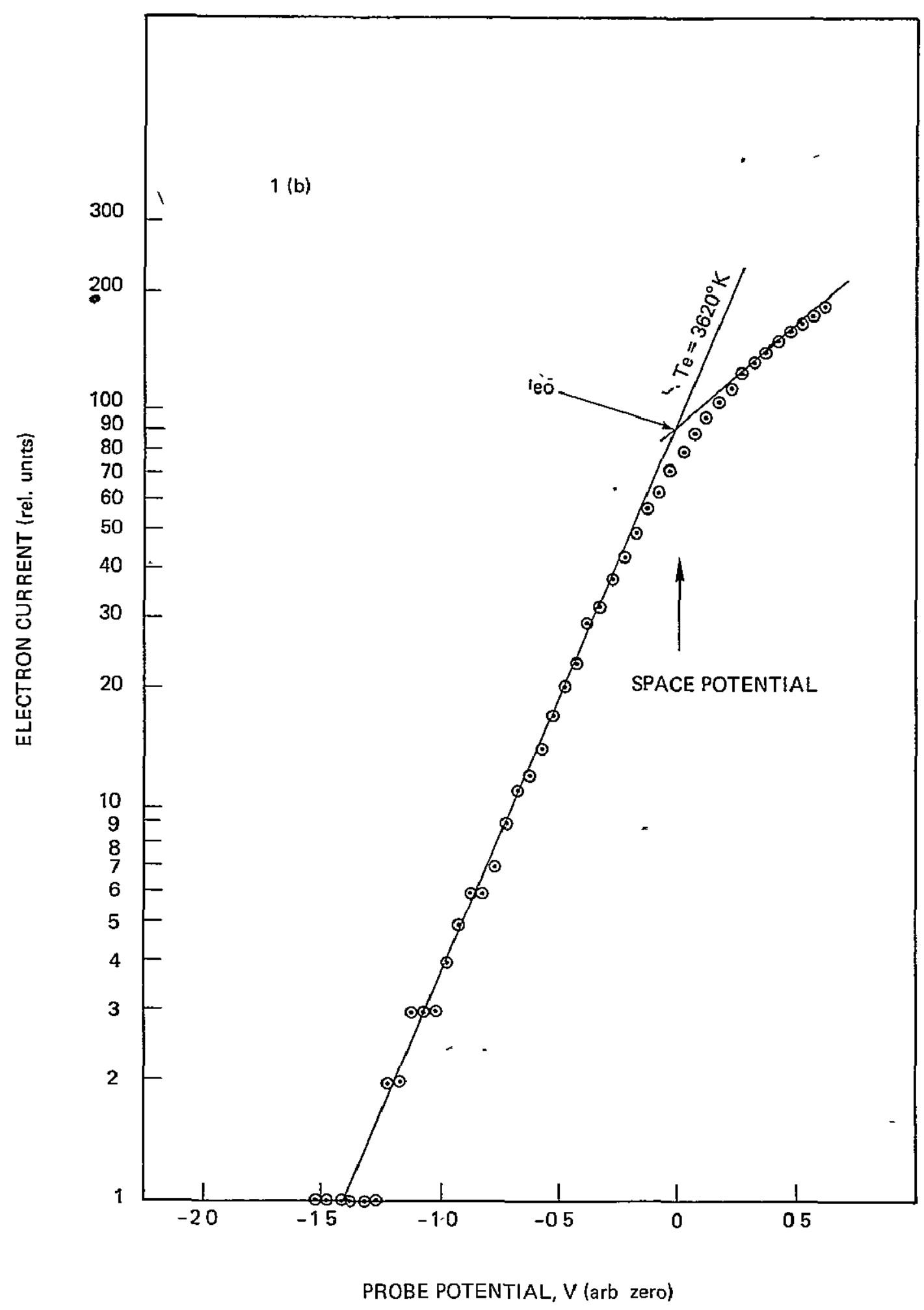

Figure 1(b). Exponential portion of the characteristic after subtraction of the con current, showing the determination of $\mathrm{T}_{\mathrm{e}^{\prime}} \mathrm{i}_{\text {eo }}$ and space potentıal. (Courtesy of Mr. L. H. Brace) 


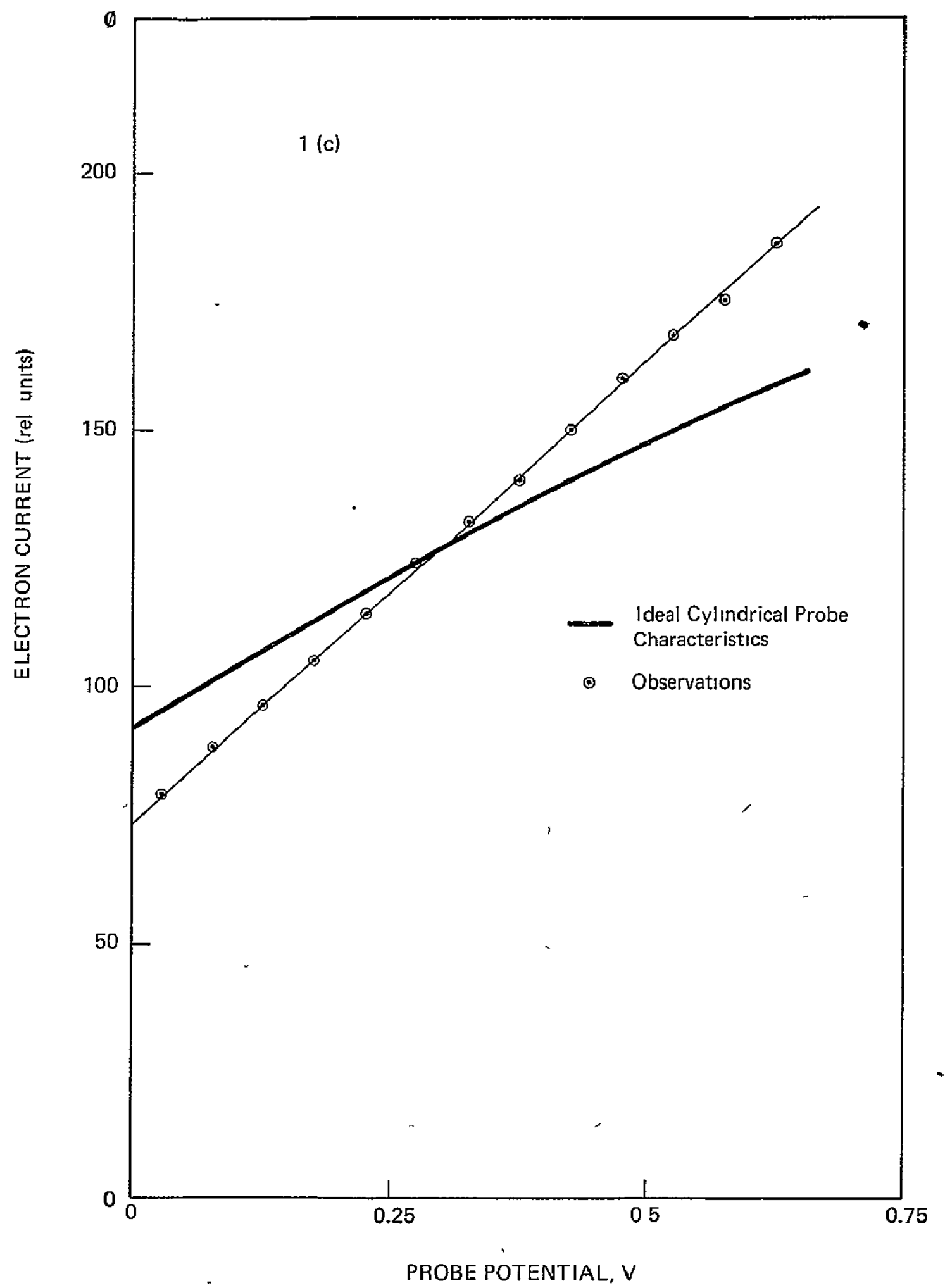

Figure ](c). Actual and Ideal characteristics in the accelerating regıme, the ideal characteristıc being calculated using $T_{e}$ and $1_{e o}$ determined from (6). [in practice, current ranges of different sensitivity would be used for the temperature and density determinations, leading to a better resolution of each quantity.] (Courtesy of Mr. L. H. Brace) 


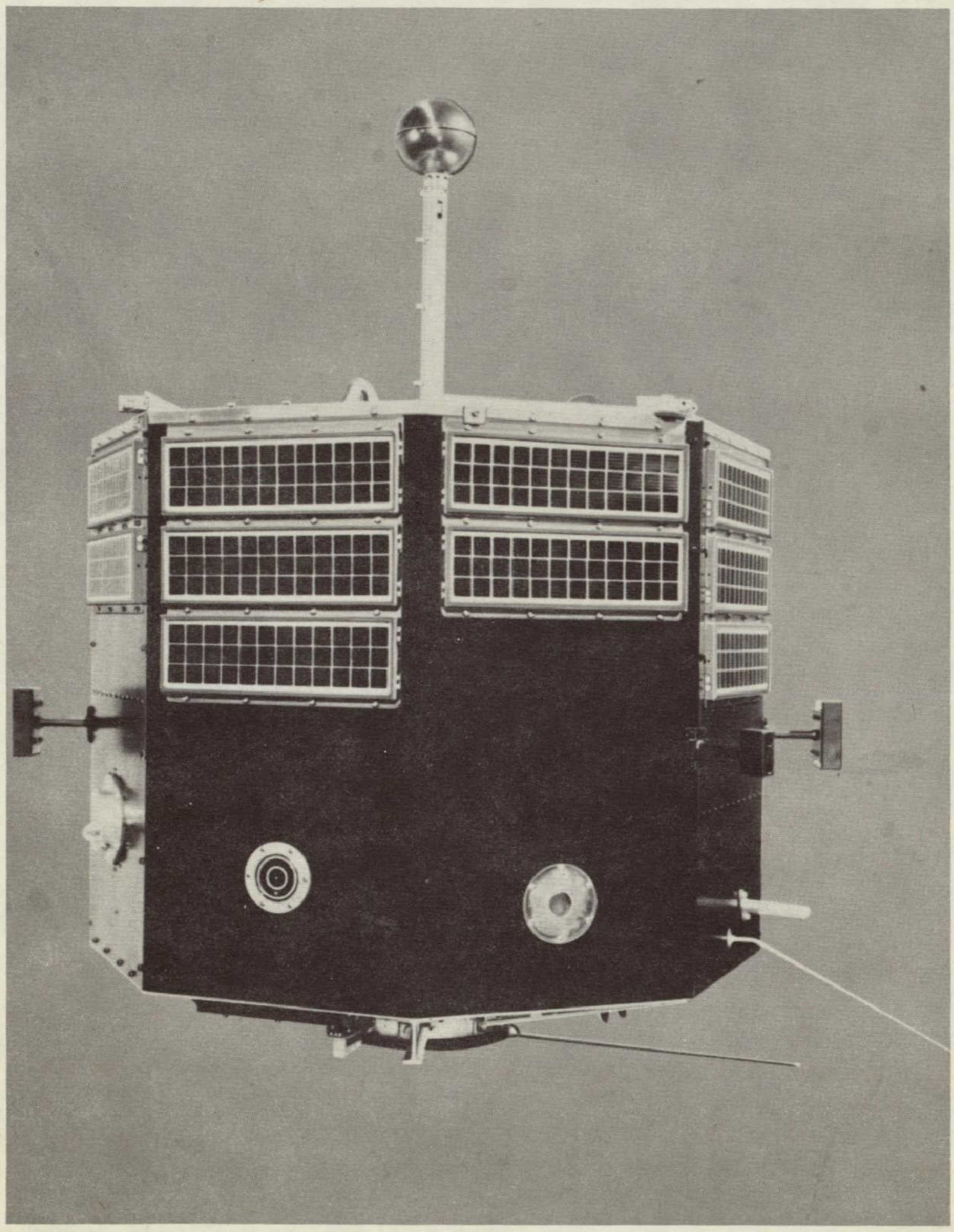

Figure 2. Explorer $\mathrm{XXXI}$, showing the Langmuir probes. A spherical ion probe is mounted at the top on a short boom. On the left front face is the ac electron probe, on the right front face the screened plane probe; on the right side projects a cylindrical probe. 
DECEMBER 16, 1965 10-31-57 Z

ALT. $527 \mathrm{Km}$ : LAT. $61^{\circ} \mathrm{S}$ : LONG. $68^{\circ} \mathrm{W}$ LOCAL TIME 06:05 hrs.
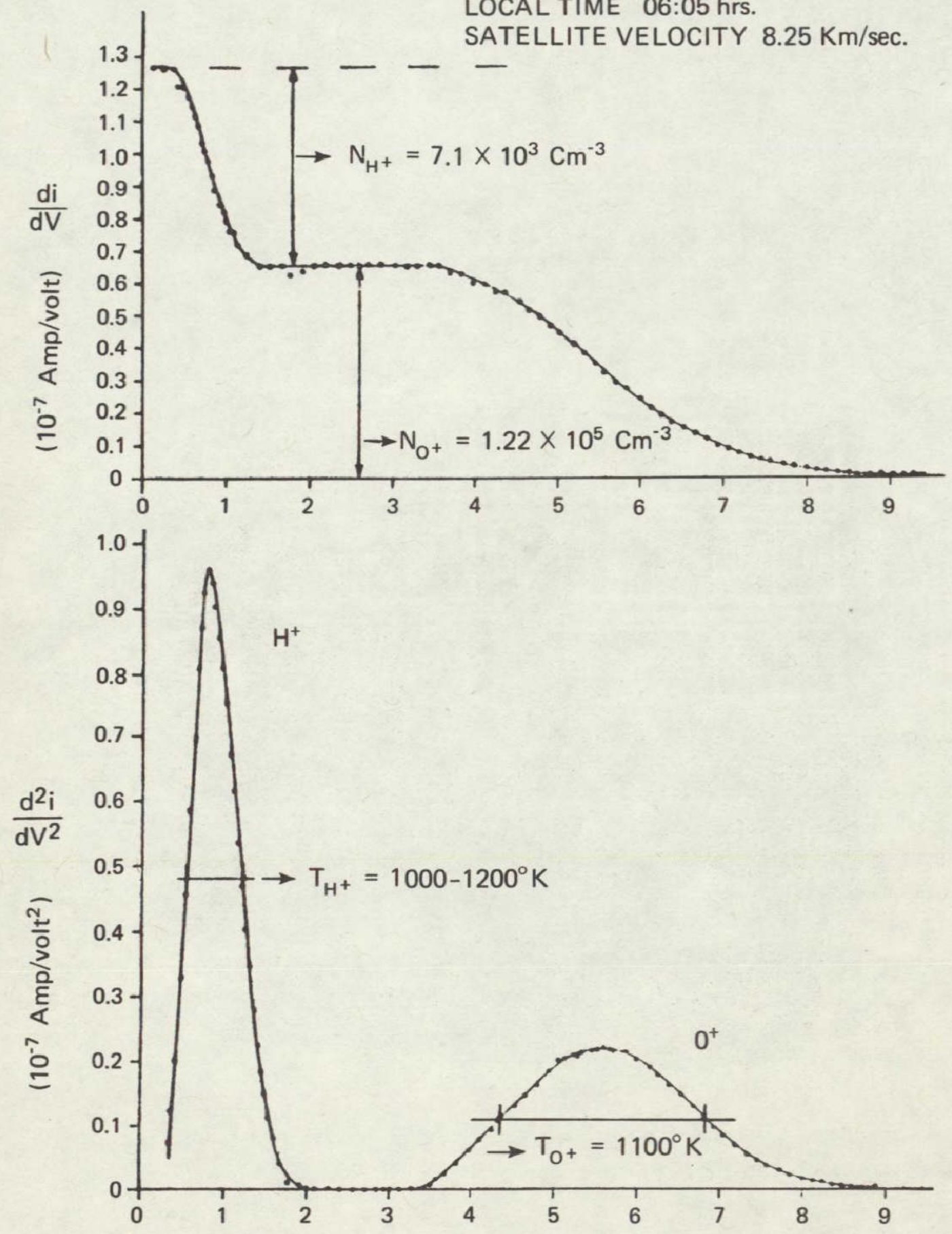

PROBE VOLTS (w-r-t satellite)

Figure 3. First and second derivatives of a spherical ion probe characteristic for an ion mixture, obtained on Explorer XXXI. [From Wrenn (1969)] 


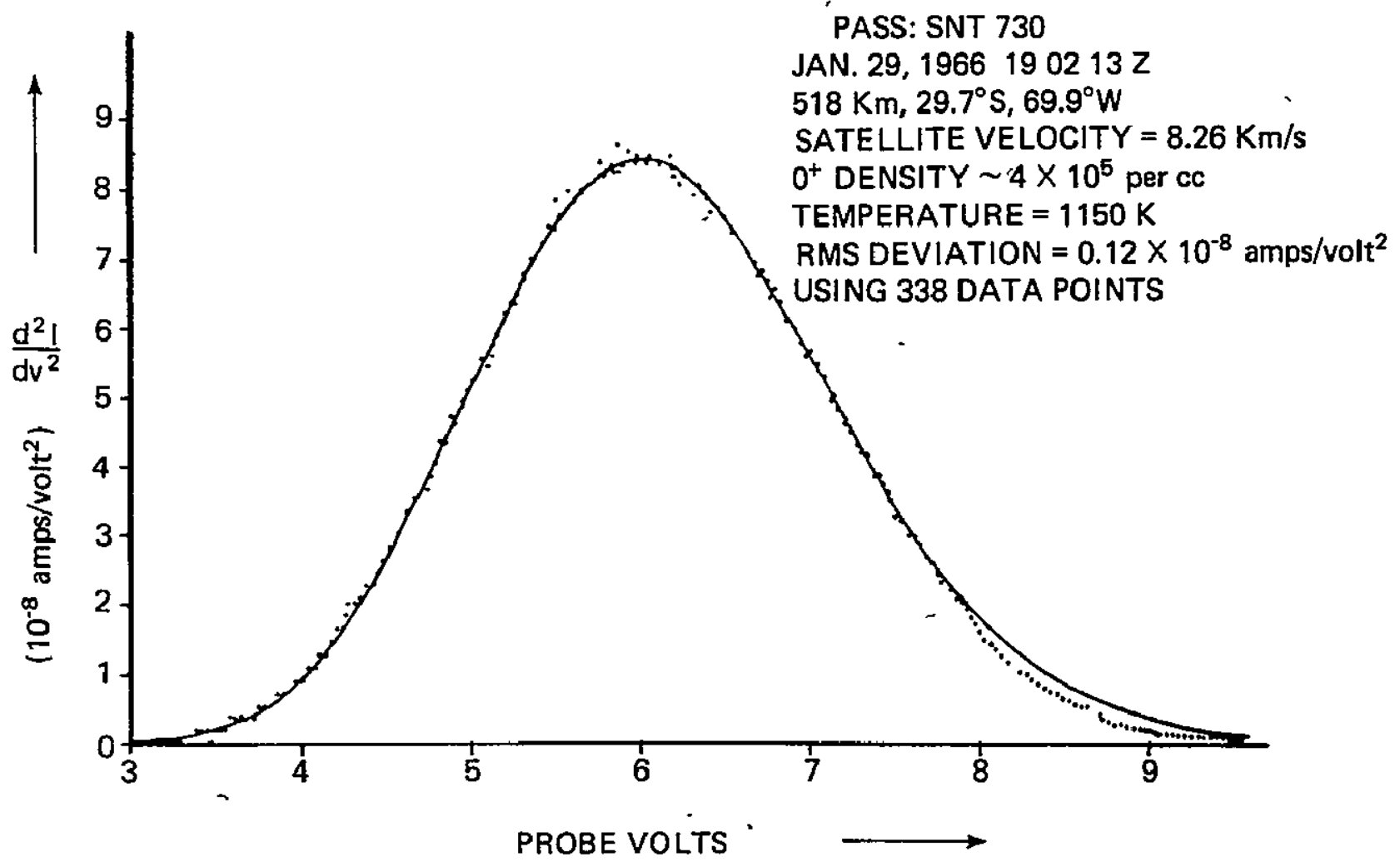

Figure 4. Comparıson of measured and theoretical second derivative characteristic for an $\mathrm{O}^{+}$plasma. The rms deviation of the measured points, is $14 \%$ of the peak amplitude.

[From Wrenn (1969)] 


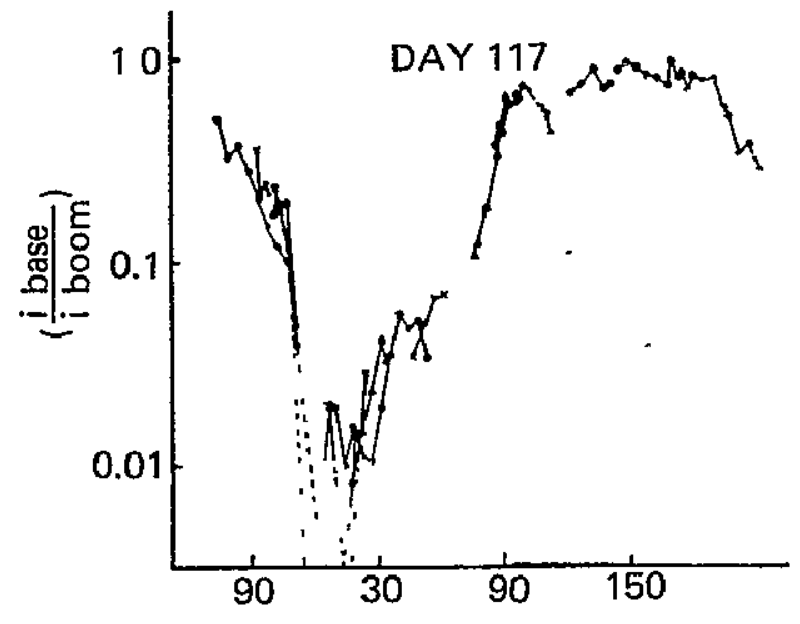

ANGLE OF ATTACK, deg

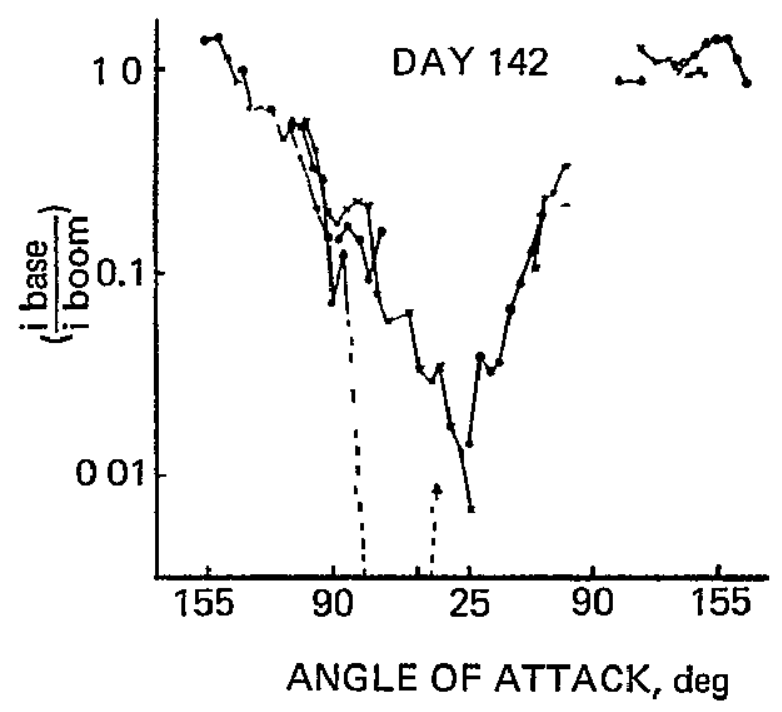

Figure 5. The wake of a satellite (Ariel 1) observed close to the surface. The relative currents to identical probes mounted on the base of the spacecraft and on a boom is relatively undisturbed plasma are shown as a function of the attack-angle, 1.e. the angle between the spacecraft axis and the velocity vector. Because the probe is in the base, it is on the forward or ram side of the spacecraft when the angle of attack is $180^{\circ}$ and in the wake when this angle is $0^{\circ}$. The predominantion was $\mathrm{O}^{+}$. [From Samir and Willmore (1965)] 


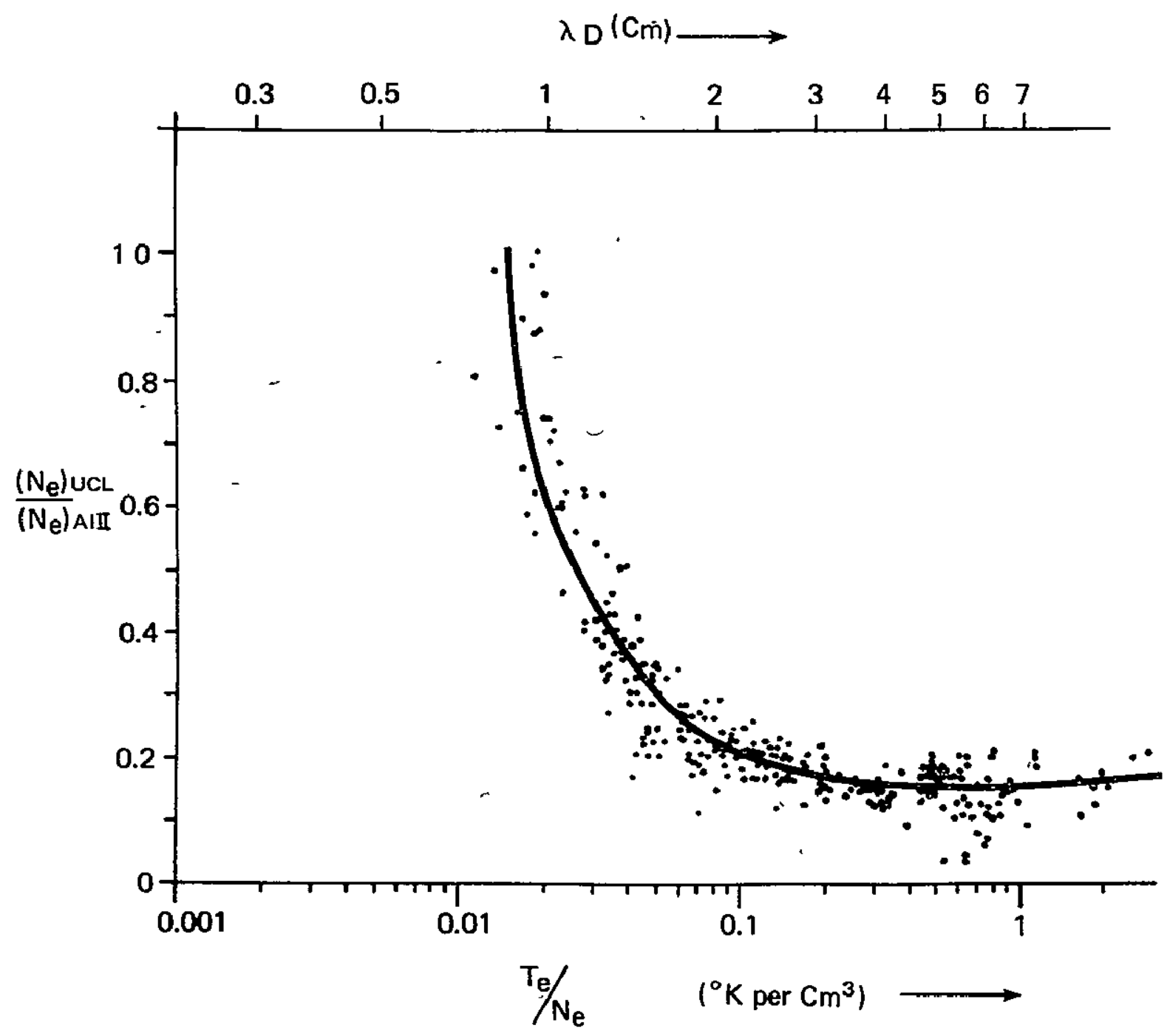

Figure 6. - Ratio of electron densities measured with a probe in the surface of Explorer $X X X I$ and those obtained by the topside sounder on Alovette II. The low densities measured at large Debye lengths are the result of the limitation of the probe current by a potential barrier caused by the proximity of the spacecraft. At about $\lambda_{\mathrm{D}}=0.8 \mathrm{~cm}$ the effect disappears when a sheath forms about the spacecraft. [Courtesy of Dr. G. W. Wrenn.] 


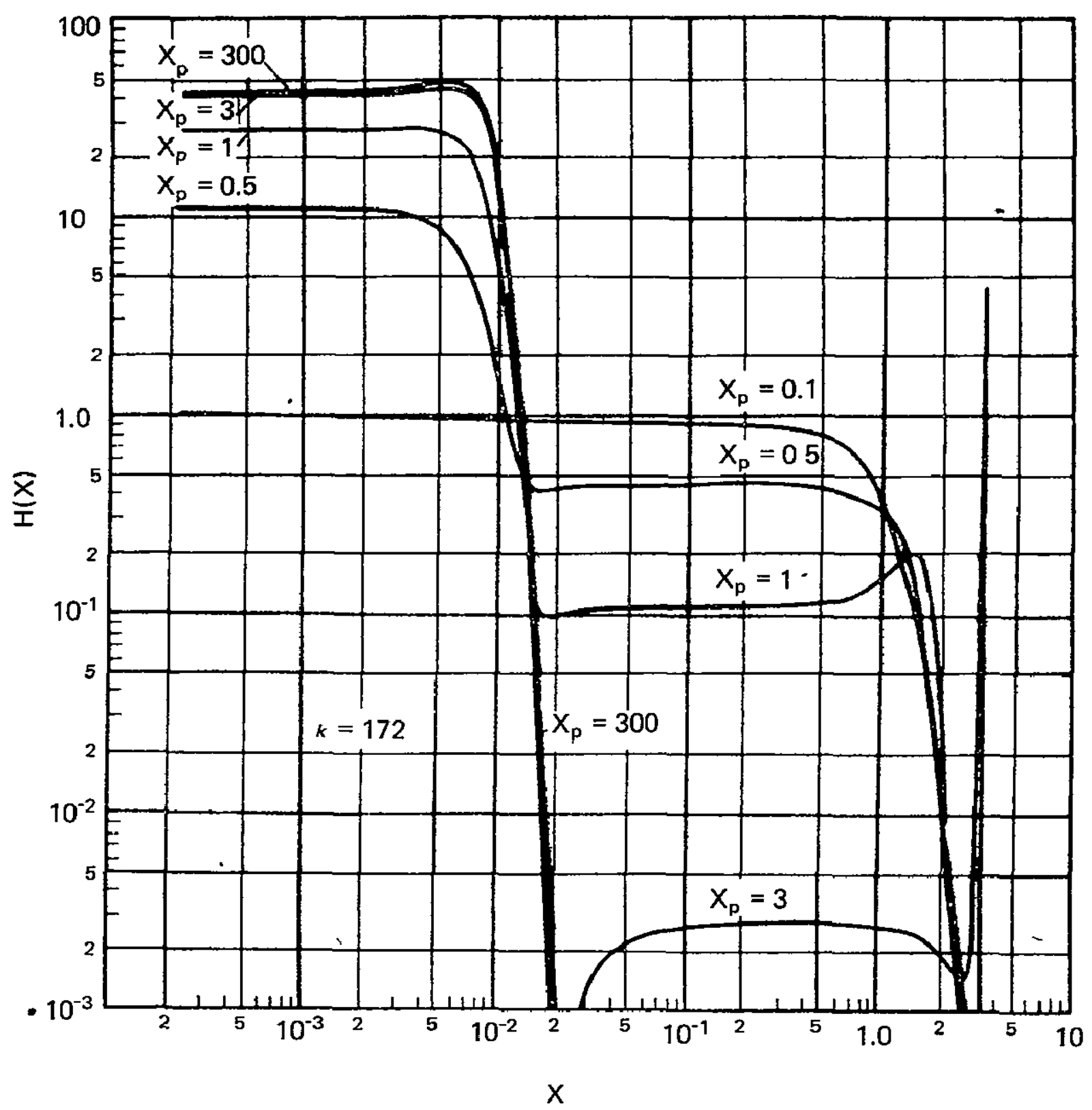

Figure 7. Normalized incoherent scatter spectra calculated for an $O^{+}$plasma $\left(K=(M / m)^{1 / 2}=\right.$ 172) for propagation parallel to the magnetic field or no magnetıc field. For $X_{p}=01\left(k \lambda_{D}=0.1\right)$ the spectral distribution is litfle affected by, the presence of the ions. For $X_{p}=3.0$, the plasma lıne can be seen at $X=3$. [From Hagfors (1962)] 


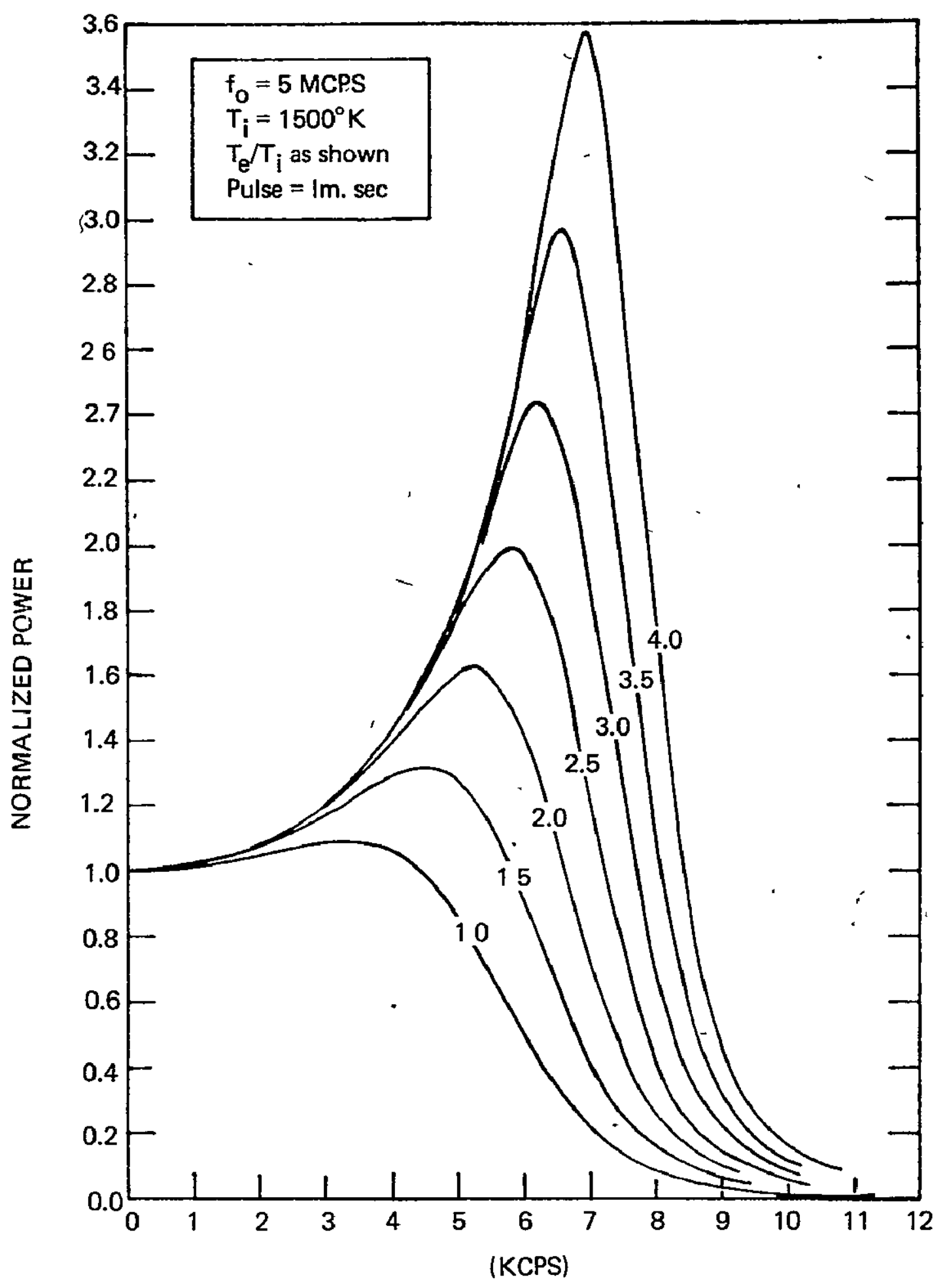

Figure 8. Computed incoherent scatter spectra for ratios of the parameter $T_{e} / T_{1}$ from 10 to 4.0 . A plasma frequency of $5 \mathrm{MHz}$ and an ion temperature of $1500^{\circ} \mathrm{K}$ were assumed. The results apply for $\mathrm{O}^{+}$ions and were made for a radar carner frequency of $440 \mathrm{MHz}$ and a pulse length of $1 \mathrm{msec}$. [From Evans (1964)] 


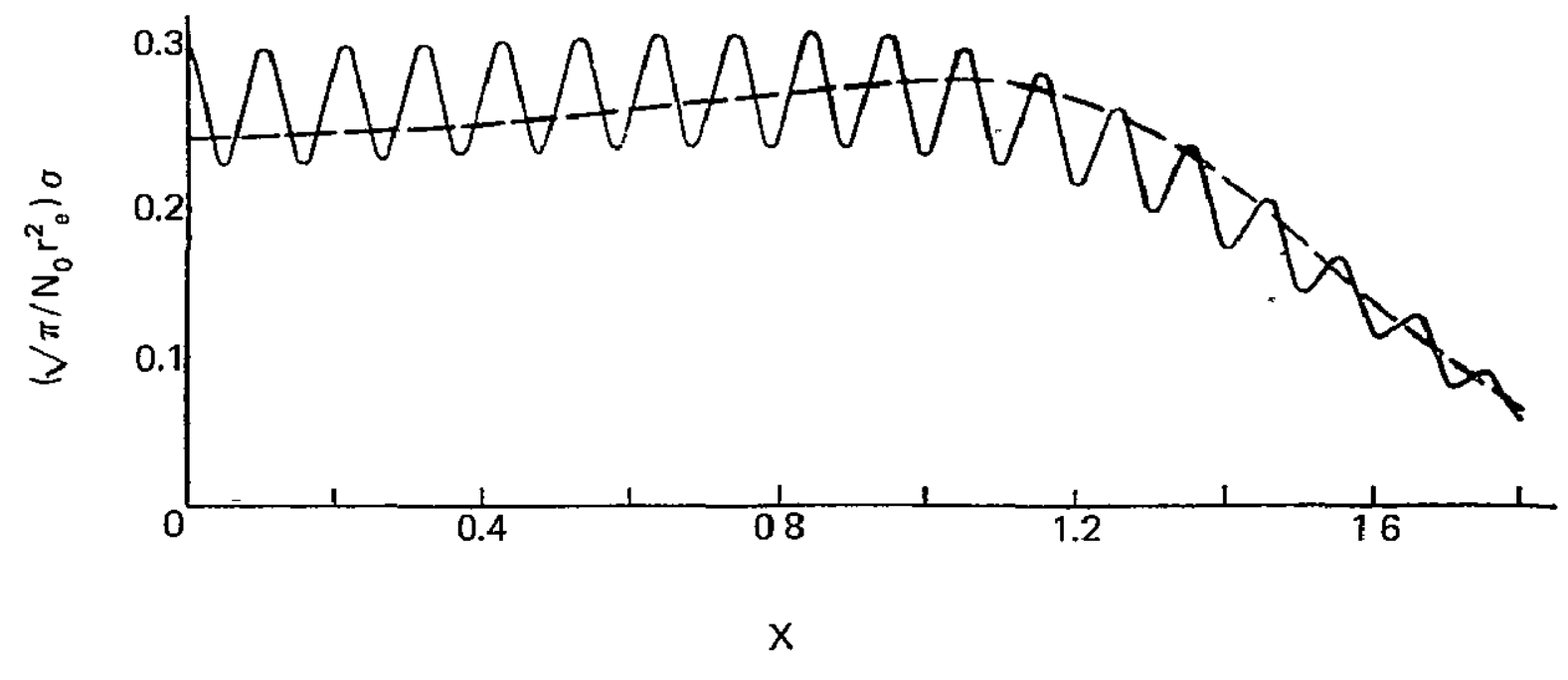

(b)

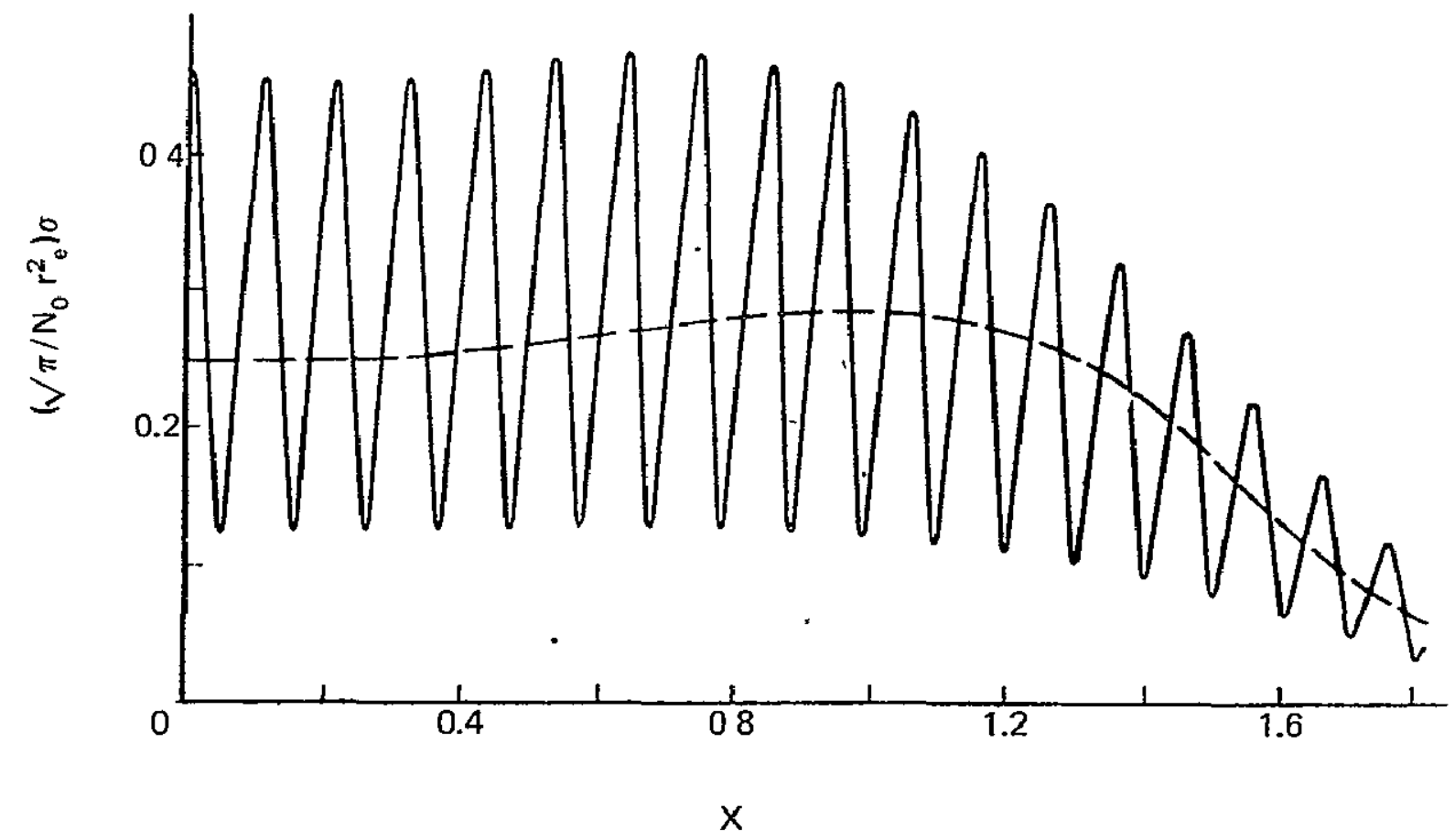

Figure 9. Computed incoherent scatter spectrum for propagation almost perpendicular to the magnetic field. The angles are (top) $87^{\circ}$ and (bottom) $88^{\circ}$; the dotted line shows the spectral distribution normal to the field. The calculations are for a radar frequency of $40 \mathrm{MHz}$ and typical ionospheric conditions. [From Farley, Dougherty and Barron (1961)] 


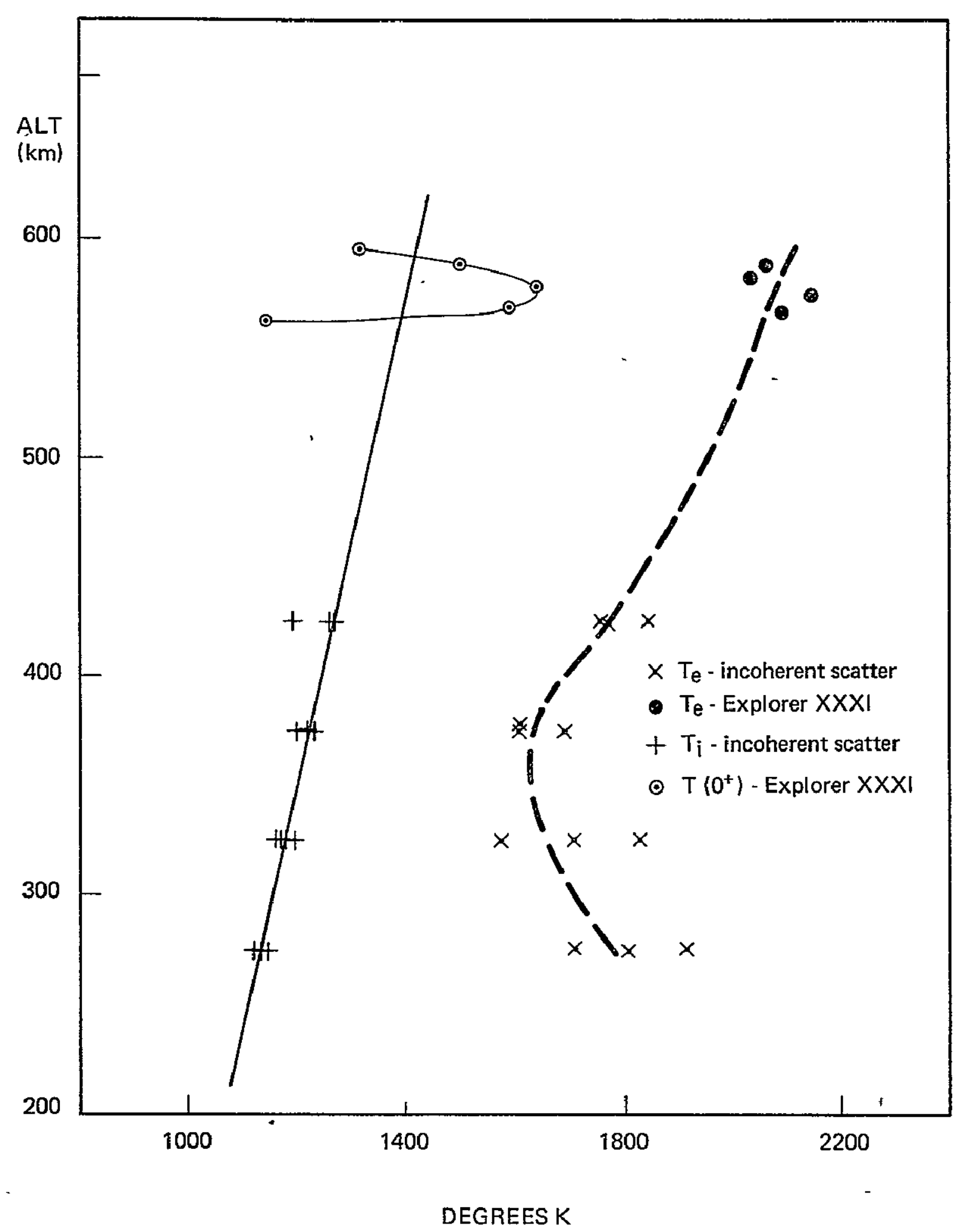

Figure 10. $T_{e}$ and $T_{1}$ measured by the ac probes on Explorer $X X X \mid$ compared with simultaneaus and near-coincident observations by the St. Santin incoherent scatter station on 1968 April 23.

[From Henderson, Wrenn and Waldreufel (1969)] 


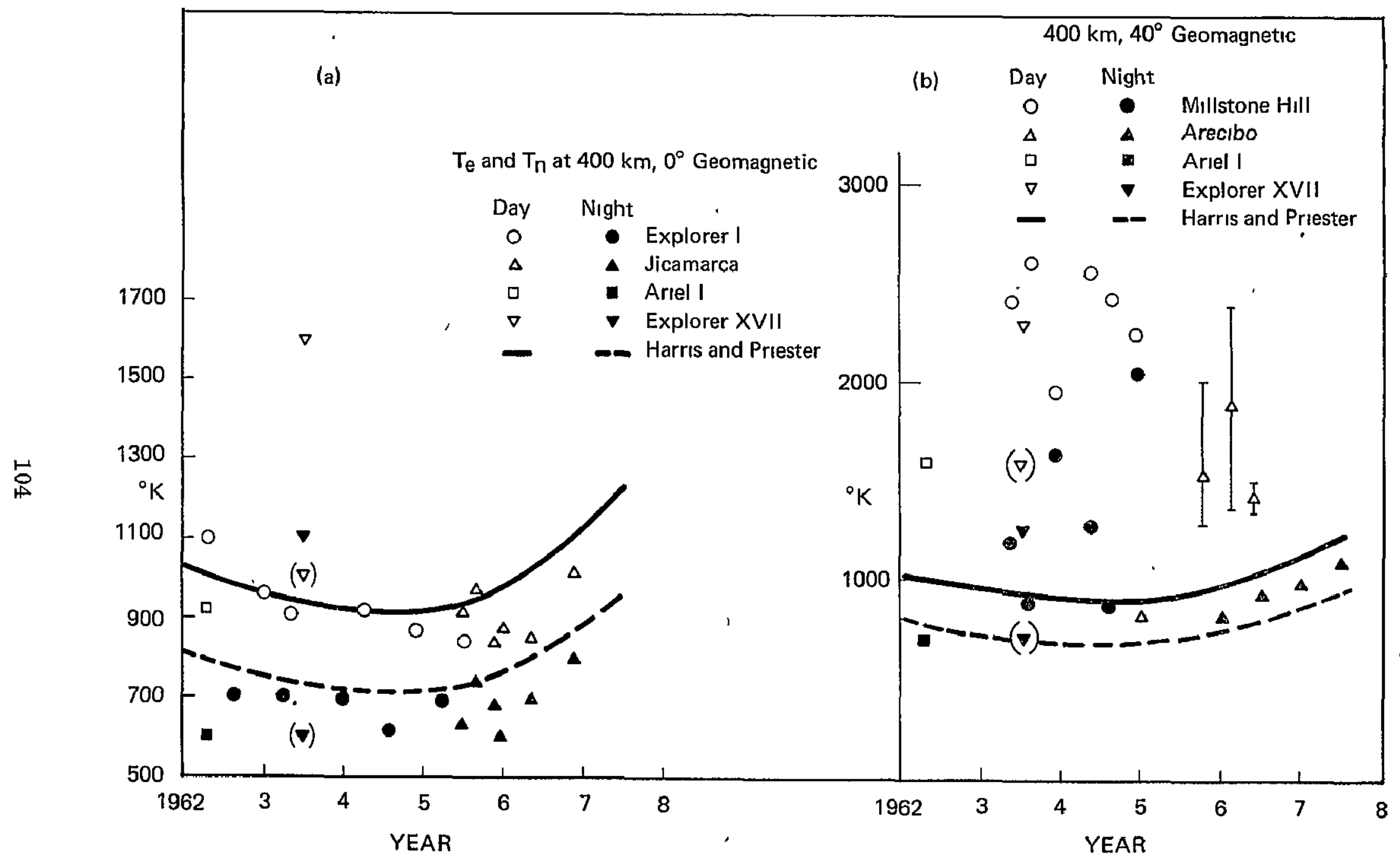

. Figure 11. Exospheric and electron temperatures determined by satellites and by incoherent scatter. The results are all for an altıtude of $400 \mathrm{~km}$ and are for latıtudes near $0^{\circ}$ and $40^{\circ}$ geomagnetıc. The bracketed Explorer XVII points show the results of adjustment according to Eq. (23). The large variation of the night temperatures at Millstone Hill is a seasonal effect. The vertical Iines on the Arecibo observations indicate the range encountered and are not an error indication. [Data for these figures was obtalned from. Explorer I - Jacchia and Slowey (1966), Jicamarca - Farley, McClure, Sterlıng and Green (1967), Ariel I - Willmore (1965), Explorer XVII

- Brace, Spencer and Dalgarno (1965), Millstone Hill - Evans (1965a, 1967b), Arecibo - Mahajan (1967a), Prasad (1968).] 
(a)

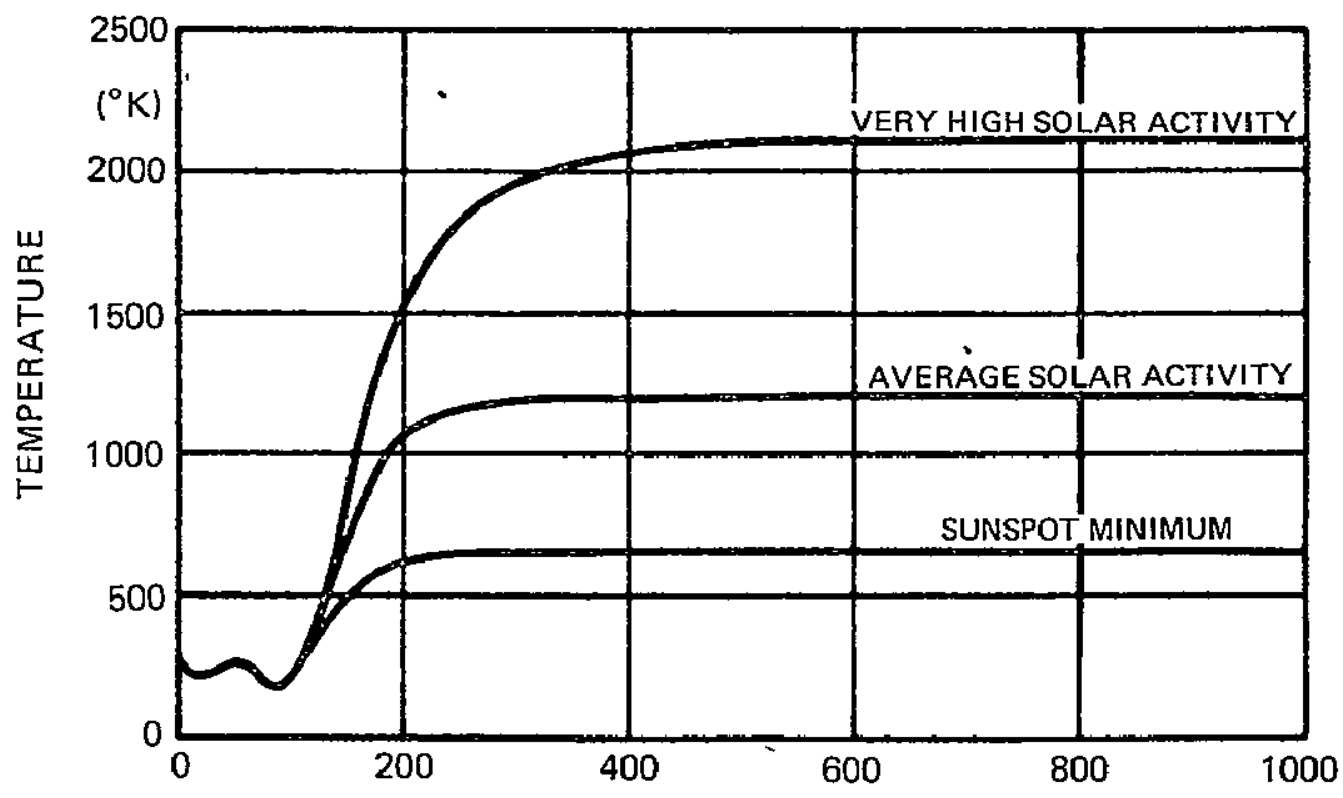

HEIGHT $(\mathrm{km})$

(b)

EXOSPHERIC TEMPERATURE DISTRIBUTION AT THE EQUINOXES

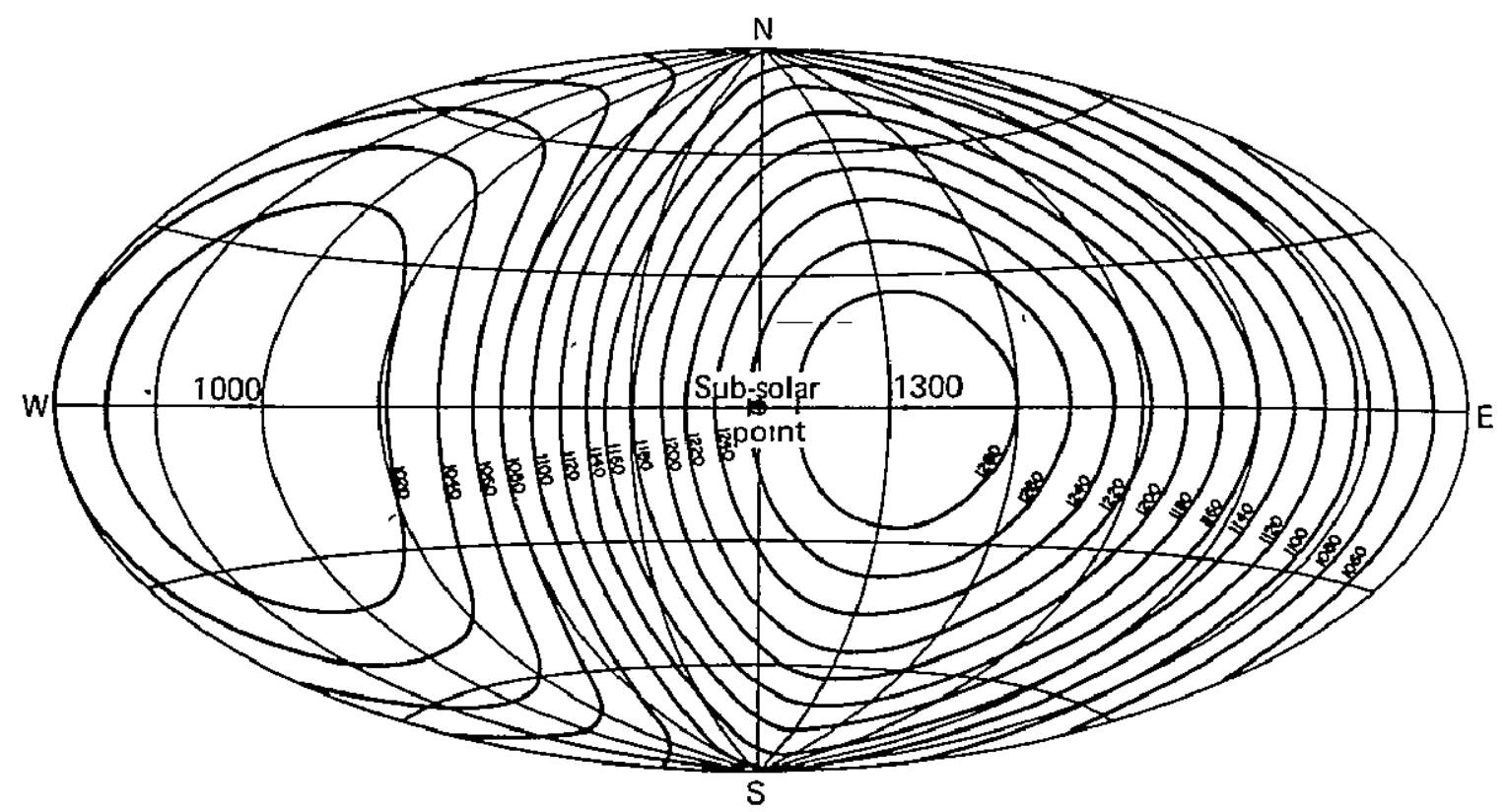

Figure 12. (a) Variation of gas temperature $\mathrm{T}_{\mathrm{g}}^{-}$with al titude in the ionosphere. (b) Variation of exosphere temperature with geographic position. [From Jacchı a (1965)] 

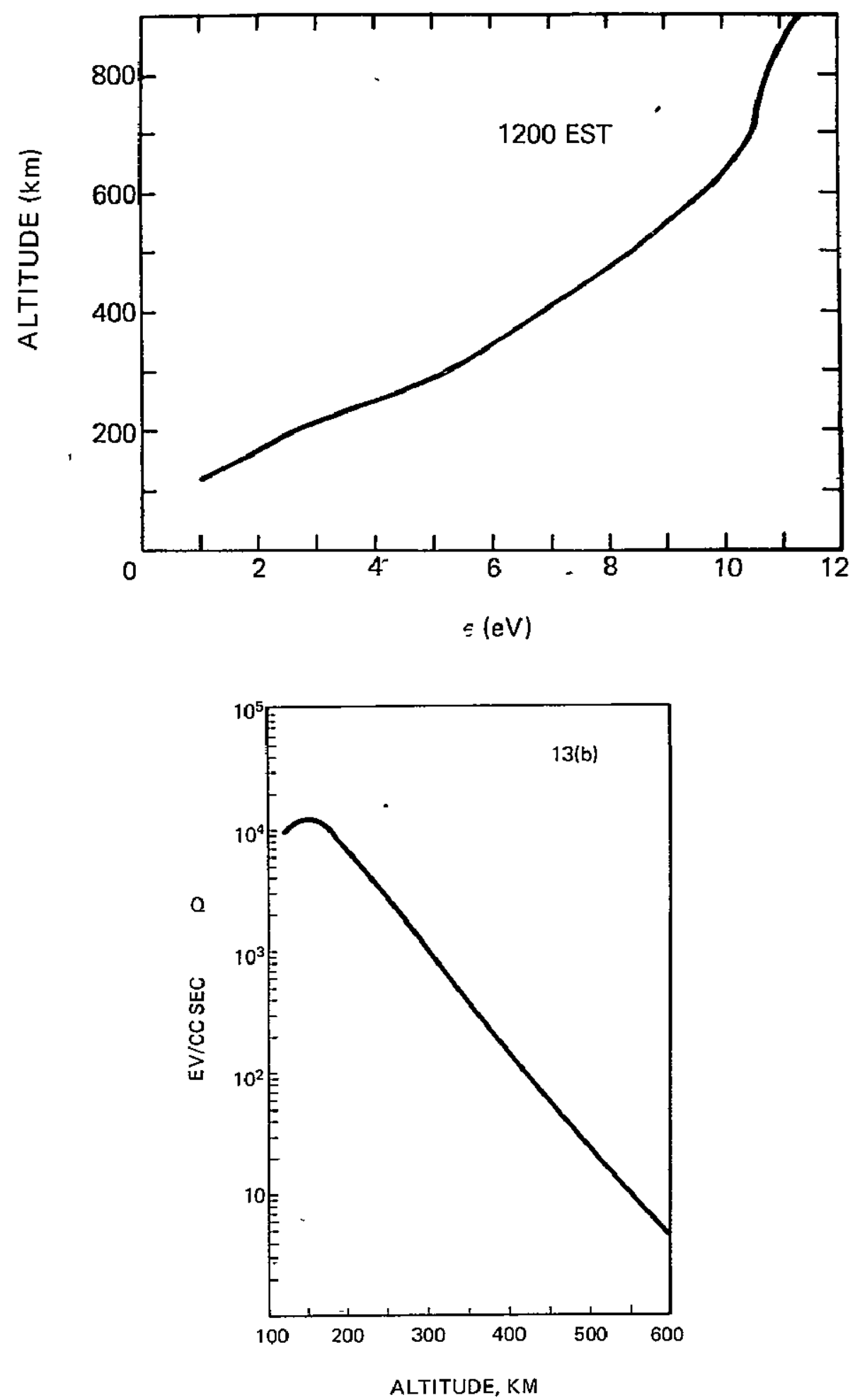

Figure 13. Variation of $(\alpha)$ the electron heating efficiency $\in$ and (b) the heat input $Q$ with altitude at noon. (Non-local heating is neglected.) _ [From Dalgarno, McElroy, Rees and Walker (1968)] 


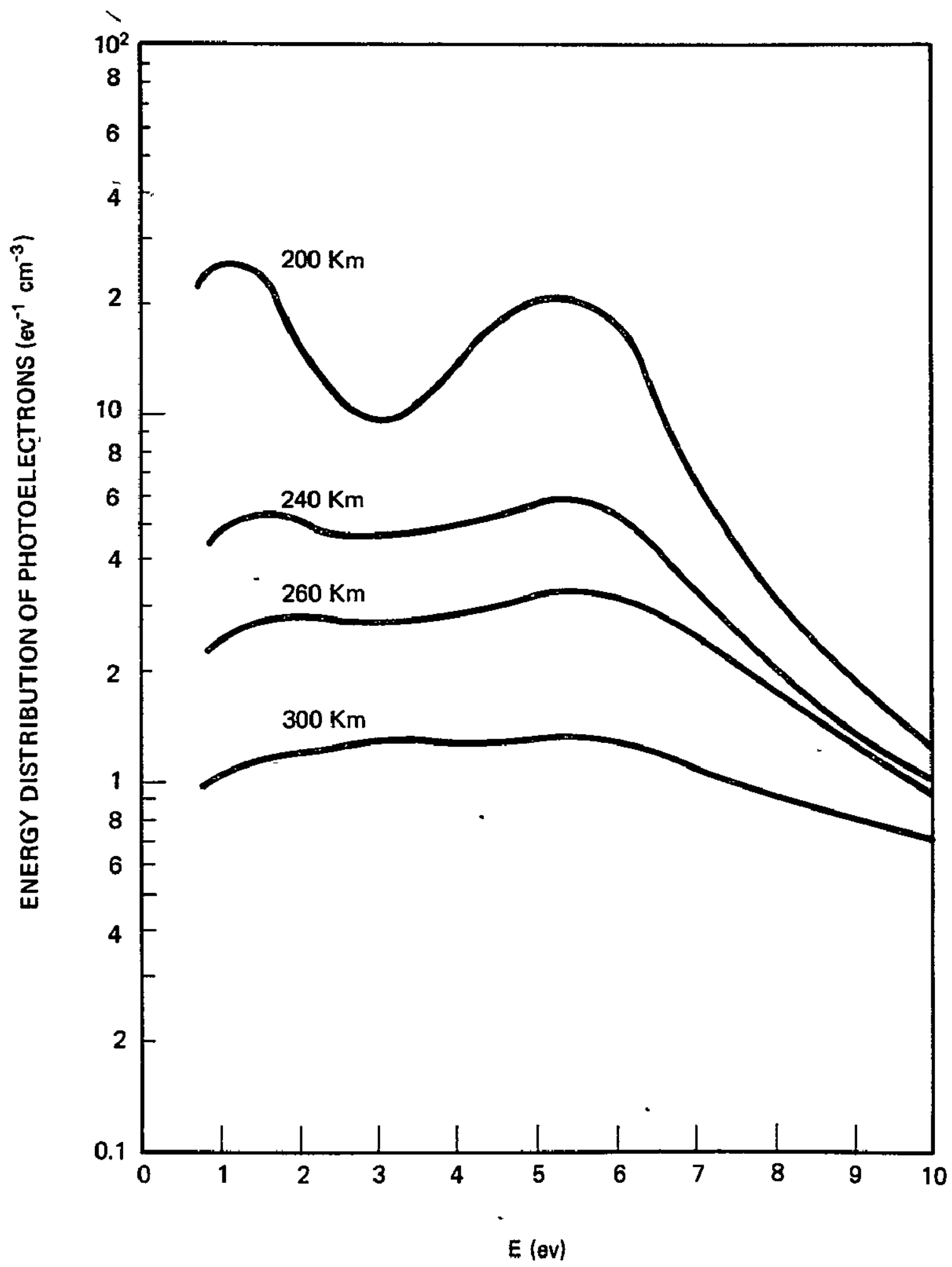

Figure 14. Photoelectron energy distribution for various alfitudes from $200-300 \mathrm{~km}$.

[From Hoegy, Fourrier and Fontheım (1965)] 


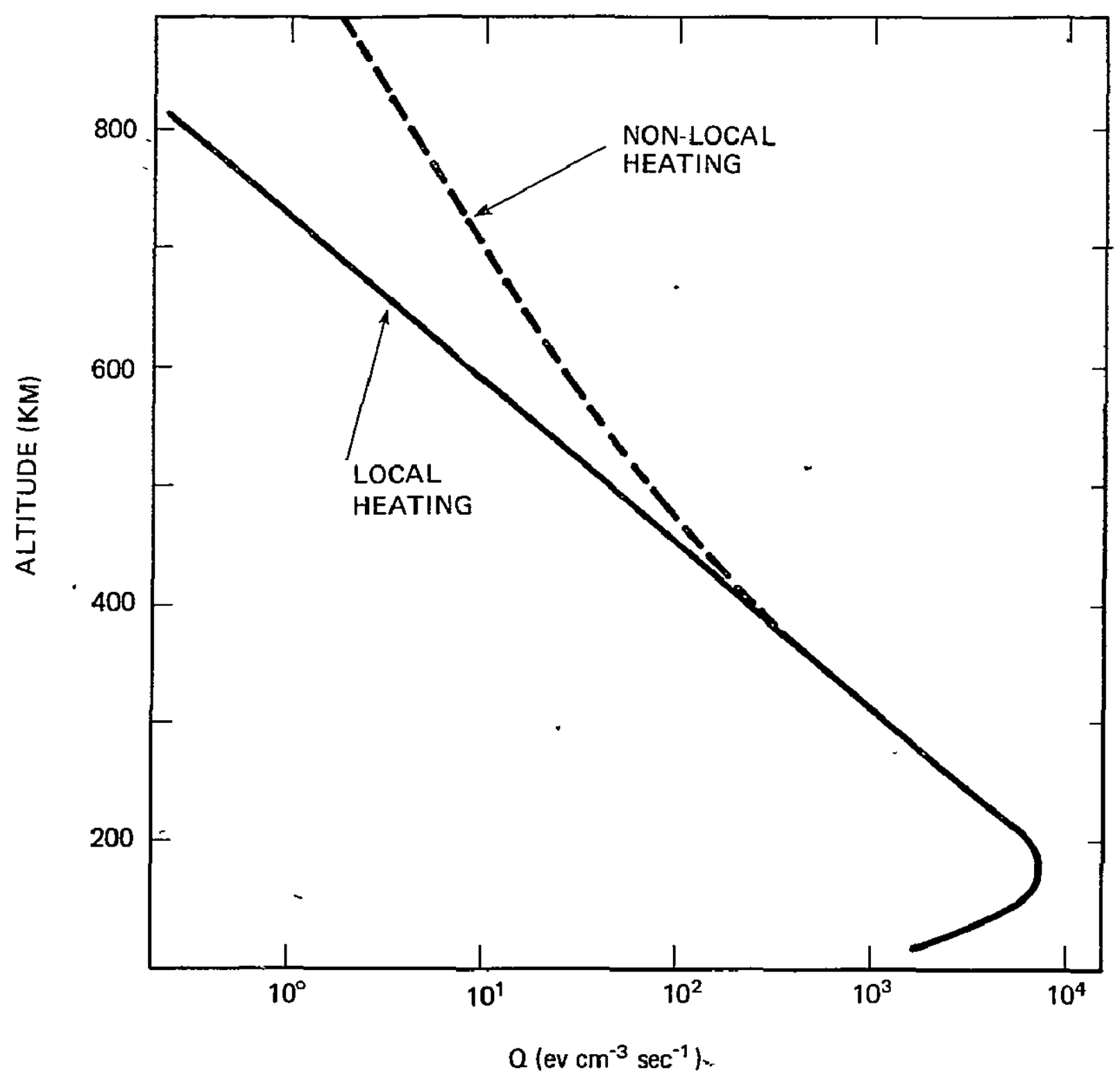

Figure 15. Varıation with altutude of the heat input $Q$ showing both the local heating and also the additional non-local heating which results from including the contribution from photoelectrons orıginating below $300 \mathrm{~km}$. [From Geisler and Bowhıl] (1965)] 


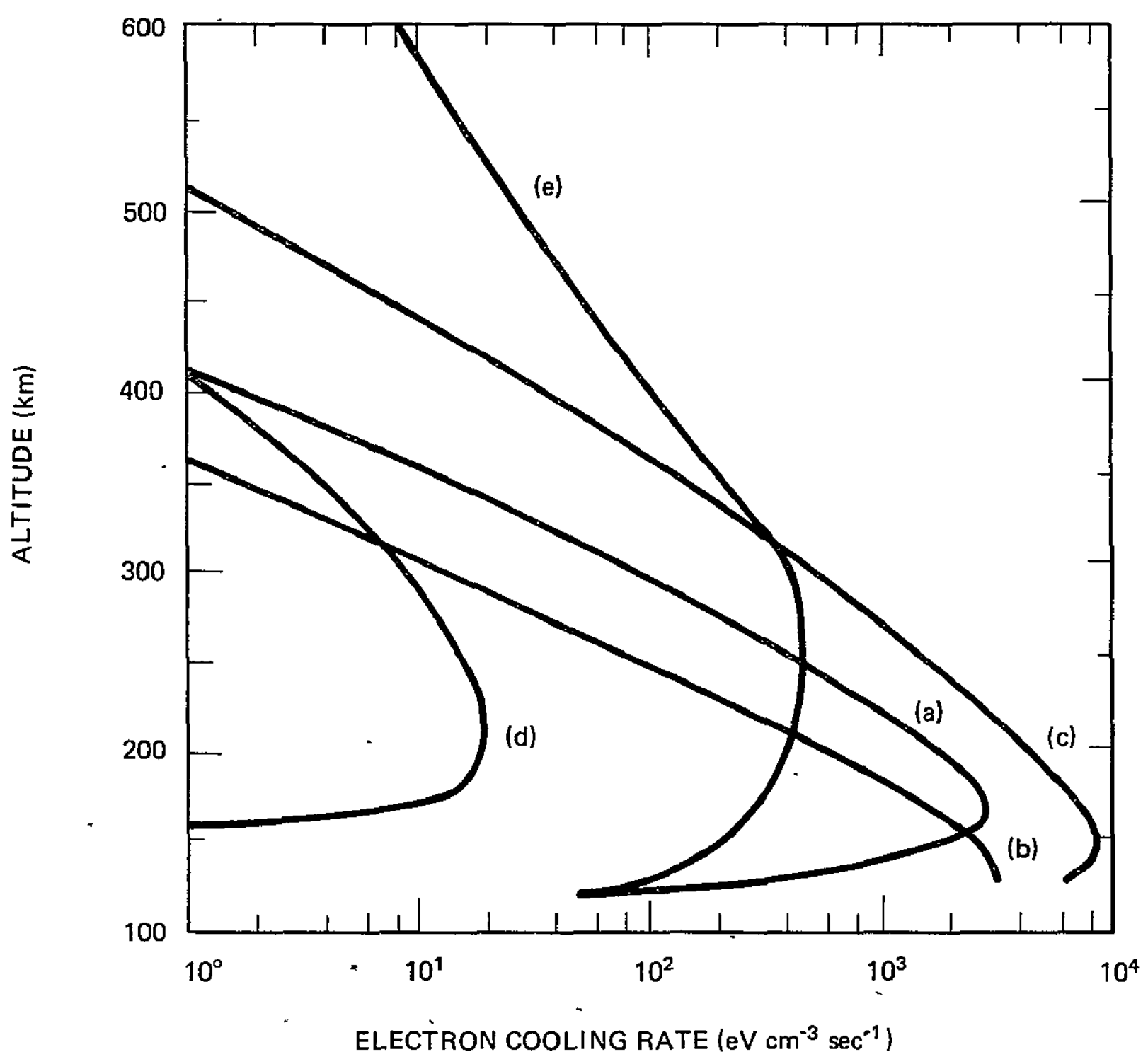

Figure 16. Calculated electron cooling rafes by various collision processes for 1963 July at noon. The curves refer to excitation of (a) vibrational level seof $\mathrm{N}_{2^{r}}$ (b) rotational levels of $\mathrm{N}_{2^{\prime}}$ (c) finestructure levels of $O$, (d) metastable levels of $O$, and (e) elastic collisions with positive ions. The cooling due to elastic collisions with neutrals and from rotational excitation of $\mathrm{O}_{2}$ are negligible. [From Dalgarno, McElroy, Rees and Walker (1968)] 


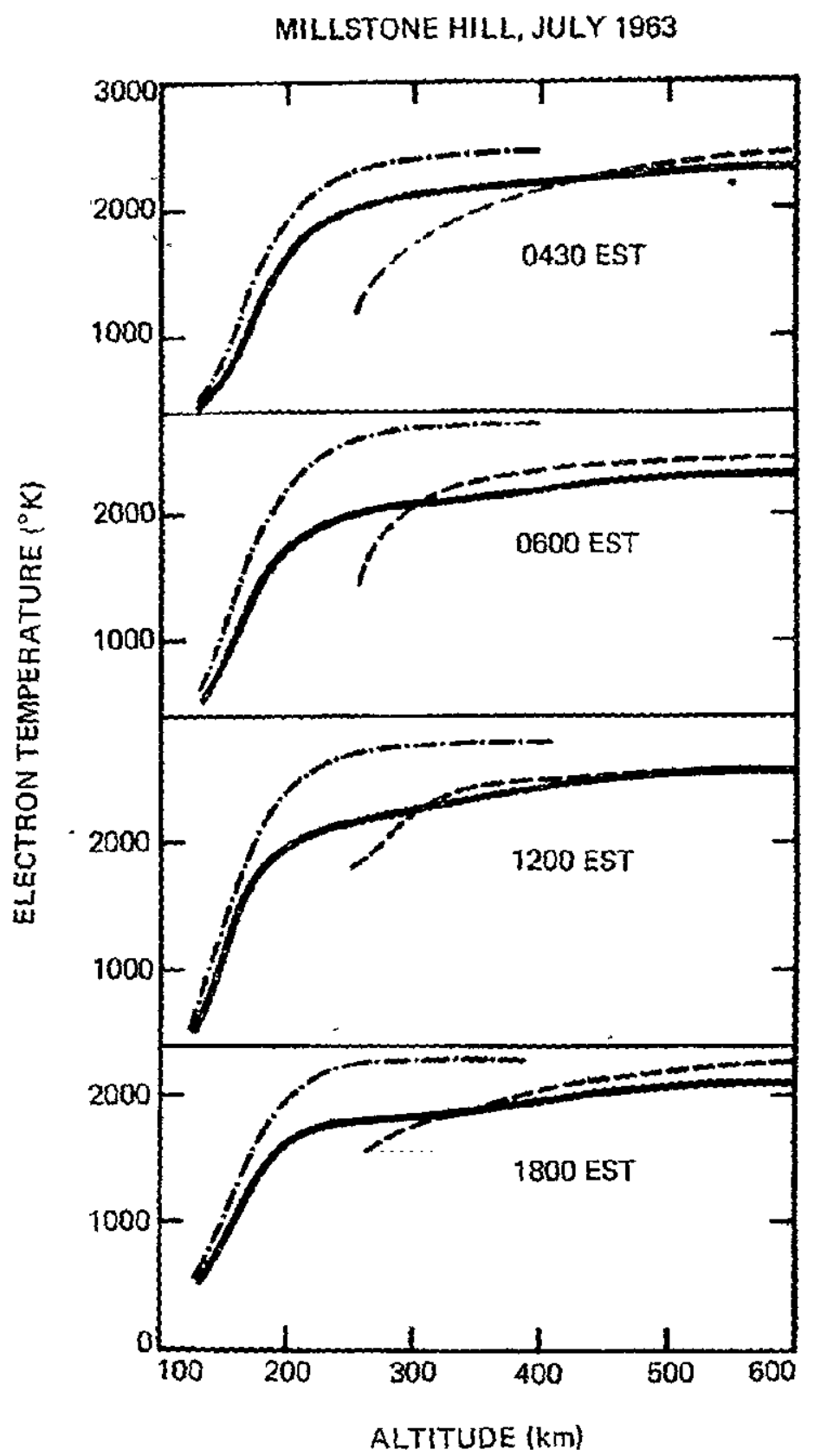

Figure 17. Variation of electron temperature with altitude at Millstone Hill for 1963 July af various local times. The solid curves are calculated including fine-structure cooling by atomic axygen whilst it is neglected in the dosh-dot curves. The dashed curves are values measured by Evans by incoherent scatter. [From Dalgarno, McElroy, Rees and Walker (1968)\} 


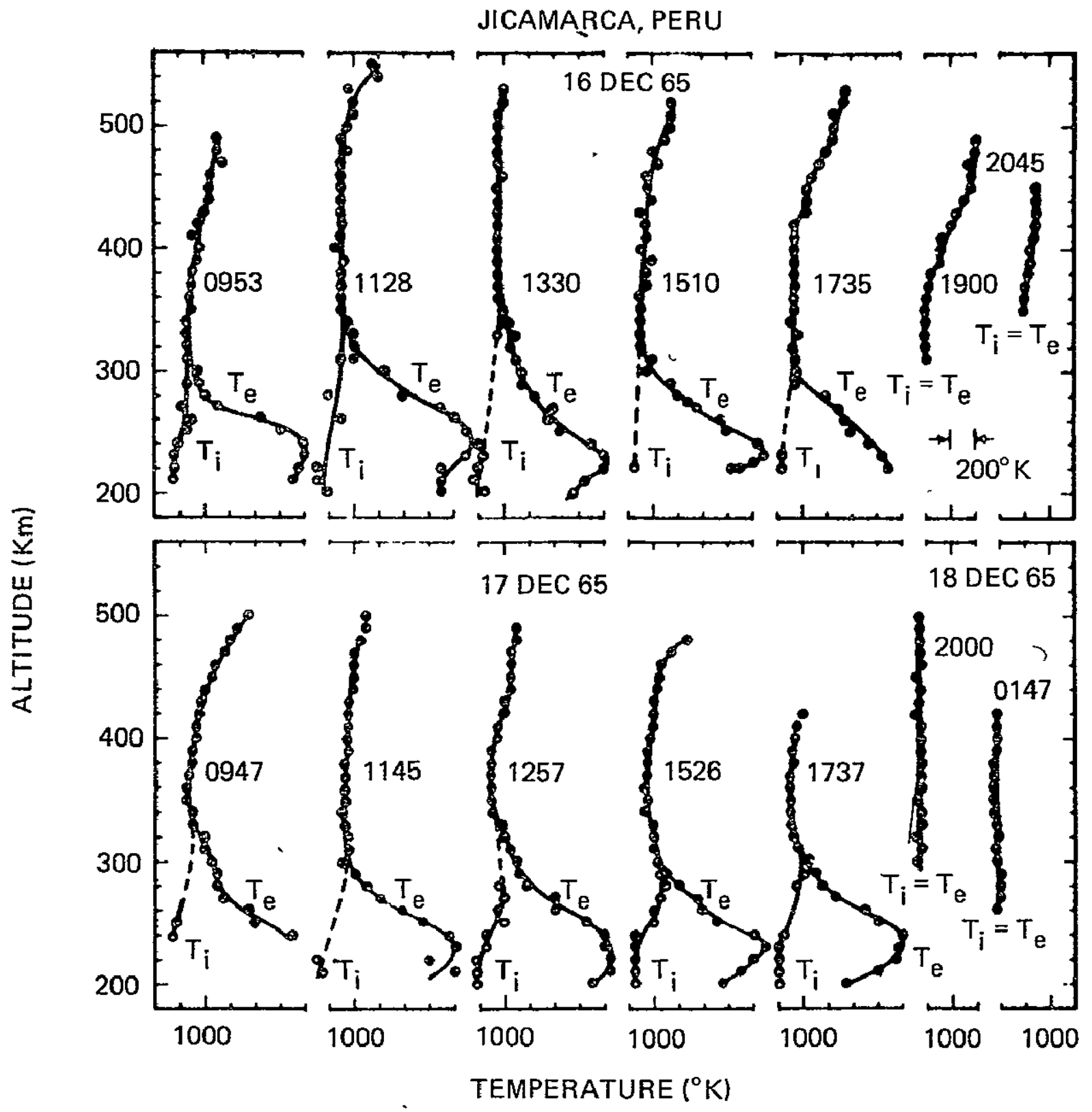

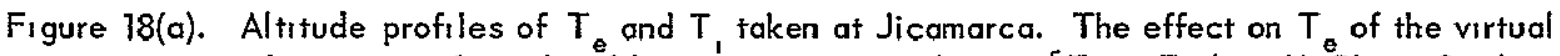
suppression at Jicamarca of non-local hesting is very strikıng. [From Farley, McClure, Sterling and Green (1967) and Evans (1965)] 

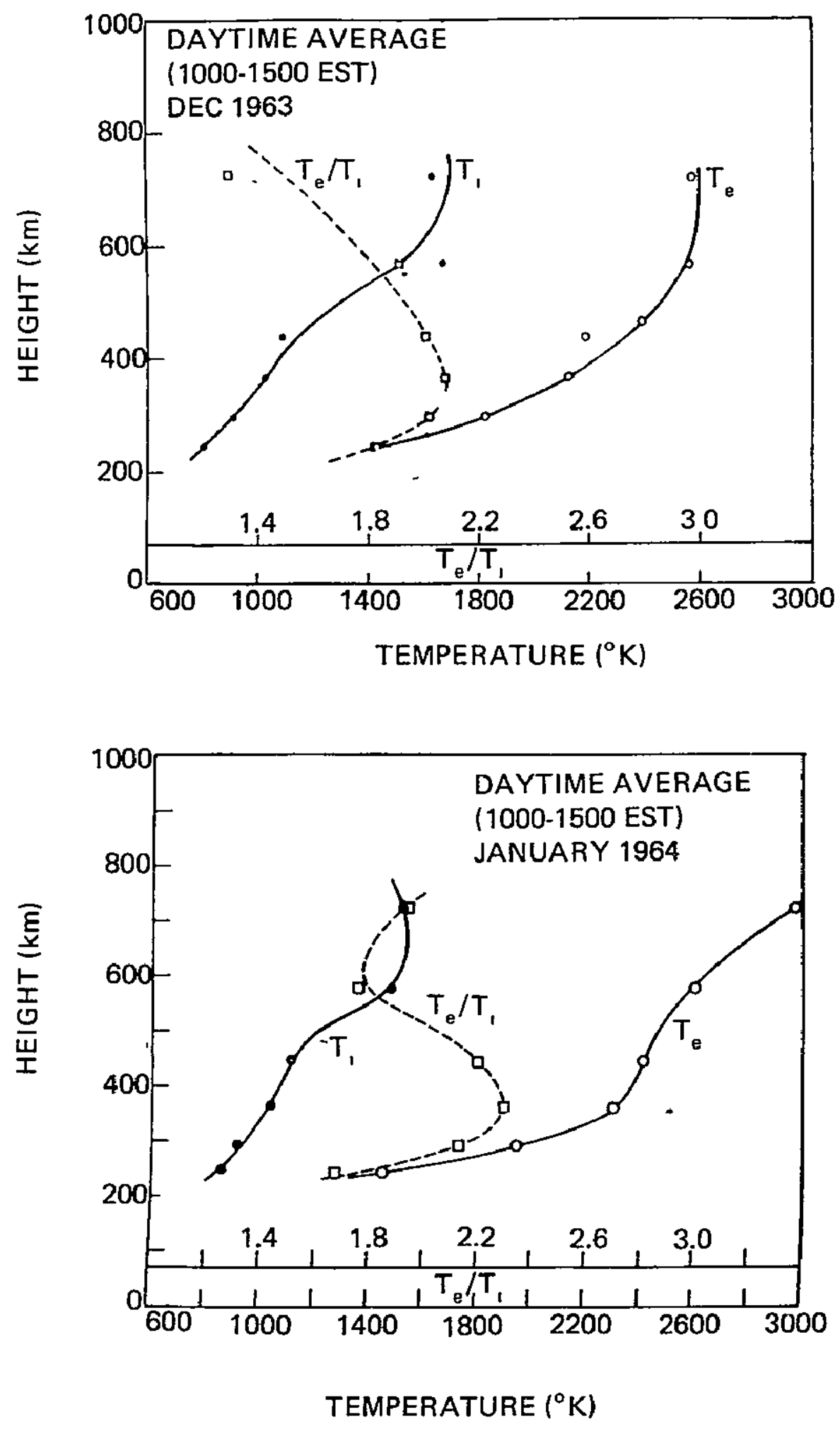

Figure 18(b) Altitude profiles of $T_{e}$ and $T_{1}$ taken at Millstone Hıll. [From Farley, McClure, Sterlıng and Green (1967) and Evans (1965)] 

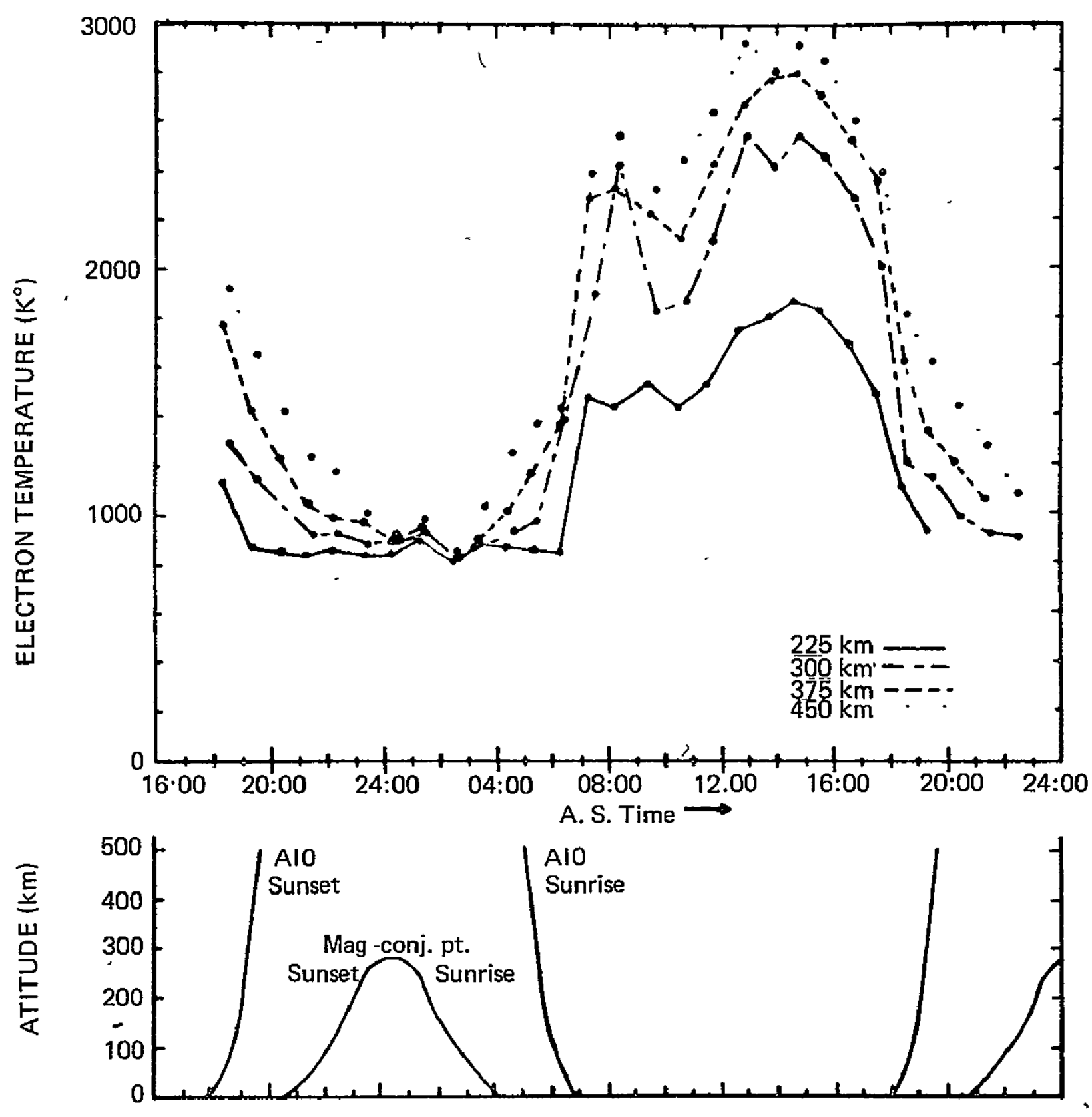

Figure 19. Diurnal variation of $T_{e}$ at Arecibo in winter. Also shown are times of sunrise and sunset at Arecibo and at the magnetically conjugate location. Whilst at $225 \mathrm{~km} \mathrm{~T}$ falls sharply at local sunset, and rises again at sunrise, at $400 \mathrm{~km}$ it decines steadily to a minimum in the early morning hours, starting to rise again at sunrise in the conjugate ionosphere. The early morning maximum is most pronounced at $300 \mathrm{~km}$ on this occasion. [From Carl son (1966)] 

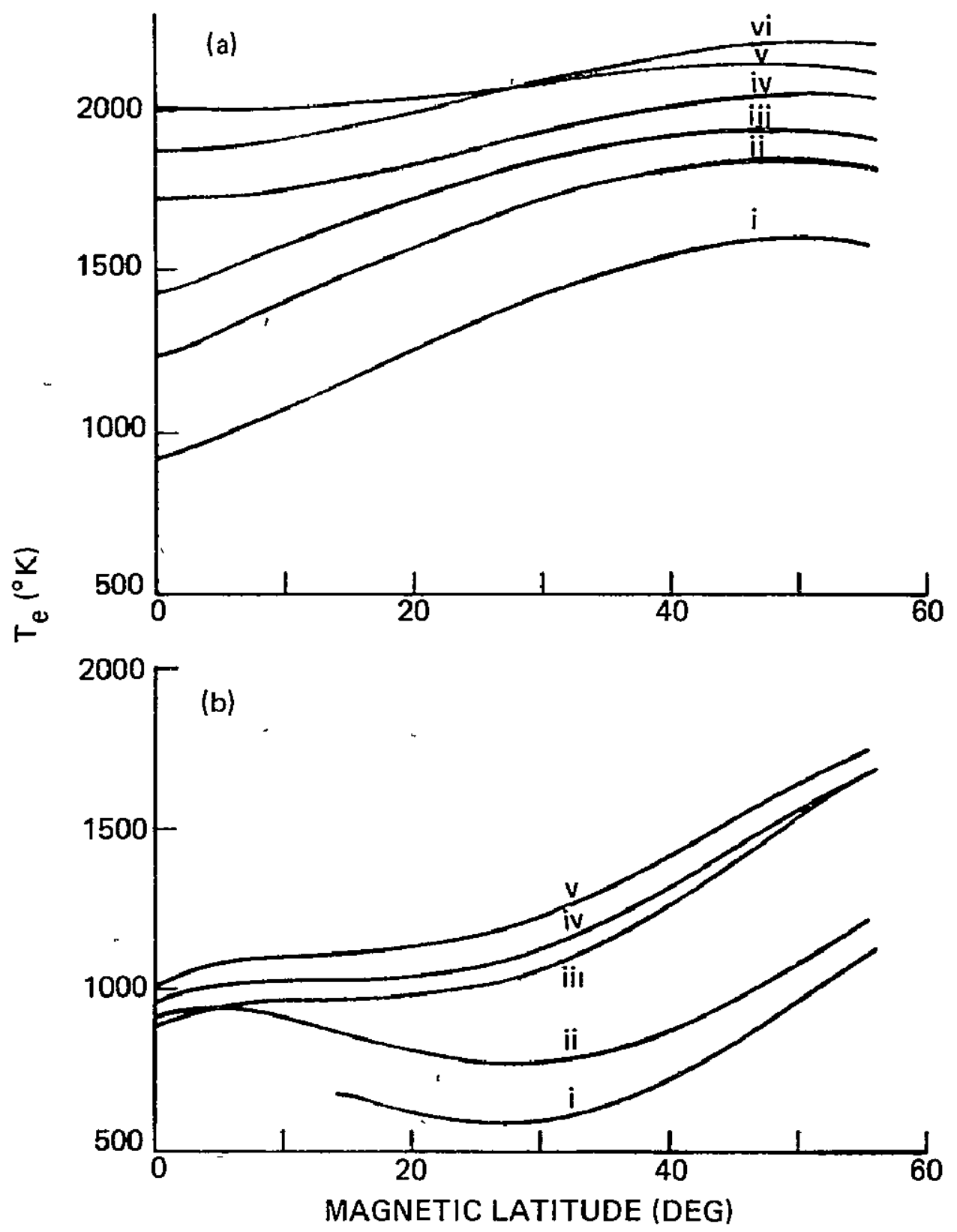

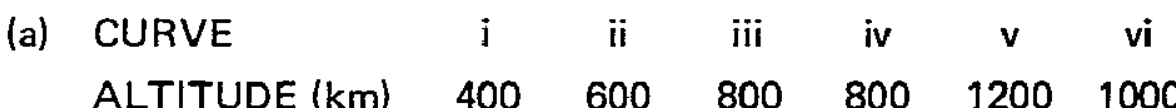
$\begin{array}{lllllll}\text { LOCAL TIME (h) } & 12 & 12 & 12 & 15 & 15 & 15\end{array}$

(b) CURVE 1 ii iii iv $N$

ALTITUDE (km) $\quad 400 \quad 400 \quad 1200 \quad 1000 \quad 1200$

LOCAL TIME (h) $\quad 00 \quad 03 \quad 00 \quad 22.5 \quad 22.5$

Figure 20( $a$ and $b$ ). Latitude variation of $T_{e}$ as determined by probe measurements on Ariel I. [From Willmore (1965) and Brace, Reddy and Mayr (1967)] 
(c)

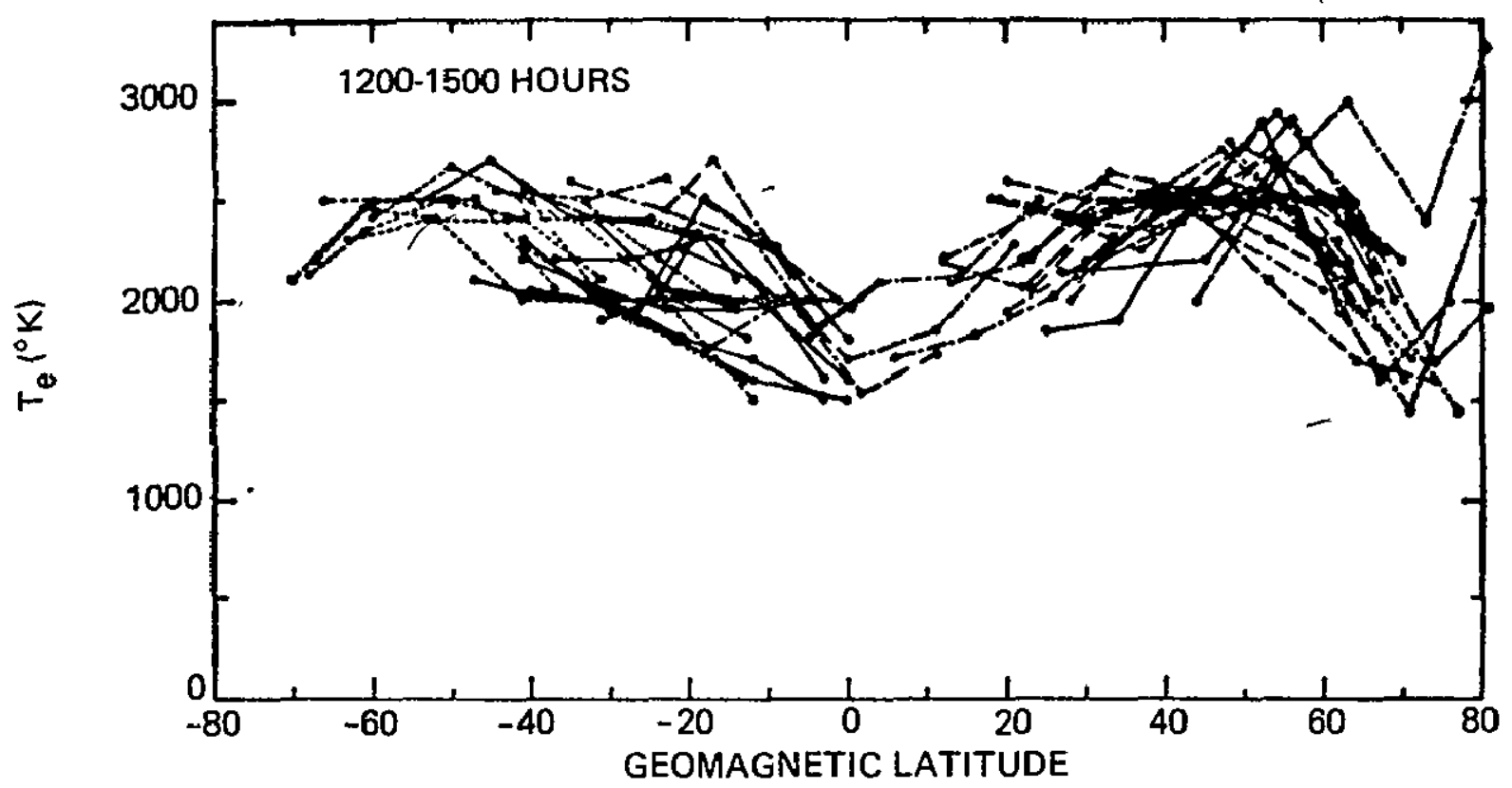

(d)

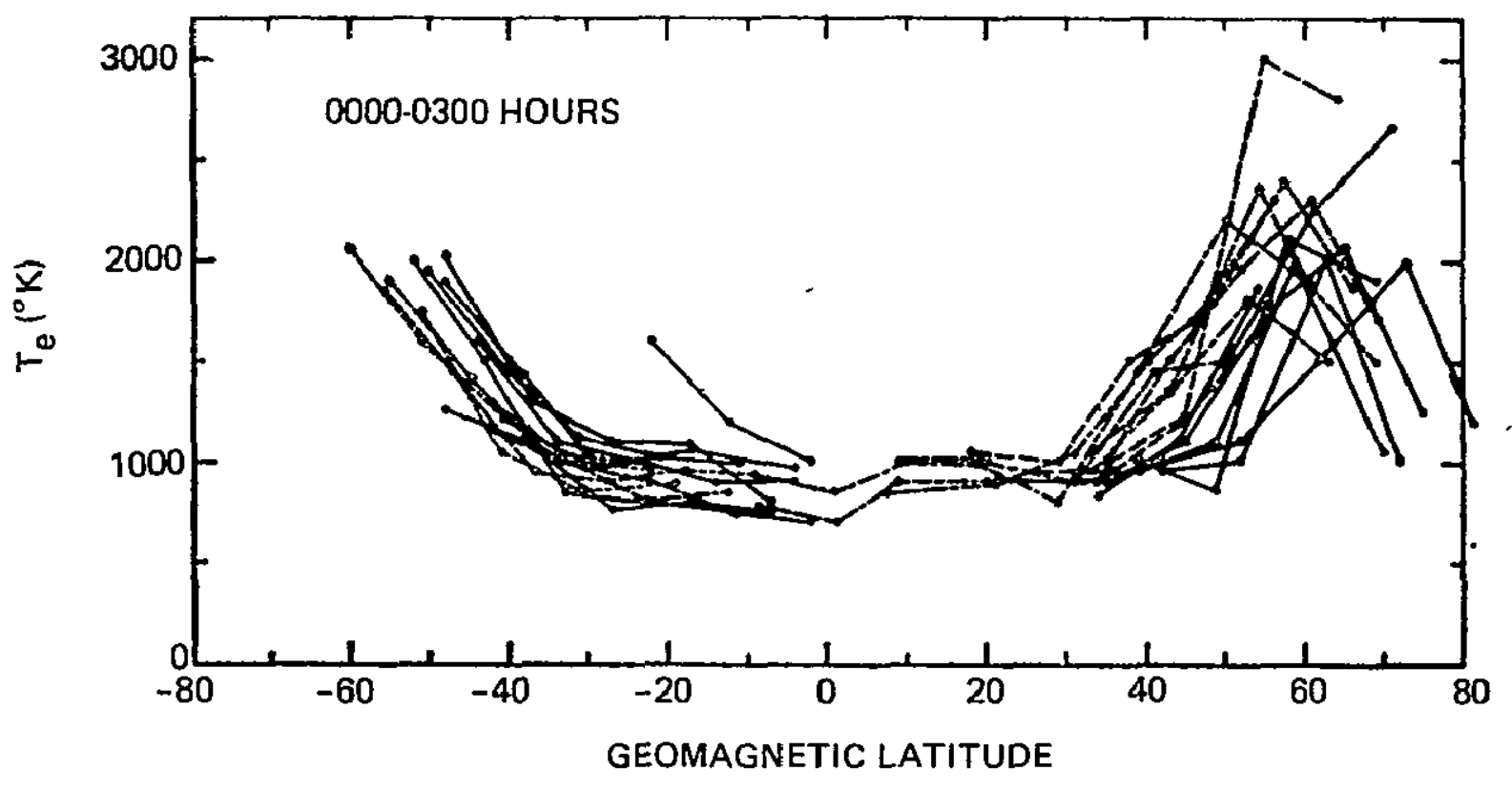

Figure 20(c and d). Latitude variation of $T_{e}$ as determined by probe measurements on Explorer XX. The Explorer XX results refer to an altitude of $1000 \mathrm{~km}$. [From Willmore (1965) and Brace, Reddy and Mayr (1967)] 


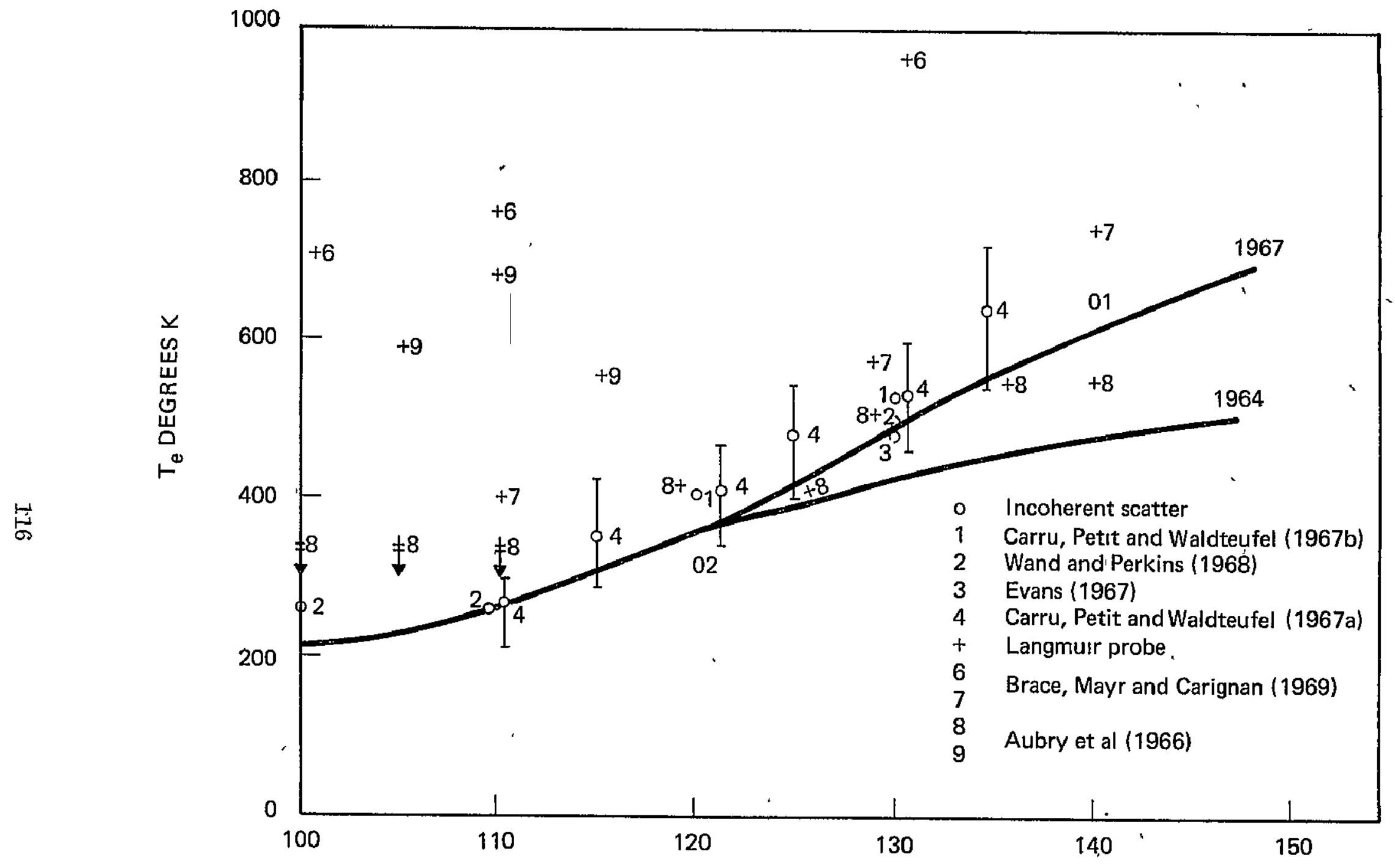

ALTITUDE, KM

Figure 21. Measurements of $T_{e}$ in the E-region by Langmuir probes and incoherent scatter compared with gas temperature from CIRA 1965 (solid lines). 6 and 7 refer to similar rocket flights, 6 near midnight and 7 near noon 8 and 9 were al so similar, the two flights occurring at approximately the same local time, two days apart. 


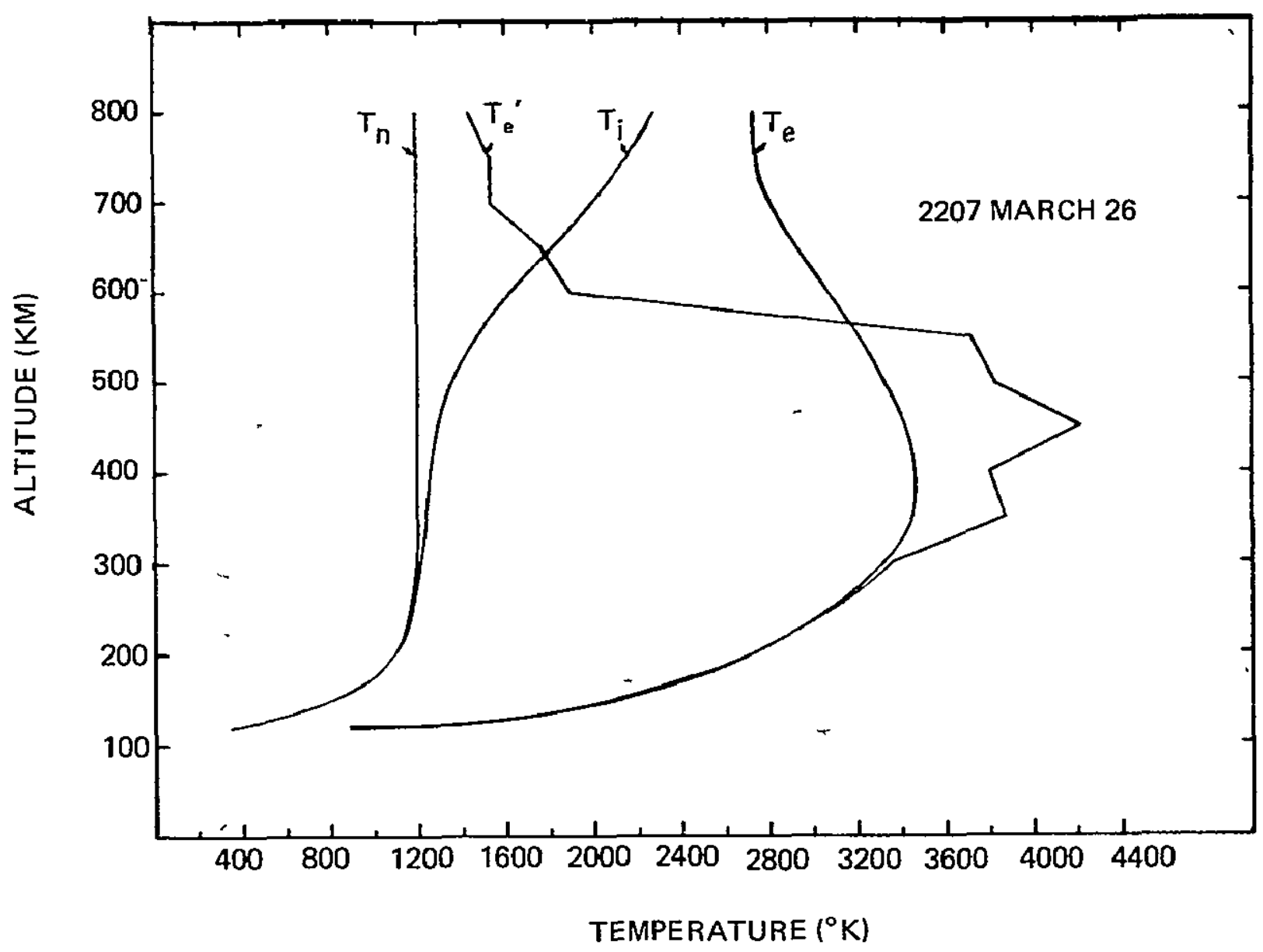

Figure 22 Calculated temperature profiles for an auroral arc with $\lambda 3914 \AA$ brightness of $347 \mathrm{kR}$. $\left[T_{e}^{\prime}\right.$ is the result neglecting thermal conduction, from Walker and Rees (1968a)] 
(a)

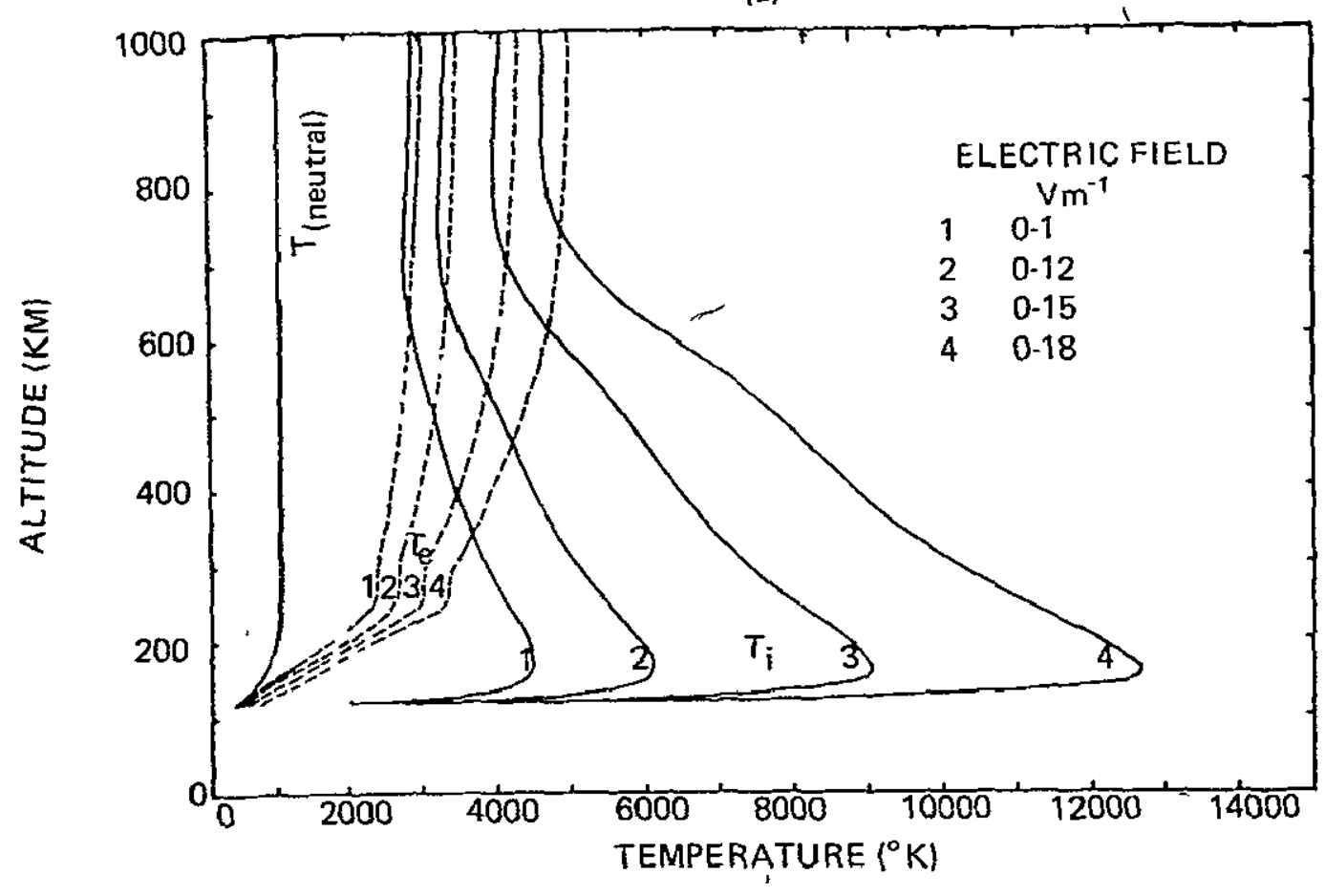

(b)

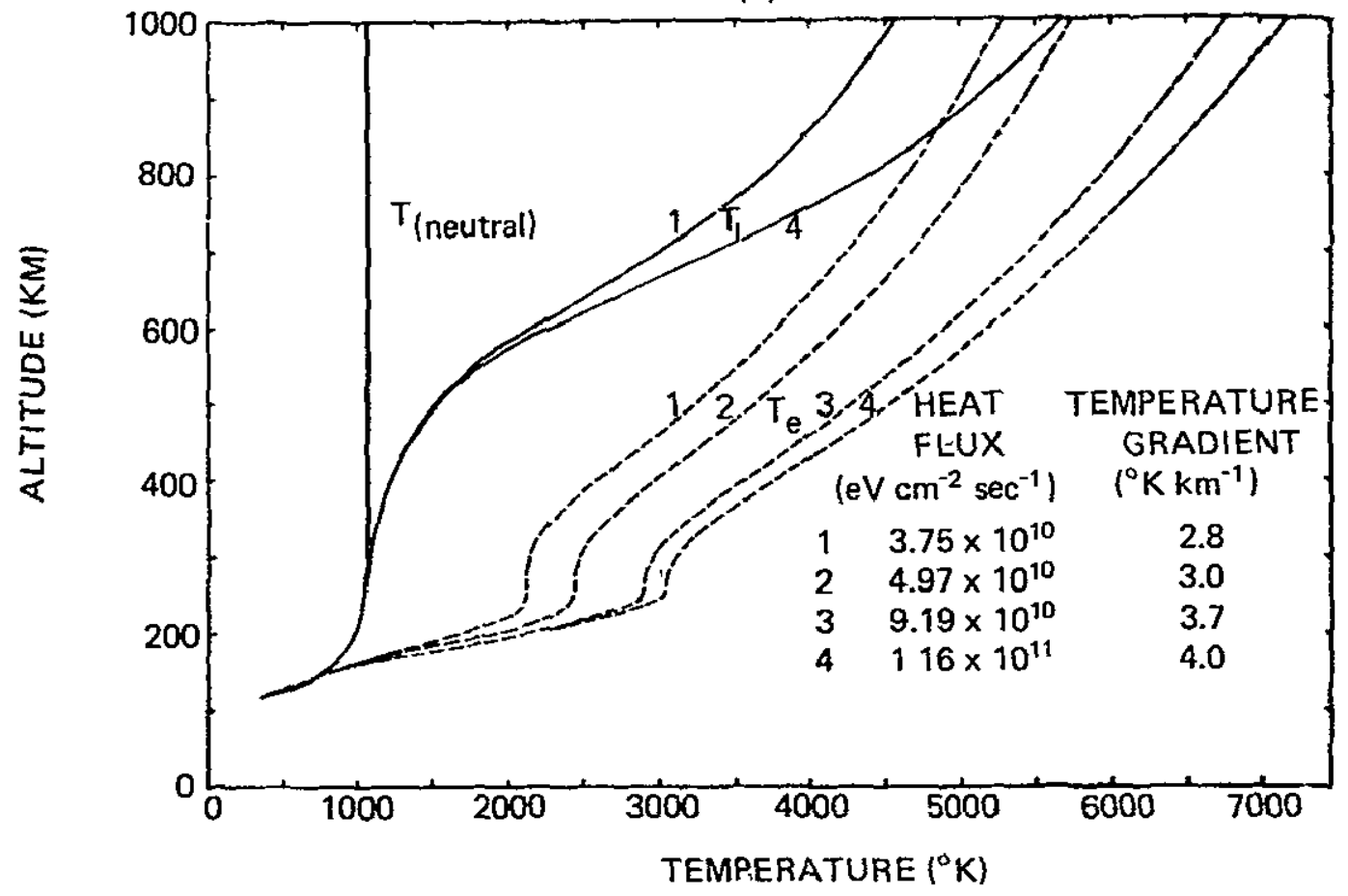

Figure 23. Calculated temperature profiles in a SACARC when the heating is supposed to result from (a) electric fields of various magnitudes normal to the magnetic field and (b) heat fluxes conducted from the magnetosphere. The temperature gradients are those at $1000 \mathrm{~km}$. [From Walker and Rees (1968b)] 